\title{
Human pluripotent stem cell modeling of tuberous sclerosis complex reveals lineage-specific therapeutic
} vulnerabilities

Running title: TSC2 directs lineage-specific catabolic signaling

Sean P. Delaney*1,2,3, Lisa M. Julian*1,3†, Adam Pietrobon ${ }^{1,2,3}$, Julien Yockell-Lelièvre ${ }^{1}$, Carole Doré ${ }^{1}$, Ting T.

Wang $^{4}$, Valerie C. Doyon ${ }^{1,2}$, Angela Raymond ${ }^{1}$, David A. Patten ${ }^{3,5}$, Arnold S. Kristof ${ }^{6}$, Mary-Ellen Harper ${ }^{3,5}$, Hongyu $\operatorname{Sun}^{4}$, William L. Stanford ${ }^{1,2,3,5 \dagger}$

${ }^{1}$ Ottawa Hospital Research Institute, Regenerative Medicine Program, Ottawa, ON, Canada, K1H 8L6;

${ }^{2}$ Department of Cellular \& Molecular Medicine, University of Ottawa, Ottawa, ON, Canada, K1H 8M5; ${ }^{3}$ Ottawa Institute of Systems Biology, Ottawa, Ontario, Canada, K1H 8M5; ${ }^{4}$ Department of Neuroscience, Carleton University, Ottawa, ON, Canada, K1S 5B6; ${ }^{5}$ Department of Biochemistry, Microbiology \& Immunology, University of Ottawa, Ottawa, Ontario, Canada, K1H 8M5; ${ }^{6}$ Research Institute of McGill University Health Centre, Montreal, Quebec, Canada

*Equal contribution, ${ }^{\dagger}$ Corresponding author

\section{Primary Correspondence:}

William L. Stanford

Ottawa Hospital, 501 Smyth Rd, Box 511

Ottawa, ON K1H 8L6 CANADA

613-737-8899 ext. 75495

wstanford@ohri.ca 


\section{SUMMARY:}

mTORC1 hyperactivation resulting from inactivating TSC2 mutations underlie the multi-system tumor disorder tuberous sclerosis complex (TSC) and the rare pulmonary neoplasm lymphangioleiomyomatosis (LAM).

Mutation-bearing neural precursor cells (NPCs) lead to the formation of TSC brain tumors during development, while the cell of origin of TSC mesenchymal tumors such as LAM is unknown. We report the first model of multi-system TSC cell types, characterized by NPCs and neural crest cells (NCCs) differentiated in parallel from multiple engineered $T_{S C} 2^{-/}$human pluripotent stem cell (hPSC) lines. These cells successfully model defining phenotypes of neural and mesenchymal TSC, with transcriptomic signatures reflecting those observed in patient tumors, thus establishing TSC2 $2^{-/}$NCCs as a powerful model of LAM. Employing this rich cellular and transcriptomic resource, we identified lineage-specific catabolic signaling mechanisms that drive divergent cell behavior and therapeutic sensitivities that, in turn, demonstrate the power of employing lineage-specific stem cell models to dissect multi-system diseases.

KEYWORDS: CRISPR, disease models, human pluripotent stem cells, lymphangioleiomyomatosis, lysosome, neural precursor cell, neural crest, mTORC1, proteostasis, tuberous sclerosis 


\section{INTRODUCTION}

Inactivating mutations in TSC1 or, more commonly, TSC2 underlie the neoplastic disorder tuberous sclerosis complex (TSC) (Dabora et al., 2001), a multisystem disease characterized by neurocognitive deficits and lowgrade neural and mesenchymal-like tumors in the brain, kidneys, heart, eyes, lungs, and skin (Delaney et al., 2014). TSC1 and TSC2 function together in a physical partnership, along with TBC1D7, to negatively regulate mTORC1, a central signaling complex whose precise regulation is critical for tissue development and homeostasis and whose dysfunction is broadly implicated in cancer, aging and disease (Saxton and Sabatini, 2017). Affecting $30 \%$ of female TSC patients, and also occurring spontaneously through somatically acquired mutations, lymphangioleiomyomatosis (LAM) takes its form as a progressive pulmonary disease in which clusters of aberrant smooth muscle-like cells, typically enveloped by $\mathrm{PMEL}^{+}$(identified by HMB45 antigen) epithelioid cells, expand throughout the lung interstitium. These LAM nodules drive the development of tissuedestructive cysts, and are hypothesized to arise in the lung following metastasis of tumorigenic cells from other mesenchymal lesions such as renal angiomyolipomas (rAMLs) or uterine tumors (Henske and McCormack, 2012). The age of onset of distinct TSC tumors spans a wide range. In the brain, cortical tubers and often subependymal astrocytomas are established during embryonic development and persist throughout life; alternatively, mesenchymal TSC manifestations can arise prenatally, such as cardiac rhabdomyomas which spontaneously resolve, or at later stages, with LAM occurring only in post-pubescent females (Henske and McCormack, 2012; Moss et al., 2001). Molecular and functional features are also unique, with neurological TSC tumors expressing markers of immature neuronal differentiation, enhanced gliogenesis, neuronal hyperactivity, and neural stem and progenitor cells (Bateup et al., 2013; Goto et al., 2011; Talos et al., 2012). Alternatively, mesenchymal TSC cells are characterized by aberrant smooth muscle and adipocyte differentiation (Dixon et al., 2011; Krymskaya, 2008), increased migratory capacity (Crooks et al., 2004; Yu et al., 2001), and expression of female hormone receptors and melanocytic antigens in some populations (Gao et al., 2014; Hoon et al., 1994). Thus, the biological consequences of TSC2-deficiency can vary quite markedly according to developmental stage and cell lineage. Uncovering the mechanisms driving biological responses to TSC2-deficiency in a lineagespecific and longitudinal context would provide critical insights on tumorigenesis and resultant therapeutic 
vulnerabilities in TSC and LAM; this would additionally enhance our understanding of tissue development and homeostasis, as well as mTORopathies more broadly.

The genetic loss of TSC1 or TSC2 leads to a constitutive inability to restrict mTORC1 activation which, depending on the cellular context, can significantly affect cell function including uncontrolled growth and proliferation, reprogramming of energy metabolism, and altered organelle biogenesis and function (Delaney et al., 2014; Henske and McCormack, 2012). Pharmacological mTORC1 inhibition with rapamycin analogues has emerged as a leading clinical strategy to treat many manifestations of TSC. Although providing clinical benefit, this approach is not curative and produces purely cytostatic relief in responsive patients (Canpolat et al., 2018; Franz and Capal, 2017; McCormack et al., 2011); thus, identification of alternative therapeutic strategies to treat, and ultimately eliminate, TSC tumors are required. Progress toward this goal has been limited in large part because existing experimental models fail to accurately reflect important clinical aspects of the disease; TSC1 and TSC2-deficient rodent strains, fibroblasts derived from these animals, and transformed patient tumor-derived cell lines (Darling et al., 2010; Goncharova et al., 2012; Kwiatkowski, 2010; Yu et al., 2004) often do not reflect the relevant cell lineages, proliferation characteristics, or human cellular origin relevant to patient tumors. Human pluripotent stem cell (hPSC)-derived TSC1- and TSC2-deficient neuronal cultures have also recently been reported, which recapitulate the aberrant gliogenesis and hypertrophic neurons observed in TSC brain tumors (Blair et al., 2018; Costa et al., 2016). These studies provide proof-of-concept that hPSC-based approaches can model defining features of TSC tumor cells; however, as reported they were limited in biological reproducibility, provided little insight into tumorigenic mechanisms of TSC2-deficient cells, and only partially modeled the critical cell types relevant to TSC brain tumors while not considering mesenchymal TSC cells at all (Crino et al., 1996; Goto et al., 2011; Lee et al., 2003). Thus, a hPSC-based model system that reflects all TSC tumor-relevant cell types and lineages while incorporating multiple cell lines to account for biological variability, is crucial to elucidate the biological mechanisms driving the breadth of manifestations in TSC.

Murine models utilizing promoter driven TSC1 and TSC2 knockouts have largely established the cell of origin for neurological TSC tumors as neural stem and progenitor cells (NPCs) (Feliciano et al., 2011; Magri et al., 2013; Zhou et al., 2011), and evidence suggests mesenchymal-like progenitors contribute to the formation of other TSC tumor types (D'Armiento et al., 2016; Delaney et al., 2014; Henske and McCormack, 2012; Kenerson 
et al., 2002; Liang et al., 2018). A recent TSC patient-derived smooth muscle cell model recapitulates important aspects of LAM cells (Julian et al., 2017), yet the impact of TSC2 loss in mesenchymal progenitor populations has not been investigated. There is significant evidence that neural crest cells (NCCs) or a NCC-like cell is the origin of mesenchymal TSC tumors; cutaneous TSC tumors are found in proximity to sites populated by NCCs during development (Simoes-Costa and Bronner, 2013), and mesenchymal TSC tumors broadly composed of mixed cell types that reflect NCC progeny, including adipocytes, smooth muscle cells, and melanocytic markers. Additionally, NCCs emerge simultaneously with NPCs, the known origin of TSC brain tumors, at the interface of the neural plate and non-neural ectoderm during the neurulation stage of embryonic development (Bronner, 2012); studying the impact of TSC2-deficiency at this developmental juncture can thereby identify the earliest processes that distinguish neural from mesenchymal TSC tumors.

Here, we present the first multi-system experimental model of TSC, which recapitulates both the neural and mesenchymal manifestations of TSC in parallel. This was achieved by engineering TSC2 knockouts in four hPSC lines and directing this resource of isogenic WT and $T S C 2^{-/}$stem cells through two lineage induction protocols to favor the generation of either NPCs or NCCs. We demonstrate that $T S C 2^{-/}$neuronal and glial progeny, as well as newly induced and culture-maintained $T S C 2^{-/} \mathrm{NPCs}$, each model critical features of neurological TSC tumors. We additionally show, for the first time, that $T S C 2^{-/}$NCCs display a highly similar transcriptomic signature to pulmonary LAM (P-LAM) cells while recapitulating several characteristic features of mesenchymal TSC that are elusive in other models of this disease. We further provide a comprehensive resource of RNA-sequencing (RNA-seq) datasets capturing the transcriptional landscape over a developmental time course of NPC and NCC differentiation of WT and TSC2 ${ }^{-/}$hPSCs. Harnessing these data, we identified pronounced lineage-specific differences in proteostasis signaling mechanisms adopted by newly differentiated $\mathrm{TSC}^{-/}$cells, in which NPCs uniquely mount pro-catabolic mechanisms that counter typical mTORC1 signaling paradigms and lead to chronic adaptations of lysosomal signaling and metabolic reprogramming over time. Alternatively, $T S C 2^{-/}$NCCs exhibit canonical pro-anabolic mTORC1 responses and a reduced dependency on mTORC1 inhibition during lineage induction. These biological differences underlie a selective sensitization of $T_{S C} 2^{-/}$NPCs to cell death via proteasome inhibition with clinically relevant compounds, irrespective of mTORC1 inhibition with rapamycin. While proteasome inhibition has been considered as a broad therapeutic 
bioRxiv preprint doi: https://doi.org/10.1101/683359; this version posted February 14 2020. The copyright holder for this preprint (which was not certified by peer review) is the author/funder, who has granted bioRxiv a license to display the preprint in perpetuity. It is made available under aCC-BY-NC-ND 4.0 International license.

strategy in TSC, predominantly as one element of combination therapy, our work suggests that this approach holds promise as a stand-alone therapy or complimentary treatment to existing regimens for the neurological, but not mesenchymal, features of TSC. 


\section{RESULTS}

\section{$T S S C 2^{-/-}$hPSCs maintain pluripotency potential but fail to negatively regulate mTORC1 signaling}

Due to the higher prevalence and more severe TSC phenotypes associated with mutations in TSC2 compared to TSC1 (Dabora et al., 2001), the TSC2 locus was targeted for genetic modification via CRISPR/Cas9. To ensure genetic diversity and permit robust discovery of lineage and disease-relevant phenotypes we utilized multiple, well-characterized hPSC lines within this study, selecting two male (H1 \& 168) and two female (H7 \& H9) lines (Figure 1A). Each parental line was modified at the AAVS1 locus with CRISPR/Cas9 to express mCherry and Zeocin resistance to aid in live cell assays and future in vivo studies (supplementary materials). There is a wide array of documented pathogenic mutations in TSC2 (over 2600 unique variants) with no mutational 'hotspot' within coding regions or tendency towards a particular mutation type (e.g. small deletion, nonsense mutation) (Au et al., 2007; Fokkema et al., 2011; Martin et al., 2017a). To effectively knockout TSC2 expression, exon 3 was selected for targeting due to its ubiquity across all documented variants and its proximity to the $\mathrm{N}$-terminus of its protein product. To achieve the highest possible editing precision across all four TSC 2 knockout cell lines, a homology directed repair strategy was employed. Using a single stranded oligonucleotide containing a 35-base 'stop-codon' donor sequence (Gagnon et al., 2014), a frame shift-inducing insertion containing stop codons in all frames was introduced into TSC2 exon 3, confirmed by PmeI digestion of PCR amplicons of the target site (Figure 1B).

Homozygous integration of the stop-codon sequence $\left(T S C 2^{-/}\right)$resulted in complete ablation of TSC2 expression, with no detectable protein by immunofluorescence or western blot (Figure 1C, S1A). Much like their WT counterparts, $T S C 2^{-/-}$hPSCs maintain characteristic undifferentiated colony morphology and can be maintained in an undifferentiated state indefinitely and exhibit normal expression levels of hallmark pluripotency markers OCT4, SOX2, and NANOG (Figure 1D), demonstrating that the pluripotency gene regulatory network functions unperturbed. Furthermore, TSC2-deficiency does not overtly affect pluripotency, as all $\mathrm{TSC}^{-/} \mathrm{hPSCs}$ were able to form tissues of ectodermal, mesodermal, and endodermal origin during in vivo teratoma assays (Figure 1E, S1B). A defining characteristic of both neurological and mesenchymal TSC lesions is their inability to properly regulate mTORC1 signaling, attributed to loss of function of the inhibitory TSC1/TSC2 complex. Under maintenance conditions, both undifferentiated WT and TSC2 $^{-/}$hPSCs exhibited 
active mTORC1 signaling as indicated by the phosphorylation of mTOR (Ser2448) and the downstream effectors of the mTORC1 complex, p70 S6K (S6K; Thr389) and S6 ribosomal protein (S6; Ser235/236). However, when exposed to stress conditions ( $6 \mathrm{~h}$ at $\left.1 \% \mathrm{O}_{2}\right), T S C 2^{-/-} \mathrm{hPSC}$ maintain constitutive phosphorylation of the mTORC1 axis, while WT cells repress this pathway (Figure $1 \mathrm{~F}, \mathrm{~S} 1 \mathrm{C}$ ). Thus, all four $T S C 2^{-/-} \mathrm{hPSC}$ lines successfully recapitulate the mTORC1 signaling abnormalities observed in TSC-associated lesions.

Having engineered a hPSC-based system through which to model TSC cell types, we then sought to generate the putative cells of origin for both central nervous system (CNS) and mesenchymal tumors that develop in TSC. Genetic mouse models have shown that NPCs are the likely cell of origin for the CNS tumors of TSC (Feliciano et al., 2011; Magri et al., 2013; Zhou et al., 2011). In contrast, the cell of origin for mesenchymal TSC has yet to be identified; however, given that mesenchymal TSC neoplasms demonstrate characteristics of NCCs we reasoned that NCCs are a candidate cell of origin for mesenchymal TSC (Delaney et al., 2014). To explore this hypothesis, publicly available single cell RNA-sequencing (scRNA-seq) datasets were used to compare the gene signature of P-LAM cells originating from multiple LAM patients (Guo et al., 2019) to the gene signatures of both trunk and cranial neural crest subtypes identified in the developing mouse (Soldatov et al., 2019). Analysis of these gene sets revealed significant gene set overlap of P-LAM cells with both trunk and cranial NCCs (Figure S1D), confirming that P-LAM cells are neural crest-like, if not derived from this cell lineage, warranting their use to model P-LAM.

Thus, to investigate lineage-specific mechanisms contributing to the pathogenesis of TSC, we conceived parallel cell differentiation strategies to generate cultures enriched for either NPCs or NCCs based on small molecule dual SMAD signaling inhibition of hPSCs (Figure 1A, 1G). This approach promotes rapid exit from pluripotency and induction of a predominant dorsal neuroectoderm fate, with consequent potential to drive enrichment of NE-derived NPCs or NCCs by defined culture conditions (Chambers et al., 2009; Tchieu et al., 2017). Validating previous findings and our rationale, RNA sequencing (RNA-seq) of end-point cultures revealed that dual SMAD inhibition of high density adherent monolayer hPSCs resulted in a dominant NPC gene signature (Figure 1G, S1E); conversely, an embryoid body (EB) induction approach permitted NCC marker gene enrichment (Figure 1G, S1E). In this latter protocol, EBs are neuralized for 5 days and then plated onto a fibronectin substrate, which permits outward migration of $\mathrm{HNK}-1^{+} / \mathrm{SOX} 9^{+} / \mathrm{p} 75^{+} \mathrm{NCC}$ from $\mathrm{PAX} 6^{+} \mathrm{NPC}$-rich 
cell clusters as they are progressively induced (Figure S1F-H). Thus, we employed the 12-day adherent monolayer and EB-based induction strategies (Figure 1G) to respectively establish cultures enriched for NPCs and NCCs from each of our four isogenic paired WT and TSC2 $2^{-/}$hPSC lines. Notably, WT and TSC2 $2^{-/}$end-point cultures similarly expressed appropriate lineage-associated genes (Figure S1E). This included a substantial increase in expression, compared to the undifferentiated state, of NCC determinant genes such as $S O X 9, P A X 3$, $R X R G, Z E B 1, L E F 1$ and NGFR (encodes p75) uniquely in EB-derived NCC cultures, and a monolayer NPCspecific enrichment of CNS neural progenitor markers including PAX6, SHH, NEUROG2, OTX1, and GLIS3.

\section{TSC2 $^{-/}$NPCs model key features of TSC neurological manifestations}

TSC2-deficiency results in cognitive abnormalities and the growth of low-grade tumors in the developing brain, specifically cortical tubers, subependymal nodules (SENs) and subependymal giant cell astrocytomas (SEGAs), that persist throughout life and contain molecular features indicative of aberrant neural lineage differentiation, maturation, and organelle dysfunction (Goto et al., 2011). In addition to dysplastic neurons and astrocytes, which to date have been the predominant focus within the field in understanding TSC brain tumors, enlarged cells that demonstrate atypical neural progenitor identity are primary constituents of these tumors (Martin et al., 2017a;

Zhou et al., 2011). To ultimately model both progenitor-like and mature TSC brain tumor cell types, we induced hPSC cultures into NPCs using the high density monolayer SMAD inhibition protocol (Figure 1G). Within 96 hours, we observed that $T S C 2^{-/}$cells were visibly enlarged and had accumulated an abundance of globular structures which persisted throughout the differentiation time course (Figure S2A). This struck us as being highly reminiscent of vesicle accumulation observed in mTORC1 hyperactive cells in patient tumors (Goto et al., 2011). WT and $T S C 2^{-/}$cultures were harvested 12 days following initiation of NPC induction and maintained in neural progenitor expansion medium for multiple passages to examine long-term progenitor phenotypes. $\mathrm{TSC}^{-/}$cultures exhibited increased phosphorylation of S6 at serine 235/236 (P-S6) under fully supplemented media conditions, indicating mTORC1 hyperactivation (Figure 2A\&B, S2B), and were larger than their WT counterparts (Figure S2A\&C). Both WT and TSC2 $2^{-/}$cells expressed the NPC lineage markers SOX2, NESTIN and PAX6, demonstrating a progressive increase in expression of NPC determinants and the glial marker GFAP in $T S C 2^{-/}$cells as they aged in culture (Figure 2A\&C, S2D\&E). Mitochondrial content was also progressively 
increased in $\mathrm{TSC}^{-/} \mathrm{NPCs}$ (Figure 2A\&D). These phenotypes reflect the aberrant organelle and lineage development observed in patient tumors and imply a dynamic regulation of cell fate and mitochondrial content in NPCs lacking TSC2. Altogether these data reveal that $T S C 2^{-/} \mathrm{NPC}$ cultures reflect multiple phenotypes reflective of patient brain tumors in TSC and can be exploited to model not only their progression, but also the earliest stages of disease initiation.

Neuronal differentiation produced $T S C 2^{-/}$cultures with enlarged soma and an expanded neurite network (Figure 2E) and an increased capacity for spontaneous gliogenesis in mature cultures (Figure S2F), modeling neuronal structure, network and neural and glial cell fate phenotypes observed in TSC brain lesions. To determine whether $T_{S C} 2^{-/}$cultures exhibited functional hyperactivation typical of TSC epileptic and cognitive phenotypes, we isolated AMPA receptor-mediated spontaneous excitatory post-synaptic currents (sEPSCs) and measured the amplitude (Figure 2F) and frequency (Figure S2G) of these events via whole-cell patch clamp technique. Indeed, $T S C 2^{-/}$cells showed significant increases in the amplitude of AMPAR-mediated sEPSCs compared to untreated WT cells. Additionally, this could be rescued by rapamycin during differentiation (Figure $2 \mathrm{~F}$ ), revealing that the neuronal hyper-excitability in $T S C 2^{-/}$cells is mTORC1-dependent (Figure $2 \mathrm{~F}, \mathrm{~S} 2 \mathrm{G}$ ).

Thus, $T S C 2^{-/}$NPCs and differentiated neuronal cultures together permit the recapitulation of molecular and functional aspects of all major cell types observed in TSC brain tumors, thus establishing the most comprehensive model to date of TSC brain tumor cell types.

\section{$\mathrm{TSC}^{-/}$NCCs accurately recapitulate mesenchymal TSC tumor phenotypes}

The most significant mesenchymal features affecting the quality of life of TSC patients include rAMLs and LAM nodules, the latter being associated with high morbidity and mortality (Oprescu et al., 2013). These lesions are composed of potential neural crest progeny: rAMLs and LAM nodules consist of proliferative spindle-shaped cells that express smooth muscle markers (e.g., $\alpha$-SMA) and larger epithelioid cells that react with HMB45 (a monoclonal antibody that recognizes the melanoma-associated protein gp100), with adipocytes contributing to rAMLs only. Other melanocyte markers are also expressed within rAMLs and LAM nodules (e.g., TRYP1, MART1, GD3) (Gilbert et al., 2013; Grzegorek et al., 2015; Klarquist et al., 2009). These data suggest that the 
cell-type of origin for LAM is neural crest-like, a hypothesis supported by our comparative analysis of P-LAM transcriptomic signature to those of NCCs subtypes in the developing mouse (Figure S1D).

To establish a NCC-based model of mesenchymal development and TSC tumorigenesis, an attached EBbased dual SMAD inhibition approach was employed (Figure 1G) to spatially enrich for NCCs (Chambers et al., 2009). By day 10 of differentiation, when NCC specification genes were upregulated in both WT and TSC2 ${ }^{-/-}$ cultures (Figure S1D), SOX9 ${ }^{+}$cells can be observed migrating away from $\mathrm{PAX}^{+}$neural clusters (Figure S1E). Selective dissociation of migratory outgrowths at day 12 efficiently enriched for p75 expressing cells in all cell lines, regardless of TSC2 genotype (Figure S1F\&G). This resulted in highly enriched SOX9 $9^{+} \mathrm{HNK}-1^{+}$ maintenance cultures with minimal contamination of PAX6 expressing NPC populations (Figure 2G, S3A). As expected, P-S6 staining confirms $T S C 2^{-/}$NCCs are unable to negatively regulate mTORC1 signaling following 24h starvation (Figure 2H). Irrespective of TSC2-deficiency, the generated NCCs are multipotent and can be differentiated to both ectodermal and mesodermal lineages, including smooth muscle cells and adipocytes which are characteristic of TSC mesenchymal tumors (Figure S3B). NCCs also displayed classic mesenchymal stem cell phenotypes. RNA-seq of day $10 \mathrm{NCC}$ differentiation samples revealed WT and $T S C 2^{-/}$cells express comparable levels of epithelial to mesenchymal transition (EMT) related genes (Figure S3C); however, $T S C 2^{-/-}$ cells showed a significant increase in migratory potential compared to WT cells assayed via live cell tracking over a $6 \mathrm{~h}$ time period (Figure 2I, Supplemental multimedia). This suggests that $T S C 2^{-/-}$NCCs can model the metastatic potential of LAM cells. In both $\mathrm{WT}$ and $T S C 2^{-/} \mathrm{NCCs}$, rapamycin significantly reduces the migratory potential of $T S C 2^{-/-}$NCCs. However, rapamycin-dependent reduction in migratory potential of $T S C 2^{-/} \mathrm{NCCs}$ is merely normalized to that of the isogenic WT controls, suggesting mTORC1-independent mechanisms contribute to cell motility in TSC2-deficient cells.

To investigate the increased migratory potential observed in $T S C 2^{-/} \mathrm{NCCs}$, we performed functional enrichment analysis of significantly (padj < 0.05) differentially expressed genes (DEGs) between $T S C 2^{-/}$and WT NCCs at day 10 of differentiation. Interestingly, the terms "Signaling by Receptor Tyrosine Kinases" and "VEGF ligand-receptor interactions" showed significant enrichment from the Reactome database using g:Profiler (Raudvere et al., 2019). Indeed, several receptor tyrosine kinase (RTK)-signaling associated genes involved in cell motility displayed increased expression in $T S C 2^{-/-} \mathrm{NCCs}$ compared to their WT counterparts, 
such as LAMB3, MET, and PDGFR $\alpha$ (Figure S3D). Most notable, however, is the increased expression of VEGFD transcripts in TSC2 $2^{-/}$NCCs. This result is highly reflective of the increased serum levels of VEGFD observed in LAM and TSC patients with rAMLs; VEGFD has emerged as an established biomarker for disease severity (Dabora et al., 2011; Seyama et al., 2006). In addition to VEGFD, VEGFB and VEGFC were significantly upregulated in TSC2 ${ }^{-/}$NCCs, along with FLT1 (VEGFR1) (Figure S3D) whose downstream signaling through the PLC $\gamma$ and PI3K pathways has been implicated in the promotion of cell motility (Weddell et al., 2018). Thus, although EMT-related genes are expressed in both WT and $T S C 2^{-/}$NCCs (Figure S3C), the increased motility observed in TSC2 $2^{-/}$NCCs is likely attributed to cell signaling mechanisms upstream of mTORC1, with VEGF signaling likely being a substantial contributing factor.

Common histological markers for mesenchymal TSC tumors include HMB45, $\alpha$-SMA, and elevated PS6 indicative of mTORC1 hyperactivation. Furthermore, PDGFRß expression is also elevated within TSC lesions (Arbiser et al., 2002; Liang et al., 2014; Siroky et al., 2014). To determine whether TSC2 ${ }^{-/}$NCCs express these hallmark mesenchymal TSC markers, NCCs were fixed $24 \mathrm{~h}$ after completion of the differentiation protocol. Similar to patient tumor explants, HMB45 staining revealed a significant subpopulation of $T S C 2^{-/}$cells reactive with this marker, displaying similar staining patterns to that seen in primary LAM cells (Figure 2J\&K) (Pacheco-Rodriguez et al., 2007). Both WT and TSC2 $2^{-/}$NCCs stained positive for P-S6 and $\alpha$-SMA at comparable levels (Figure 2J, S3E). In addition, immunoblotting of NCC maintenance cultures revealed expression of the LAM/TSC biomarker VEGFD in both WT and TSC2 $2^{-/}$NCCs, with significantly increased PDGFRß protein levels in TSC2 ${ }^{-/}$NCCs (Figure 2L, S3F). The expression of hallmark TSC tumor markers in both WT and $\mathrm{TSC}^{-/}$cells suggests that mesenchymal TSC cells are neural crest-like, aligning with the significant overlap observed comparing the P-LAM gene signature to trunk and cranial NCCs (Figure S1D). Indeed, elevated HMB45 reactivity along with increased VEGFD and PDGFR $ß$ expression, together with the enhanced migratory mesenchymal phenotype of $T S C 2^{-/}$NCCs, strongly support the use of these cells as an accurate model of the mesenchymal manifestations of TSC2-deficient cells in TSC and LAM. 
We next sought to elucidate the molecular basis for the development of tumors and broad disease phenotypes in $\mathrm{TSC}^{-/} \mathrm{NPC}$ and NCC progenitors. Given that cell lineage induction is heavily determined by dynamics in transcriptional regulatory programs, we reasoned that elucidating the genome-wide transcriptional events underlying the generation of these cell types would offer critical insights and reveal whether developmental transcriptional programs underlie tumor development in TSC. Thus, we performed genome-wide RNA-seq along a developmental time course of $T S C 2^{-/-}$and WT hPSCs as they were induced to differentiate through the NPC and NCC lineages using our parallel dual SMAD inhibition strategies (Figure 1G). RNA-seq timepoints were selected to monitor global gene expression throughout the high-density monolayer NPC-differentiation protocol corresponding to states of pluripotency (day 0), early neural induction (day 1), neuralization (days 3\&5), and neural precursor specification and maturation (days $8 \& 12$ ). To identify transcriptional changes at various stages of the EB-based NCC protocol, RNA-seq time points were similarly selected to emphasize phases of transition during differentiation: EB-formation (day 1), neuralization (days 2\&4), NCC specification (day 7) and enrichment (day 10) (Figure 1G). RNA-seq was performed on all four isogenic paired lines, serving as biological replicates for analysis of expression patterns within each respective differentiation time course for a total of 96 sequenced libraries. Principle component analysis (PCA) revealed distinct trajectories between WT and TSC2 $2^{-/-}$ samples within each differentiation time course, indicating dynamic transcriptional changes between genotypes from pluripotency to target cell lineage (Figure 3A). Clear separation between WT and $T S C 2^{-/}$samples was attributed to principle component (PC) 2 during NPC differentiation and to PC4 during NCC induction, implying that TSC2-deficiency is more impactful to transcriptional variance in NPC differentiation.

Confirming our findings that TSC2-deficiency does not affect maintenance and pluripotency of hPSCs (Figure 1D\&E), the number of DEGs between WT and $T S C 2^{-/}$cells at day 0 (pluripotent state) was negligible (6 and 19 genes identified respectively in NPC and NCC data sets) (Figure 3B). Likewise, very few DEGs were detected at day 1 of NCC induction (59 genes), a time-point representing a change in cell substrate interactions (switch from Matrigel adherence to suspension EB formation) but prior to the initiation of neuralization by SMAD inhibition. Strikingly, $T S C 2^{-/}$cells in both differentiation paradigms demonstrated a substantial number of DEGs compared to WT within 24 hours of neural induction (day 1 NPCs, 621 genes; day 2 NCCs, 189 genes), which expanded to thousands of DEGs at 3 days post-induction (day 3 NPCs, 3626 genes; day 4 NCCs, 
2830 genes) (Figure 3B). While the TSC2-mTORC1 signaling axis has been implicated in transcriptional regulation in various biological settings this has not been previously evaluated in the context of lineage induction during embryonic development. The magnitude of DEGs that we observed within 24-72 hours of neural induction was highly unexpected; during both induction protocols, the number of WT versus $T S C 2^{-/}$DEGs peaked 3 days following the addition of neuralization cues and remained substantially elevated at each respective end-point (day 12 NPCs, 898 genes; day 10 NCCs, 609 genes) (Figure 3B). Notably, NPC cultures exhibited larger gene expression differences across all differentiation time-points compared to NCCs. Altogether, these findings reveal that TSC2 is a potent regulator of genome-wide transcriptional programs at specific developmental stages, initiating at neurulation and persisting predominantly throughout NPC lineage progression.

\section{Gene signatures of TSC2 $^{-/}$NPCs and NCCs reflect those of primary TSC and LAM tumors}

To benchmark the $T S C 2^{-/}$NPC and NCC cell models of TSC and LAM, their respective gene signatures at differentiation endpoint respective to day 0 were compared to publicly available datasets of primary human TSC and LAM samples. Significantly up-regulated genes $\left(\log _{2} \mathrm{FC}>2\right)$ of WT and $T S C 2^{-/}$NPCs were compared to up-regulated genes $(\log 2 \mathrm{FC}>2)$ of a comprehensive RNA-seq dataset of two classes of TSC-associated brain tumors isolated from TSC patients, cortical tubers $(n=15)$ and SEN/SEGAs $(n=15)$ (Martin et al., 2017b). The gene signature of $T_{S C} 2^{-/}$NPCs intersects with $15.1 \%$ of SEN/SEGA DEGs and $16.8 \%$ of cortical tuber DEGs (Figure S4A), with WT NPCs displaying corresponding gene set overlaps of $10.3 \%$ and $10.1 \%$, respectively. Analysis of these gene sets revealed markedly increased proportions of gene set overlap of $T S C^{-/-}$NPCs with TSC brain tumors are than those of WT NPCs. Considering the RNA-seq data from TSC-associated brain tumors were derived from uncultured primary cells, the strong correlation of TSC2-deficient NPCs cultured at high density provide a robust tractable model of the CNS manifestations of TSC.

To further explore common pathway enrichments between $T S C 2^{-/}$NPCs, cortical tubers, and SEN/SEGAs, comparative KEGG-pathway enrichment analysis was performed utilizing up-regulated DEGs of TSC $^{-/-}$NPCs respective to their WT counterparts at differentiation endpoint (Figure S4B). Comparing KEGG pathway enrichment between these datasets reveals notable pathway enrichment between $T S C 2^{-/} \mathrm{NPCs}$ and 
SEN/SEGA datasets, including 'antigen processing and presentation', 'lysosome', and 'human

immunodeficiency virus 1 infection', with 'phagosome' and 'complement and coagulation cascades' being common terms between all three datasets. These shared pathway enrichments suggest that $T S C 2^{-/} \mathrm{NPCs}$ model differentially regulated pathways in both cortical tubers and SEN/SEGAs, however $T S C 2^{-/}$NPCs may be more applicable to modeling the SEN/SEGA component of neurological TSC manifestations.

Until recently, the transcriptomic signature of primary LAM cells has been difficult to resolve, due to the limitations of gene expression arrays and bulk RNA-seq experiments on primary samples of LAM tumors, which are well known to be of mixed cells types. However, Guo and colleagues recently characterized the pulmonary LAM (P-LAM) gene signature through scRNA-seq of primary samples isolated from multiple LAM patient lungs (Guo et al., 2019). To explore the relevance of the NCC-based model of TSC to P-LAM, the P-LAM gene signature was compared to the gene signature of both WT and TSC2 ${ }^{-/} \mathrm{NCC}$ s using only protein coding genes. Strikingly, both WT and TSC2 ${ }^{-/}$NCCs show a high degree of overlap with the P-LAM dataset (111 and 109 genes, respectively); both WT and $T S C 2^{-/}$gene signature show highly significant overlaps with strong association with P-LAM as determined by Fisher's exact test (Figure 3C). The size of these gene set overlaps are comparable to the 141 gene overlap observed between P-LAM and uterine LAM lesions identified within the work presented by Guo and colleagues. Notably, the overlapping gene sets of both WT and TSC2 $2^{-/}$NCCs with P-LAM includes multiple markers of LAM, including ACTA2 ( $\alpha$-SMA), MMP2, and the matrix proteins associated with P-LAM pathology, lumican (LUM) and decorin (DCN). Moreover, the P-LAM gene signature contains many NCC signature genes including TWIST1, SNAI2, FRZB, and PRRX1 (Soldatov et al., 2019). These data once again demonstrate that P-LAM cells are highly neural crest-like, echoing the results comparing the gene signatures of mouse NCCs to the P-LAM gene signature (Figure S1D) in a human in vitro model system. Importantly, TSC2 ${ }^{-/}$NCCs express hallmark markers of LAM - VEGFD, PDGFR $\alpha$, and PDGFR $\beta$ are unique to the intersection of the P-LAM and $T S C 2^{-/}$gene signatures. Although $T S C 2^{-/}$NCCs do not show transcriptional up-regulation of PMEL (epitope of HMB-45), PMEL is markedly more abundant at the protein level with $23.3 \pm 9.9 \%$ of $T S C 2^{-/}$NCCs expressing this diagnostic biomarker (Figure $2 \mathrm{~J} \& \mathrm{~K}$ ). This is highly reflective with the frequency of HMB-45 reactive cells (approximately 25\%) observed in pathologic sections of P-LAM (Valencia et al., 2015). This clearly demonstrates the power of this NCC based model, which, to the best 
of the authors' knowledge, is the only known cell model of LAM that expresses this characteristic biomarker of LAM.

To benchmark the NCC model of LAM, these hallmark LAM markers were cross referenced with published gene expression signatures of other commonly used LAM cell models. These included the immortalized renal angiomyolipoma (rAML) derived 621-101 cell line, Tsc2-null mouse fibroblast cell lines derived from $T s c 2^{-/}$mouse embryos (Himes et al., 2018; Zhang et al., 2003) and neonatal dermal fibroblasts (NDFs) from Prxxl-cre driven conditional Tsc2 knockout mice (Klover et al., 2017). Significant differential gene expression of these LAM markers was lacking in all of these cell lines, excluding MMP2 in 621-101 cells and DCN in $T_{s c 2^{--}}$NDFs. However, these cell models of LAM do indeed share overlapping gene signature with the P-LAM signature (77 with 621-101, 72 with $T s c 2^{-/-}$MEFs, 58 with $T s c 2^{-/-}$NDFs), supporting their use in modeling some aspects of LAM cell biology. The expression profiles of these cell models was compared with those of TSC2 $2^{-/}$NCCs, P-LAM cells, and TSC-associated rAMLs (Martin et al., 2017b) through comparative KEGG pathway analysis (Figure 3D). Overlapping pathway enrichment with P-LAM or rAML was not observed in 621-101, Tsc2 $2^{-/}$MEFs, or Tsc2 $2^{-/}$NDFs. Strikingly, we found that only the $T S C 2^{-/}$NCCs display significant pathway enrichment with P-LAM, sharing 'PI3-Akt signaling pathway' and multiple pathways involving signaling governing the extracellular matrix. The terms 'Focal adhesion' and 'relaxin signaling pathway' were additionally enriched among the $T S C 2^{-/} \mathrm{NCC}, \mathrm{P}-\mathrm{LAM}$, and rAML datasets, highlighting that aberrant regulation of cellular-extracellular matrix interactions, implicated in LAM pathogenesis, is a common phenotype observed among LAM-relevant TSC2-deficient cells. The unique enrichment of several pathways between $T S C 2^{-/}$NCCs and P-LAM thereby suggests that $T S C 2^{-/}$NCCs closely recapitulate the transcriptional profile of primary LAM cells.

\section{NPCs and NCCs exhibit opposing anabolic-catabolic signalling profiles during development}

To assess the biological impact of differential gene expression caused by TSC2-deficiency across NPC and NCC differentiation, gene ontology (GO) enrichment analysis was performed on significant DEGs between $T S C 2^{-/-}$ and WT samples at each time point. The most dominant GO biological process terms resulting from this analysis were related to endoplasmic reticulum (ER)/proteostatic-stress, response to unfolded protein, and autophagy 
(Figure S4C, red box). During TSC2 $2^{-/}$NPC differentiation these GO term groupings were over-represented across most timepoints, all being significantly enriched until day 5 and with autophagy-related terms being maintained until day 8. In contrast, these terms were only over-represented at days 2 and 4 of TSC2 $2^{-/}$NCC differentiation. This temporal enrichment pattern is consistent with KEGG pathway analysis, which revealed enrichment for "protein processing in the ER", "lysosome", "phagosome", and "antigen processing and presentation" in $T S C 2^{-/}$compared to WT cultures (Figure 3E). These results are reminiscent of the comparative KEGG pathway analysis of $T S C 2^{-/}$NPCs with primary TSC brain tumors (Fig S4B). Similar to GO enrichment analysis (Fig S4C), the KEGG pathway terms associated with ER/proteostatic stress response and catabolic vesicular signaling, recently implicated as a primary component of the ER stress response (Martina et al., 2016), are enriched only transiently during $T S C 2^{-/} \mathrm{NCC}$ differentiation, specifically at days 4 and 7 . Of note, these time points are associated with the neuralization stages of differentiation (days 2 and 4) and precede NCC enrichment (day 7) when adherent neuralized clusters predominate the differentiating cultures. This implies that the activation and stability of an ER/proteostatic stress and catabolic signaling response in $T S C 2^{-/}$cells is associated with neuralization of the differentiating cultures and maintenance of an NPC fate. Corroborating this, expression of NE determinant genes in both WT and $T_{S C}^{-/}$cultures was largely induced at days 3 and 5 in monolayer-NPC cultures, further increasing or remaining high through day 12. These same genes were induced to a similar degree at day 4 (and some at day 7) in EB-based NCC cultures but did not increase further or were completely lost at later time points (Figure S4D). In contrast, expression of neural crest lineage genes was much higher in EB-based NCC cultures, initiating at day 4 and further increasing through day 10, revealing the progressive emergence of a dominant NCC fate in these cultures following initial neuralization (Figure S4E).

RNA-seq analyses of NPC and NCC differentiation revealed significant enrichment of genes involved in catabolic signaling in differentiating $T S C 2^{-/}$populations. These genes were differentially expressed throughout the entire monolayer-NPC differentiation protocol, whereas during EB-based NCC induction, these enrichment terms were transient. To investigate this further, hierarchical clustering was performed on all RNA-seq samples comparing $\mathrm{TSC}^{-/}$to WT gene expression at each time point, focusing on genes associated with lysosome signaling and formation (Figure 4A). As expected, NCC differentiation sample day 4, the height of EB neuralization, clusters with NPC differentiation days 3 and 5, showing distinctive upregulation of lysosome- 
associated genes (Figure 4A, red box). In contrast, early NPC time points cluster well with both early and late NCC differentiation time points and display limited differential gene expression from WT cells (Figure 4A, green box). Thus, gene-set specific hierarchical clustering of DEGs between WT and $T S C 2^{-/}$cells in both NPC and NCC datasets reveals that lysosome/autophagy gene expression dysregulation reaches its peak at differentiation time points associated with neuralization of the respective cell populations, and that this catabolic signaling phenotype persists uniquely within the NPC lineage. Lysosome staining of differentiating NPC cultures with both a LAMP1 antibody and Lysosensor live cell dye confirmed that lysosomal content is significantly increased in $T S C 2^{-/}$cells throughout the differentiation time course post-neuralization (Figure 4B\&C, S5A). This phenotype is rescued when the mTORC1 inhibitor rapamycin is included in culture medium starting 6 hours prior to SMAD inhibition, revealing the dependency of TSC2 on mTORC1 for lysosomal regulation during early neural lineage induction.

Our findings suggest that NCCs resolve this developmental catabolic response as they are specified and acquire migratory capacity. To investigate this, day $7 \mathrm{~EB}$ differentiation cultures were fixed and probed for lysosome and autophagosome indicators by immunostaining and paired with lineage specific markers for NCCs (SOX9) and NPCs (PAX6) (Figure 4D, S5B). As expected, neuralized rosette clusters stain positive for PAX6, while migrating NCCs are $\mathrm{SOX} 9^{+}$. Neuralized rosette clusters, however, display a clear increase in lysosomal content compared to $\mathrm{SOX} 9^{+}$cells, as indicated by LAMP1 expression and Lysosensor staining (Figure 4D, S5C). Furthermore, autophagosome content was also increased in neural clusters as indicated by LC $3 \beta$ staining and autophagosome staining with Cyto-ID live cell dye (Figure 4D, S5C). Of note, lysosomal and autophagosome content appeared increased in TSC2 $2^{-/}$neuralized EB clusters compared to WT cells. Both LAMP1 and LC3 $\beta$ were detected in migrating $\mathrm{SOX} 9^{+}$cells; however, their expression is visibly diminished compared to NPC-rich clusters. TSC2 $2^{-/-}$monolayer cultures demonstrated reduced autophagosome staining compared to isogenic WT cultures during early induction. This is an expected consequence of TSC2 loss, however, an atypical increase in autophagosome content was observed at late differentiation (Figure S5D). This suggests a dynamic regulation of autophagy signaling in $T S C 2^{-/}$cells particularly as they differentiate through the neural lineage, with a lineagedependent induction of autophagy signaling which, together with their increased lysosomal content, reflects the 
observed accumulation of vesicular structures in these cultures (Figure S2A) as well as TSC tumors specifically within the brain (Di Nardo et al., 2014; Goto et al., 2011).

\section{TSC2-deficiency drives long-term lysosomal and proteostatic dysregulation in NPCs but not NCCs}

To determine whether the observed developmental cell stress responses we observed led to long-term lineagespecific differences in catabolic signaling, we measured levels of endosomal vesicles in NCCs and NPCs after multiple passages in maintenance culture. Reflecting developmental phenotypes, lysosomal content was highly increased in $\mathrm{TSC}^{-/-}$NPCs (Figure 5A) compared to WT counterparts, but only slightly elevated in NCCs (1.4fold versus 6-fold in NPCs) (Figure 5B\&C). In contrast, rapamycin treatment had no effect on Lysosensor levels in either cell type at this stage. This indicates a biphasic mechanism driving lysosomal content dysregulation in $\mathrm{TSC}^{-/-}$NPCs, whereby the initial cause in newly induced cells is an inability to inhibit mTORC1 activity but secondary, mTORC1-independent, adaptations are established and become the primary driving mechanism as cells mature over time. Autophagosome content was unchanged between WT and TSC2 ${ }^{-/}$NCCs (Figure 5C) as measured by CytoID live cell dye; however, we observed a 7-fold increase in autophagosome intensity in $T S C 2^{-/-}$ NPCs compared to WTs (Figure 5D). Autophagosome intensity was further increased following chloroquine treatment, demonstrating that both WT and TSC2 $2^{-/}$NPCs undergo autophagic flux (Figure 5D). This indicates that increased autophagosome content in $T S C 2^{-/-}$NPCs is primarily a consequence of increased biogenesis of these vesicles and not flux inhibition, contrary to the current paradigm of how mTORC1 hyperactivation is presumed to direct autophagy signaling. This unexpected observation was corroborated by a progressive increase in LC3 $\beta$ and autophagosome levels during $T S C 2^{-/}$NPC induction (Figure 5E, S5D), revealing an early establishment of this altered autophagy mechanism during lineage development.

To investigate likely mechanisms by which $T S C 2^{-/}$NPCs are capable of promoting autophagy in the presence of hyperactive mTORC1 activity, we examined the phosphorylation status of ULK1, a kinase with essential roles in the early stages of pre-autophagosome formation. Phosphorylation of ULK1 at serine-757 is a critical event through which mTORC1 inhibits autophagy signaling. We confirmed both mTORC1

hyperactivation, based on increased P-S6 (serine-235/236) (Figure 5E, S6A), and increased phosphorylation of ULK1 serine-757 in $\mathrm{TSC}^{-/}$cells during NPC induction (Figure S6C). AMPK is a secondary kinase with ULK1- 
dependent activity, with its phosphorylation of serine-555 driving autophagy. While AMPK levels were similar across genotypes (Figure S6D), we observed an increase in ULK1 serine-555 phosphorylation in differentiating $T_{S C} 2^{-/}$NPCs (Figure 5E, S6E), revealing activation of this alternative autophagy-promoting pathway in these cells. Corroborating pro-autophagy signaling in $T S C 2^{-/}$NPCs, total, unprocessed and lipidated forms of LC3 $\beta$ were increased in $\mathrm{TSC}^{-/}$cultures during monolayer-NPC induction, indicating increased autophagosome content (Figure 5E, S6F). An increased LC3 $\beta$-II/ LC3 $\beta$-I ratio was also observed, demonstrating that autophagic flux is also elevated in $\mathrm{TSC}^{-/}$cells during NPC induction (Figure S6F).

Comparative gene ontology (GO) enrichment analysis of our RNA-seq data (Figure 3E, S4C) illustrated an early activation of the misfolded protein response, which may function as a driving event for catabolic signaling activation in $\mathrm{TSC}^{-/}$cells during differentiation. We confirmed an increase in protein aggregate accumulation in $\mathrm{TSC}^{-/}$cells during neural differentiation using Proteostat aggresome indicator dye (Figure $5 F \& G)$. This phenotype was transient, however, with aggregate levels peaking at day 8 of differentiation and reducing to normal levels in end-point $T S C 2^{-/}$NPC cultures. Reflecting endosomal phenotypes and lineage specificity in proteostasis regulation, Proteostat intensity was more predominant in differentiating neural clusters than in migratory NCCs (Figure 5G). Accordingly, we observed low levels of aggregates during early stages of maintenance culture, but by late passages reflecting extensive aging they had accumulated selectively in $T S C 2^{-/-}$ NPCs (Figure S6G). Together these data suggest that $T S C 2^{-/}$cells mount an early developmental response to increased protein production, and that a selective reliance on lysosome-autophagy signaling in TSC2 $2^{-/}$NPCs is required to limit protein aggregate accumulation over time.

Underscoring the concept of an early protein stress response in $T S C 2^{-/}$cells, levels of the mTORC1 effector P-S6K and especially its target P-S6, a mark of active protein translation, were strongly reduced within the first 24 hours of dual SMAD inhibition in WT cultures, but this inhibition was incomplete at early time points in $T_{S C 2} 2^{--}$cells (Figure 5E, S6A\&D). Interestingly, P-S6 is undetectable by day 8 of NPC differentiation in spite of mTORC1 hyperactivation in $T S C 2^{-/}$cells (Figure 5E). P-S6 staining of day 7 NCC differentiations reveal P-S6 ${ }^{+}$migratory NCCs delaminating from largely P-S6 negative neural clusters (Figure S6B), revealing that NPCs specifically down-regulate S6 phosphorylation during lineage induction. Demonstrating the dependence of this signaling axis on mTORC1 regulation, P-S6 levels were strongly reduced by rapamycin 
treatment (Figure 5E); partial restoration of P-ULK1 serine-555, LC3 $\beta$ and autophagosome levels by rapamycin reflects a mechanistic connection between proteostasis and endosomal regulation in $\mathrm{TSC}^{-/-} \mathrm{NPCs}$ (Figure 5E, S5D).

\section{Bioenergetic reprogramming by TSC2 loss is highly lineage-specific to NPCs}

mTORC1 is a well-established regulator of cellular metabolism, and it is becoming increasingly clear that endosomal signaling is highly integrated with cellular bioenergetics. Previous culture models have revealed metabolic abnormalities in TSC1 or TSC2-deficient cells and have largely focused on increased glycolytic capacity. However, given the pervasive cell type-specific differences in endosomal signaling observed in our system, we sought to investigate the lineage-specific metabolic profiles of $T S C 2^{-/}$cells. $T S C 2^{-/-} \mathrm{NPCs}$ accumulate mitochondrial content in our model (Figure 2A\&C) as well as in patient tumors (Goto et al., 2011), and exhibit elevated levels of reactive oxygen species (Figure S7A), indicating likely effects on mitochondrial metabolism and oxidative phosphorylation in neural cells. Extracellular flux analysis at resting levels and under conditions of induced mitochondrial stress revealed that $T S C 2^{-/}$cells possess an overall increased capacity for mitochondrial oxygen consumption as NPCs (Figure 6A) but that this effect is limited in NCCs (Figure 6B; S7B\&C). Increased extracellular acidification in these same assays in $T_{S C} 2^{-/}$NPCs (Figure 6C), but not NCCs (Figure 6D), additionally indicate that $T S C 2^{-/}$NPCs uniquely exhibit increased glycolytic flux. Both TSC2deficient NPCs and NCCs have a higher capacity for ATP production compared to WT cells (Figure 6E\&F). In NPCs, this is attributed to both glycolytic and oxidative pathways (Figure 6E); in NCCs, this is due solely to oxidative capacity and is observed only under fully stressed conditions and not at resting state (Figure 6F).

These data suggest a high degree of bioenergetic flexibility specifically in TSC2-deficient NPCs that permits these cells to uniquely adapt to metabolic stress. To directly test this hypothesis, we measured the amount of ATP produced in each cell type from oxidative phosphorylation and glycolysis throughout the mitochondrial stress test using a recently published data analysis platform (Mookerjee et al., 2018). This integrated analysis confirmed that $T S C 2^{-/}$NPCs uniquely exhibit a highly increased bioenergetic capacity (Figure 6G\&H). TSC2-deficient NPCs are capable of increasing ATP generation under conditions of metabolic stress ('max') compared to 'resting' states (Figure 6G), while their WT counterparts and NCCs of both 
genotypes exhibit limited metabolic flexibility (Figure 6H). Comparing oxygen consumption post-treatment with the mitochondrial oxidative phosphorylation uncoupler FCCP with the resting state additionally demonstrates that TSC2-deficiency imparts an increased spare respiratory capacity to a much larger degree in NPCs than in NCCs (Figure 6I). These findings confirm previous assertions that TSC2-deficient cells adopt substantial metabolic signaling adaptations; yet we demonstrate that this occurs in a manner that is markedly lineagespecific, and in NPCs is more highly directed toward reprogramming of oxidative as opposed to glycolytic metabolism.

\section{Clinically approved proteasome inhibitors permit selective, lineage-specific cytotoxicity of $\operatorname{TSC}^{-/-}$cells}

The accumulation of lysosomes and autophagosomes, paired with the abundance of aggresomes within NPC populations as they both differentiate and self-renew is indicative of the importance of functional proteolytic machinery in the maintenance of NPC homeostasis. TSC2-deficiency exacerbates these phenomena, offering a potential vulnerability of $T S C 2^{-/}$cells that could be exploited for therapeutic benefit if protein degradation pathways are rendered inoperative pharmacologically. To test this, both NPCs and NCCs were exposed to the FDA-approved proteasome inhibitors bortezomib and carfilzomib, as well as the lysosomal inhibitor chloroquine, both alone and in combination. To investigate the compatibility and/or potential synergistic effects of these treatments with mTOR inhibitors, these drugs were administered both in the presence and absence of rapamycin. After $48 \mathrm{~h}$ exposure to proteasome inhibitors, selective toxicity to $T S C 2^{-/-} \mathrm{NPCs}$ was observed at 40nM, with minimal effect on WT NPCs (Figure 7A\&B). At 200nM of bortezomib or carfilzomib, TSC2 ${ }^{-/-}$NPC samples continued to display increased sensitivity to proteasome inhibition, although WT cells began to show low level toxicity. These trends were observed following $24 \mathrm{~h}$ exposure to proteasome inhibitors, though less pronounced (Figure S7D\&E). In contrast, both WT and $T S C 2^{-/}$NCCs showed nearly identical toxicity profiles with increasing concentrations of proteasome inhibitors at both $24 \mathrm{~h}$ and $48 \mathrm{~h}$ (Figure 7A\&B, S7D\&E). Interestingly, treatment with the mTORC1 inhibitor rapamycin or targeting the lysosomal/autophagy pathway with chloroquine did not affect the viability of either NPCs or NCCs (Figure 7C, S7F), nor did chloroquine or rapamycin display any synergistic cytotoxic effects when combined with bortezomib or carfilzomib (Figure S7G). Taken together, these data demonstrate that $T S C 2^{-/}$NPCs, but not WT NPCs, are specifically sensitized to 
proteasome inhibition. Furthermore, these effects are cell-lineage dependent, as both WT and TSC2 $2^{-/}$NCCs are unable to tolerate low levels of proteasome inhibition (Figure 7D).

\section{DISCUSSION}

Patients with TSC experience the development of low-grade tumors in multiple organs. Elucidation of therapeutic strategies that can eliminate TSC tumors has been a challenging and as yet unrealized goal; a major contributing factor is likely the lack of experimental models that consider the breadth of TSC tumors that exist and the cell types that comprise them. Given that $T S C 1^{-/}$and $T S C 2^{-/}$mouse models die embryonically with failed neural tube closure (Kobayashi et al., 1999; Kobayashi et al., 2001; Onda et al., 1999) and that proliferative neural and mesenchymal progenitors have been implicated as cells of origin for TSC tumors (Delaney et al., 2014), we reasoned that loss of TSC2 in NPCs and mesenchymal-like NCCs, which develop in parallel, would have substantial biological consequences reflective of disease etiology. Thus, we engineered and herein present the first multi-system model of TSC, which provides a number of advantages over existing models: a strategy to establish, in parallel, both neural and mesenchymal cells that carry TSC2 inactivating mutations; the potential to direct induction of disease-relevant cell types to permit analysis from initial stages of lineage induction through stages of progenitor cell maturation, differentiation and aging of derivative cell types; and the ability to generate TSC-relevant cell types that are of human origin and can be extensively expanded in culture. Recently reported TSC stem cell models have focused on investigating aberrant glial and neuronal cells (Blair et al., 2018; Costa et al., 2016); however, these cell types are non-proliferative components of neural TSC lesions and thus the consequences of TSC2-deficiency in the precursor cell pools that drive tumorigenesis and persist in these lesions have been overlooked. By uncovering critical biological pathways during early lineage induction and studying $T_{S C} 2^{-/}$NPCs longitudinally as they mature in culture, we provide the first expandable culture model of this tumor-relevant NPC sub-type. Furthermore, we show that the TSC2 $^{-/}$hPSC-derived NCCs we have established broadly reflect the mesenchymal tumors that develop in multiple tissue systems such as kidney (rAML) and lung (LAM) in TSC patients. The transcriptomic signature of $T S C 2^{-/}$NCCs strongly reflects that of P-LAM cells, far more faithfully than previously reported models of LAM. Molecular features are also highly indicative of a population reflective of LAM cells, including expression of the diagnostic antigen HMB45 
in a subset of cells which reflects patterns observed in LAM lesions. Our findings strongly support the use of $\mathrm{TSC}^{-/} \mathrm{NCC}$ as a model for LAM and suggest LAM cells are highly neural crest-like, if not originating from this multipotent cell lineage. Further expanding on the utility of this NCC-based model, directed differentiation of these $T S C 2^{-/}$NCCs towards smooth muscle cells and adipocytes could facilitate the investigation of nichespecific disease phenotypes of TSC2 deficient cells found in rAMLs and LAM nodules. Future studies of this nature would undoubtedly further accelerate the development of cell-type and context-specific therapeutic strategies.

Pre-clinical studies of TSC have predominantly focused on investigating non-progenitor cell types (neurons and glial cells), genetically engineered fibroblasts, or end-point cell types harvested from tumor biopsies; thus, there is little knowledge of the biological impacts of TSC2-deficiency in newly induced progenitors that may represent the earliest stages in tumor development. Toward this end, we provide a rich resource of the transcriptomic signatures that accompany human NCC and NPC development in both WT and $\mathrm{TSC}^{-/}$conditions comprised of 96 samples analyzed by RNA-seq among distinct cell lines, cell types and developmental time-points. This resource is intended to provide an in-depth understanding of genome-wide signatures during the early development and specification of neural and mesenchymal progenitors with high relevance to TSC tumor cells. Intended to be widely shared, this dataset and cell lines will help fuel continued discovery of biological mechanisms and therapeutic vulnerabilities in TSC, as well as neural and neural crest lineage development. Our focus in analysis of this dataset, and subsequent validation with molecular approaches across all four of our engineered isogenic cell lines, allowed us to demonstrate that early neuroepithelial development is associated with aberrant activation of a proteostatic stress response in $\mathrm{TSC}^{-/-}$cells, which is differentially resolved in neural and neural crest precursors and characterized by the adoption of lineage-specific lysosomal signaling mechanisms. This is a clear demonstration of how a single mutation within a ubiquitous cellular pathway, often the case in congenital malignancies, can manifest itself in unique and even opposing ways in distinct tissues and cell types. Furthermore, we found that the developmental phenomena observed in $T S C 2^{-/}$neural cells lead to long-term molecular adaptations that drive atypical catabolic programs and subsequent metabolic reprogramming, and that lysosomal dysregulation initiates due to mTORC1 signaling dysregulation but ultimately becomes insensitive to rapamycin treatment. This time-dependent loss of rapamycin 
sensitivity, presumably driven by cell signaling adaptations in $T S C 2^{-/} \mathrm{NPCs}$ that permit acquired independence from mTORC1 complex regulation, has compelling implications for the utility of broad and long-term use of rapamycin analogues to treat TSC patients.

Several biological mechanisms have been proposed to contribute to TSC tumorigenesis, many of which have undergone investigation as potential therapeutic targets. Our findings have critical implications for understanding the pathological basis of tumor development in neurological TSC, and for the treatment of system-specific disease manifestations. Dysregulation of autophagy has clearly been linked to tumor formation (Parkhitko et al., 2011); however, lysosome and autophagosome accumulation has been reported only in TSC brain tumors and in neural-lineage specific murine and cell models of TSC (Di Nardo et al., 2014; Goto et al., 2011). Here we reconcile these previous observations by revealing that $T S C 2^{-/}$neural lineage cells, but not NCCs or hPSCs, uniquely develop elevated endosomal signaling mechanisms, and that these are surprisingly established during early stages of precursor cell specification. Mitochondrial and metabolic defects, as well as proteasome dysfunction, have also been identified as potential therapeutic targets for both neurological and mesenchymal TSC (Abdelwahab et al., 2019; Ebrahimi-Fakhari et al., 2016; McKenna III et al., 2018; Parkhitko et al., 2014; Siroky et al., 2012; Van Scheppingen et al., 2016). These previous studies did not, however, permit analysis of the development of these phenotypes during lineage specification; thus, it has been entirely unclear which biological mechanisms drive the induction of disease phenotypes, and which are secondary adaptations of $\mathrm{TSC}^{-/}$cells. Our findings reveal for the first time that proteostatic stress and aberrant lysosomal signaling are initial events in the developmental origin of TSC-relevant tumor cell types, and that lineage-specific signaling responses result in the unique metabolic and endosomal adaptations that define long-term biological differences of neural and mesenchymal TSC tumors.

Our findings suggest a decisive role for acute protein translation regulation and catabolic signaling activation following neural lineage induction from pluripotency, in both a disease context and during normal tissue development. Following the addition of neural induction cues, levels of the protein translation marker PS6 decrease sharply in both WT and $T S C 2^{-/}$NPCs, yet this is incomplete and mTORC1 remains hyperactive in $\mathrm{TSC}^{-/}$cells. In contrast, P-S6 remained comparatively high in NCCs. This discovery brings to mind the wellestablished susceptibility of neural cells to protein aggregate accumulation, a phenomenon which broadly 
underscores neurodegenerative conditions and is typically attributed to factors such as the non-cycling nature of post-mitotic neurons. Our work suggests that a developmentally hard-wired sensitivity of the neural lineage to increased proteostatic stress may also be a contributing factor. It is apparent that tight regulation of metabolic signaling and proteostasis is integral in the development of neural lineages. Indeed, catabolic signaling is quickly revealing itself to be an important pathway across multiple levels of neural development, with involvement in the exit from pluripotency, lineage specification, and the maintenance and activation of adult neural stem cell populations (Audesse and Webb, 2018; Leeman et al., 2018; Villegas et al., 2019). Here, we advance these previous observations to show that this phenomenon is highly specific to the neural lineage, with the developmentally related neural crest lineage adopting distinct mechanisms.

We establish that AMPK/ULK1-mediated pro-autophagy signaling is concurrently activated in differentiating $T S C 2^{-/}$cells, corroborating previous observations of mTORC1-independent regulation of autophagy in patient tumors and TSC1/TSC2-deficient cell lines (Di Nardo et al., 2014). Our data introduce a paradigm in which decreased global protein translation is favored under normal conditions during early neural cell fate commitment, and that $T S C 2^{-/}$NPCs, which cannot adequately regulate mTORC1-mediated protein translation and degradation (Zhang et al., 2014), potently activate catabolic signaling mechanisms as an adaptive response to promote proteolysis. As discussed above, we further demonstrate a progressive reliance on mTORC1-independent signaling mechanisms to maintain endosomal signaling in these cells. This biology is reflected in the lack of synergistic toxicity when rapamycin is combined with proteasome inhibitors to selectively target $T S C 2^{-/-}$cells. However, this catabolic adaptive response is resolved upon NCC specification, revealing dynamic, lineage-specific regulation of endosomal, metabolic and proteostatic signaling. Although lysosomal-autophagy signaling is intrinsically active in WT NPCs, this system is exacerbated and cumulative in $T_{S C} 2^{-/-}$cells. While long-term $T S C 2^{-/-}$NPC cultures exhibit intact autophagic flux at a level comparable to WT cells, we show that they exhibit an overall increase in the biogenesis of endosomal vesicles which display incomplete clearance and progressive accumulation over time. The fact that proteosome inhibitors, but not autophagic flux inhibition (chloroquine), are selectively toxic to $T S C 2^{-/-} \mathrm{NPCs}$ clearly demonstrates that these cells are ultimately dependent on proteolytic activity to maintain their survival. The increased accumulation of 
protein aggregates in late stage $T S C 2^{-/} \mathrm{NPC}$ cultures, a time-point at which their growth is dramatically inhibited, further supports this conclusion.

The lineage-specific catabolic adaptations we identified in $\mathrm{TSC}^{-/-}$cells pose consequences in the therapeutic context. Bortezomib and carfilzomib are FDA-approved proteasome inhibitors that have been considered for treatment of TSC manifestations, and this has been applied predominantly toward mesenchymal tumors. Strikingly, we show that $T S C 2^{-/}$NPCs can be selectively targeted for cell death using these agents, leaving WT NPCs unaffected. However, the same treatments display no genotype specific toxicity in NCCs. These latter findings are in contrast to previous studies demonstrating the potential therapeutic effectiveness of these treatments in vitro; however, we note that the TSC2-deficient cell types used in these studies were murine cell lines and had limited tissue-specific relevance to TSC tumors (Babcock et al., 2013; Johnson et al., 2018; Zhou et al., 2009). Indeed, in a preclinical trial using a Tsc2 heterozygous knockout mouse model, bortezomib treatment was ineffective in targeting mesenchymal renal tumors (Auricchio et al., 2012). Our approach, which utilizes four unique human genetic backgrounds, supports this conclusion and additionally demonstrates that the utility of proteasome inhibition therapy for TSC is limited to the neural lineage manifestations. These results provide a strong argument for the necessity of developing lineage-specific cellular models of genetic disease, particularly in the case of multisystem neoplastic disorders, when investigating biological disease mechanisms and therapeutic strategies most likely to have clinical impact using in vitro systems. Altogether, this in vitro model system and comprehensive RNA-seq resource are intended to serve as a platform to further investigate the mechanisms underlying TSC tumorigenesis that remain elusive, such as the sex-specific mesenchymal manifestations of LAM, and to identify previously unconsidered vulnerabilities that span multiple TSC2deficient cell lineages.

\section{Acknowledgements:}

We thank Catherine Lawrence for her inspiration, members of the Stanford Lab for thoughtful review of this paper, and the Ottawa Bioinformatics and Human Pluripotent Stem Cell Core facilities. We thank the Tier 1 Canada Research Chair Program in Integrative Stem Cell Biology (WLS) for support. This research was 
supported by grants to WLS from the Canadian Institutes for Health Research (CIHR) (FRN-153188), the McEwen Centre for Regenerative Medicine (a Special Accelerated Discovery grant supported by Green Eggs and LAM), the LAM Foundation (Pilot grant LAM0123P01-17), and the United States Department of Defense via the Tuberous Sclerosis Complex Research Program of the Congressionally Directed Medical Research Program (W81XWH-14-1-0434 to both WLS and ASK). SPD was supported by the Judith R. Raymond Scholarship in Cancer Research. LMJ was supported by CIHR Banting and Ontario Institute of Regenerative Medicine Postdoctoral Fellowships and Cancer Research Society Next Generation of Scientists Scholarship.

\section{Author Contributions:}

Conceptualization, S.P.D., L.M.J., and W.L.S.

Methodology, S.P.D. and L.M.J.

Investigation, S.P.D., L.M.J., A.P., J.Y-L., C.D., T.T.W., V.C.D., A.R., D.A.P., M.E.H., and H.S.

Formal Analysis, S.P.D., L.M.J., A.P., J.Y-L, T.T.W., and S.H.

Writing - Original Draft, S.P.D. and L.M.J.

Writing - Review \& Editing, S.P.D., L.M.J., A.P., J.Y-L., D.A.P., M.E.H., H.S., and W.L.S.

Funding Acquisition, S.P.D., L.M.J., A.S.K., and W.L.S

Resources, W.L.S.

Visualization, S.P.D., L.M.J., J.Y-L.

Supervision, W.L.S.

\section{Declaration of Interests:}

The authors declare no competing interests. 


\section{MATERIALS AND METHODS}

\section{Cell Culture}

hESC lines H9 (WiCell WA-09), H7 (WiCell WA-07), H1 (WiCell WA-01) and induced pluripotent stem cell line 168 (Chen et al., 2017) were maintained on diluted Matrigel (BD Biosciences \#354230) in Essential 8 (E8)

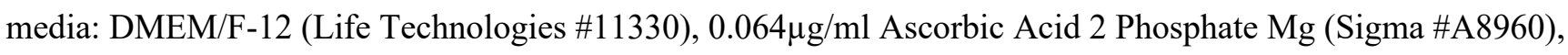
$14 \mu \mathrm{g} / \mathrm{ml}$ sodium selenium (Sigma \#S526), 0.1 $\mu \mathrm{g} / \mathrm{ml} \mathrm{FGF2} \mathrm{(Life} \mathrm{Technologies} \mathrm{\# PHG0263),} \mathrm{19.4 \mu g/ml} \mathrm{human}$ Insulin (Wisent \#511-016-CM), $10.7 \mu \mathrm{g} / \mathrm{ml}$ transferrin (Sigma \#T0665), 0.002 $\mu \mathrm{g} / \mathrm{ml}$ TGF- $\beta 1$ (Life Technologies

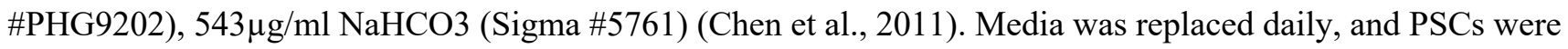
passaged every 4-5 days using 0.5mM EDTA.

NCCs were maintained on poly-L-ornithine (PLO; 0.0015\%)/fibronectin $(10 \mu \mathrm{g} / \mathrm{ml})$ coated growth surface in neural induction media (NIM): 1:1 DMEM/F-12: Neural Basal Media (Life Technologies \#21103-049), 0.5x N2 Supplement (Life Technologies \#17502-048), 0.5x B27 Supplement (Life technologies \#17504-044), 5 $\mu \mathrm{g} / \mathrm{ml}$ human Insulin, 0.02 $\mathrm{g} / \mathrm{ml} \mathrm{FGF2,} \mathrm{0.02 \mu g/ml} \mathrm{hEGF} \mathrm{(Sigma} \mathrm{\# E9644),} \mathrm{0.5x} \mathrm{GlutaMax} \mathrm{(Life} \mathrm{Technologies}$ \#35050061). Media was replenished every second day. For passaging, 90\% confluent NCCs were dissociated with Accutase and plated at a density of 20,000-25,000 cells $/ \mathrm{cm}^{2}$, approximately every 4-6 days, until a maximum of 10 passages. NPCs were maintained on diluted Matrigel in NIM (Matrigel diluted 1/18 in DMEMF12 for coating). For passaging, cells were dissociated with Accutase and plated at a density of 100,000-150,000 cells $/ \mathrm{cm}^{2}$, at the highest end of this range for the first 2 passages. Cells were supplemented with $10 \mu \mathrm{M}$ y-27632 (ROCKi; Tocris \#1254) for the first passage $2 \mathrm{~h}$ prior to harvest and for $48 \mathrm{~h}$ post-plating. A half-media change was performed every 2-3 days with 75\% of media replenished weekly. Cells were passaged when confluent, typically 2-3 weeks for the first 2 passages, and 1-1.5 weeks thereafter for a maximum of 10 passages, when growth of $T_{S C} 2^{-/}$NPCs markedly slows. All cells were maintained at $37^{\circ} \mathrm{C}, 5 \% \mathrm{O}_{2}, 10 \% \mathrm{CO}_{2}$.

\section{CRISPR/Cas9 Genome Editing}

At 80\% confluence, hPSCs were dissociated with Accutase (STEMCELL Technologies \#07920). Cells were rinsed off of the growth surface and gently triturated. Accutase was then diluted 1:4 in $\mathrm{PBS}^{-/}$(Life Technologies 
$\# 14190-250)$ and then pelleted (250g, $5 \mathrm{~min})$. Cells were resuspended in $\mathrm{PBS}^{-/-}$for counting. For each CRISPR/Cas9 transfection sample, $1 \times 10^{6}$ cells were aliquoted into microcentrifuge tubes and pelleted $(250 \mathrm{~g}, 5$

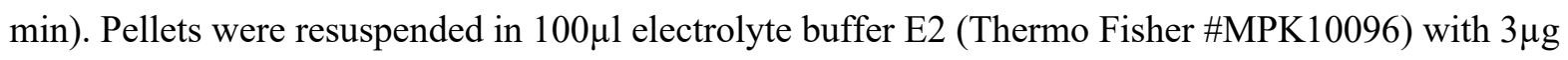

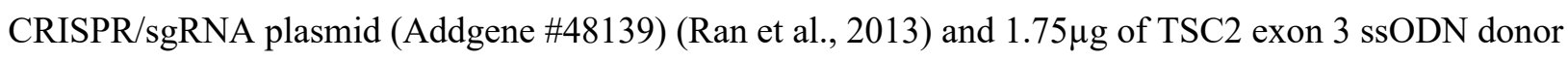

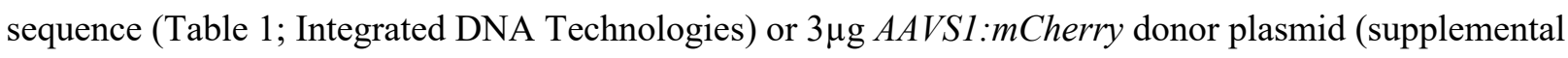
information). Samples were electroporated using the Neon Transfection System (Thermo Fisher MPK5000) using $100 \mu \mathrm{l}$ tips (Thermo Fisher \#MPK10096) at 2 pulses of 1050v, 30ms pulse width. Electroporated cells were

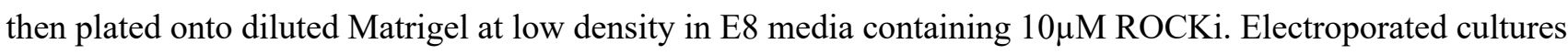
were left to grow until individual colonies formed. Expanding colonies were picked into Matrigel coated 96-well cluster plates for PCR/restriction enzyme-based screening for edited cells. Karyotypic analysis revealed no chromosomal abnormalities in 7 of the 8 CRISPR/Cas9 edited cell lines utilized in this study (data not shown). Trisomy 12, a common chromosomal abnormality in hPSC cultures (Mayshar et al., 2010), was detected in a subpopulation of $\mathrm{H} 1 \mathrm{TSC}^{-/-}$cells (35\%) and is, thus, not related to CRISPR/Cas9 editing. Guide RNA (gRNA) sequences utilized to modify the TSC2 and AAVS1 loci (Table 1) were identified and high scoring (98 and 80, respectively) (Hsu et al., 2013) gRNA sequences were selected to minimize potential off target cleavage events. To identify potential CRISPR/Cas9-induced off-target mutations in $\mathrm{TSC}^{-/} \mathrm{hPSCs}$, the highest scoring predicted guide RNA off-target sites were identified using the CRISPOR algorithm (Haeussler et al., 2016). Sequencing of these regions revealed no off-target cleavage induced mutations in any of the $T S C 2^{-/}$hPSC lines. See table 1 and supplementary methods for DNA/plasmid/oligonucleotide sequences.

\section{PCR Screening/Genotyping of CRISPR/Cas9 Edited Cells}

Genomic DNA was harvested using QuickExtract solution (screening of CRISPR/Cas9 clones; Epicentre EPIQE0905T) or NucleoSpin Tissue kit (routine genotyping; Macherey-Nagel \#740952.25). OneTaq DNA polymerase (New England BioLabs \#M0480) was utilized using primers flanking the genome editing target site of exon 3 of TSC2. Cycling parameters are as follows: $94^{\circ} \mathrm{C}$ initial denaturation for $30 \mathrm{~s}, 25 \mathrm{x}\left[94^{\circ} \mathrm{C} 20 \mathrm{~s}, 56.5^{\circ} \mathrm{C}\right.$ $\left.30 \mathrm{~s}, 68^{\circ} \mathrm{C} 30 \mathrm{~s}\right], 68^{\circ} \mathrm{C} 5 \mathrm{~m}, 4^{\circ} \mathrm{C} \infty$. PCR amplicons were then digested with PmeI restriction enzyme (New 
England BioLabs \#R0560S) in OneTaq buffer for $1 \mathrm{~h}$ at $37^{\circ} \mathrm{C}$. Agarose gel electrophoresis was utilized to resolve digested amplicons indicating successful integration of 'stop codon' donor sequence.

\section{EB-NCC Differentiation}

Day 0: Aggrewell plates (STEMCELL Technologies \#34425, \#34415) were prepared using pluronic solution ( $2 \%$ pluronic $\mathrm{w} / \mathrm{v}$ in sterile $\mathrm{H}_{2} \mathrm{O}$ ), centrifuging at $1,300 \mathrm{~g}$ for $5 \mathrm{~min}$, followed by 2 washes with prewarmed DMEM/F-12. Half differentiation culture volume of NIM $+10 \mu \mathrm{M}$ ROCKi was added to each well and placed at $37^{\circ} \mathrm{C}$ until ready for use. One day prior to routine passaging, $10 \mu \mathrm{M}$ ROCKi was added to pristine undifferentiated hPSCs $2 \mathrm{~h}$ before dissociation with Accutase. Cells were incubated in Accutase for 10-20min, until cells were easily washed off of the growth surface. Cell suspension was diluted 1:4 in DMEM/F-12 and pelleted at $250 \mathrm{~g}$ for $5 \mathrm{~min}$. Cells were resuspended in NIM $+10 \mu \mathrm{M}$ ROCKi and counted. Appropriate volumes of cell suspension were added to Aggrewells to generate 750cell EBs, and wells were topped up to $5 \mathrm{ml}$ (6 well format) or $2 \mathrm{ml}$ ( 24 well format) with NIM+ROCKi. Aggrewell plates were centrifuged at $100 \mathrm{~g}$ for $3 \mathrm{~min}$ and placed at $37^{\circ} \mathrm{C}, 5 \% \mathrm{O}_{2}, 10 \% \mathrm{CO}_{2}$. Day 1: $24 \mathrm{~h}$ later, all media was carefully removed from each well to minimize disturbing newly formed EBs in microwells. NIM +10 $\mu$ M SB431542 (Tocris: 1614) and 500nM LDN-193189 (Stemgent: 04-0074) (NIM+SB/LDN) was carefully added to each well and Aggrewell plates were returned to $37^{\circ} \mathrm{C}, 5 \% \mathrm{O}_{2}, 10 \% \mathrm{CO}_{2}$. Days 2-4: Half media changes with NIM+SB/LDN. Day 5: EBs were dislodged from microwells using a P1000 and transferred to $15 \mathrm{ml}$ conical tubes to allow EBs to gravity settle. Media was refreshed with NIM+SB/LDN, and EBs were plated onto PLO/fibronectin coated plates at a density of 40 EBs $/ \mathrm{cm}^{2}$. EBs were placed at $37^{\circ} \mathrm{C}, 5 \% \mathrm{O}_{2}, 10 \% \mathrm{CO}_{2}$ and dispersed evenly over the growth surface. Days 6-11: Media was replaced every other day with NIM+SB/LDN. Day 12: Neuralized adherent EB clusters were carefully washed off of the growth surface using a P1000, and media was aspirated. Cells were dissociated with Accutase and passed through a $40 \mu \mathrm{M}$ mesh filter to remove any remaining cell clumps. Accutase was diluted 1:4 with DMEM/F-12, and enriched NCCs were pelleted (250g, 5min), resuspended in NIM, and seeded onto $\mathrm{PLO} /$ fibronectin coated culture ware at a density of $25,000-30,000$ cells $/ \mathrm{cm}^{2}$.

\section{NCC Neural/Glial/Mesenchymal Differentiation}


At routine passaging, maintenance NCCs were seeded at a density of $20,000-25,000$ cells $/ \mathrm{cm}^{2}$ onto

PLO/fibronectin coated tissue culture ware in NIM. Differentiation towards neural, glial, and mesenchymal fates was initiated 24h later. Neural: NIM was replaced with basal NIM (bNIM; NIM without insulin, hEGF, and FGF2) supplemented with 50ng/ $\mu$ 1 BMP2 (STEMCELL Technologies \#78135). Glial: NIM was replaced with bNIM supplemented with 20ng/ml Heregulin- $\beta 1$ (STEMCELL Technologies \#78071) for 5 days. Media was then changed to bNIM supplemented with 5 $\mu$ M Forskolin (STEMCELL Technologies \#72112) and 10\% FBS (Life Tech \#12483-020). Mesenchymal: Adipocyte differentiation was carried out using the MesenCult Human Adipogenic Differentiation kit (STEMCELL Technologies \#05412) according to the manufacturer's instructions. Smooth muscle cell (SMC) differentiation was carried out by replacing NIM with bNIM supplemented with 10ng/ml TGF- $\beta 3$ (Sigma \#SRP3171). After 72h, media was replaced with 1:1 blend of bNIM and Media 231 (Life Technologies \#M-231-500) supplemented with smooth muscle growth supplement (SMGS; Life Technologies \#S00725) and 10ng/ml TGF- $\beta 3$. After a total of 7 days, media was replaced with Media 231 supplemented with SMGS and 10ng/ml TGF- $\beta 3$. Differentiating SMCs were passaged at $90-95 \%$ confluence when needed. All differentiations were carried out for 14 days, with media replacement every other day. Cultures were fixed with 3.7\% PFA at endpoint for analysis. Oil red staining of adipocytes was carried out as previously described (Mehlem et al., 2013).

\section{Monolayer-NPC Differentiation}

hPSCs were passaged as intact colonies, maintained on Matrigel, and neural lineage differentiation was initiated when the cultures were $90 \%+$ confluent to promote neuroepithelial induction (Tchieu et al., 2017), typically 3-5 days post-passage. Neuroectoderm differentiation was initiated by replacing E8 with KSR media containing $10 \mu \mathrm{M}$ SB and 500nM LDN. KSR media (for 500mL) contains 414mL of Knockout-DMEM (Life Tech, \#10829018) with 15\% Knockout-serum replacement (Life Tech, \#10828-028), 5mL of 100X Glutamax (Thermo Fisher, \#35050061), 5mL of 100X MEM-NEAA (Gibco, \#11140-050), 500uL $\boldsymbol{\beta}$-ME (Thermo Fisher, \#21985023), and $500 \mu \mathrm{L}$ Gentimicin (Wisent, \#450-135). Media was changed daily as KSR+ SB \& LDN from days 0-3. At day 4, N2 media was added in increasing amounts in the following ratios: days 0-3 100\% KSR, days 4-5 75:25 KSR:N2, days 6-7 50:50 KSR:N2, days 8-9 25:75 KSR:N2, days 10-11 100\% N2, harvest at day 12. LDN 
supplementation was maintained at all days, while SB was included only on days 0-3. N2 media composition is as follows (for 500mL): $486.5 \mathrm{~mL}$ of DMEM-F12, $15 \%$ glucose, $5 \mathrm{~mL}$ N2 supplement, $20 \mu \mathrm{g} / \mathrm{mL}$ human insulin, 2.5mL Hepes (Life Tech, \#15630080), and 500 $\mu \mathrm{L}$ Gentimicin. Cells were maintained at $37^{\circ} \mathrm{C}, 5 \% \mathrm{O}_{2}, 10 \% \mathrm{CO}_{2}$ during differentiation.

\section{NPC-neuronal Differentiation}

hPSC-derived NPCs at passage 0-2 were harvested with Accutase and plated on PLO/Laminin-coated glass coverslips (Thermo Fisher, \#12-545-101) at a density of 10,000-20,000 cells/ $/ \mathrm{cm}^{2}$. For substrate coating, coverslips were first sterilized in EtOH and washed extensively in sterile $1 \mathrm{X} \mathrm{PBS}^{-/}$, then placed in plastic wells and submerged in PLO (Sigma, P4957) solution ( $15 \%$ of $0.01 \%$ stock in sterile $\mathrm{H}_{2} 0$ ) for $2 \mathrm{~h}$ at room temperature or overnight at $4{ }^{\circ} \mathrm{C}$. PLO was aspirated and immediately replaced with $25 \mu \mathrm{g} / \mathrm{mL}$ laminin in $1 \mathrm{X} \mathrm{PBS}^{-/}$, incubated at $37^{\circ} \mathrm{C}$ for $2 \mathrm{~h}$ and stored at $4{ }^{\circ} \mathrm{C}$ for up to 1 week or at $-20^{\circ} \mathrm{C}$ for long-term storage. Differentiation to neuronal cultures was performed as described (Costa et al., 2016) with some modifications. Briefly, differentiation was induced when cells were $\sim 70 \%$ confluent, typically $2-3$ days post-plating, by replacing media with Neuronal differentiation media, containing 50:50 DMEM-F12: Neurobasal, 2.5mL N2 supplement and 5mL B27 supplement per 500mL, and 20ng/mL each of BDNF (Peprotech, 450-02) and GDNF (Peprotech, 450-10),

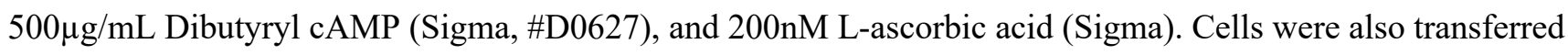
to normoxic conditions at the time of differentiation induction $\left(37^{\circ} \mathrm{C}, 5 \% \mathrm{CO}_{2}\right)$. Cells were fed twice weekly by replacing $75 \%$ of spent with fresh media. Cells were differentiated for 4-6 weeks prior to collection for functional assays or fixation for IHC. Cell fixation was performed by removing all but $250 \mu \mathrm{L}$ of cell media from each well (24-well format) and adding $250 \mu \mathrm{L}$ of $8 \%$ PFA, to limit loss of fragile neurite networks. Cells were fixed on ice for $1 \mathrm{~h}$, and then at room temperature for 30 minutes before carefully removing PFA, washing gently once in $1 \mathrm{X} \mathrm{PBS}^{-/-}$and storing at $4^{\circ} \mathrm{C}$ in $1 \mathrm{X} \mathrm{PBS}^{-/-}$.

\section{Whole-cell Patch Clamp Recording}

Cells were collected from glass coverslips in 24 -well culture plates. Before transfer to the recording chamber in an upright Nikon Eclipse E600FN microscope, culture medium was gradually changed to oxygenated artificial 
cerebral spinal fluid (ACSF) containing (mM): $124 \mathrm{NaCl}, 5 \mathrm{KCl}, 1.25 \mathrm{NaH} 2 \mathrm{PO} 4,1.2 \mathrm{MgSO} 4,26 \mathrm{NaHCO}, 2$

$\mathrm{CaCl} 2$, and 10 glucose, in 30 mins at room temperature (Gunhanlar et al., 2018). Whole-cell patch clamp recordings were obtained from differentiated neurons at 4-6 weeks following the initiation of the differentiation procedure (Sun et al., 2018). Patch electrodes with a resistance of 5-10 M were prepared from borosilicate glass capillaries with a Narishige micropipette puller (Model PC-100, Tokyo, Japan). Pipette intracellular solution contains (mM): 130 K-Gluconate, 2 MgCl2, 0.6 EGTA, 10 HEPES, 5 KCl, 2 ATP-Mg(Na2), pH 7.3. Data were collected using MultiClamp 700B amplifier. Signals were filtered at $2 \mathrm{kHz}$, digitized at $20 \mathrm{kHz}$ by a Digidata 1500 interface, acquired by the pClamp 10.7 software, and analyzed with the Clampfit 10.7 program (Molecular Devices). To characterize the intrinsic membrane properties of cells, hyper- and depolarizing rectangular pulses of 500-1000ms duration were applied. Spontaneous EPSCs (sEPSCs) were recorded at a $-60 \mathrm{mV}$ holding potential for at least 10 mins to isolate AMPAR mediated currents from NMDAR mediated currents. Additionally, picrotoxin (PTX) (100M), a GABAA blocker, was administered to further pharmacologically isolate AMPAR mediated currents. sEPSC events were detected automatically using Clampfit 10.7, and frequency and amplitude histograms were constructed using this program. All events were confirmed visually on the basis of the rise and decay times. All electrophysiology data were expressed as mean \pm SEM. Data was first tested for normality using the Shapiro-Wilk normality test. Then, statistical significance was assessed using a one-way ANOVA test followed by post hoc Bonferroni test, and a Mann-Whitney rank test for comparisons of data that were not normally distributed. Statistical significance differences are established as $\mathrm{p}<0.05$.

\section{Teratoma Assays}

Teratoma assays were performed as previously described (Chang et al., 2013). Briefly, hPSCs were harvested using Accutase 1 day prior to routine passaging, diluted 1:4 in DMEM/F-12, and pelleted (250g, 5min). Cells were resuspended in E8 media and counted. $1 \times 10^{6}$ cells were aliquoted, pelleted, and resuspended in $100 \mu 1$ ice cold Matrigel for each planned injection. Matrigel embedded cells were injected intramuscularly into the tibialis anterior of $N O D / S C I D$ mice. Once large visible leg tumors were observed (8-12 weeks), mice were sacrificed 
and teratomas were excised and fixed in 10\% formalin. Teratomas were then processed for paraffin embedding, sectioned, and stained with hematoxylin and eosin for analysis.

\section{Imaging Flow Cytometry}

hPSCs were dissociated with Accutase, diluted 1:4 in $\mathrm{PBS}^{-/}$, and then pelleted (250g, 5min). Cell pellets were resuspended in $3.7 \%$ PFA and fixed for $15 \mathrm{~min}$ at room temperature. Fixed cells were washed twice with excess $\mathrm{PBS}^{-/}$, followed by permeabilization in ice-cold $90 \%$ methanol for $30 \mathrm{~min}$ on ice, followed by 2 washes in staining buffer: 1\% BSA (Wisent \# 800-095-EG), 0.1\% Triton-X (BioShop \#TRX777) in PBS ${ }^{-/}$. Samples of 5 x $10^{5}$ cell were aliquoted into $5 \mathrm{ml}$ round bottom tubes and blocked in excess staining buffer for $30 \mathrm{~min}$ on ice.

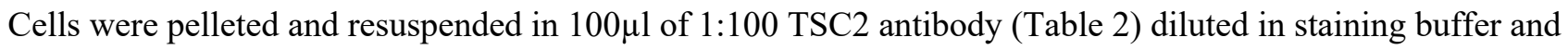
incubated at room temperature for $1 \mathrm{~h}$. Cells were washed in excess blocking/staining buffer, and resuspended in $100 \mu 1$ of 1:1000 secondary antibody diluted in staining buffer and incubated for 30min at room temperature, shielded from light. Cells were washed once with excess staining buffer and resuspended in $200 \mu 1$ containing $2 \mu \mathrm{g} / \mathrm{ml}$ Hoechst 33342 (Invitrogen \#H3570) diluted in $\mathrm{PBS}^{-/}$. Single stain and no stain controls were prepared in parallel. Cells were passed through a $40 \mu \mathrm{m}$ cell strainer (Falcon \#352340) prior to imaging on the Amnis ImageStreamX Imaging Flow Cytometer.

\section{Flow Cytometry}

EB-NCC cultures were rinsed with media to remove neuralized adherent EB-clusters using a P1000, prior to harvesting with Accutase. Matching undifferentiated hPSC lines were harvested in parallel with Accutase. Cells were gently lifted via trituration, diluted 1:4 in DMEM/F-12, and passed through a 40 $\mu \mathrm{m}$ cell strainer. Cells were pelleted, resuspended in NIM, counted, and $5 \times 10^{5}$ cells were aliquoted into round bottom tubes for staining. Cells were blocked in excess FACs buffer (4\% FBS [Life Tech \#12483-020], 100 $\mu \mathrm{M}$ EDTA in PBS $^{-/}$)

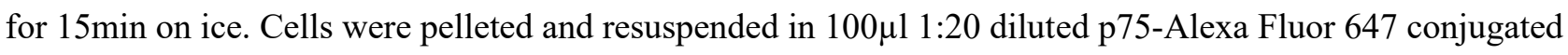
antibody (BD Biosciences: \#560326) in FACS buffer. Cells were incubated for 30min on ice, shielded from light. Cells were washed once with excess FACS buffer and resuspended in 500 $\mu 1$ of 1:2000 diluted Sytox Blue nucleic acid stain (Thermo Fisher \#S11348) in FACS buffer. Mouse $\mathrm{IgG}_{1}$-Alexa Fluor 647 isotype controls (BD 
Biosciences \#557783) and no stain controls were prepared in parallel. Cells were passed through a $40 \mu \mathrm{m}$ filter and immediately measured using the BD Biosciences LSR-Fortessa flow cytometer and analyzed with FloJo (version 10.5.3).

\section{Western Blotting}

Cell lysates were collected after washing cells with ice cold $\mathrm{PBS}^{-/-}$, followed by brief incubation on ice with RIPA cell lysis buffer: $150 \mathrm{mM} \mathrm{NaCl}, 1 \%$ Triton-X, 0.1\% SDS, 50mM Tris, 1x PhosSTOP phosphatase inhibitor mix (Sigma \# 4906845001), 1x complete protease inhibitor mix (Sigma 11873580001). Cells were scraped and transferred to microcentrifuge tubes and rotated at $4^{\circ} \mathrm{C}$ for $30 \mathrm{~min}$, followed by centrifugation at $16,000 \mathrm{~g}$ at $4^{\circ} \mathrm{C}$ for $20 \mathrm{~min}$ to generate cleared lysates. Lysates were stored at $-80^{\circ} \mathrm{C}$. After thawing for analysis, protein concentrations were normalized and probed via western blot, imaged using the Odyssey Classic Infrared System (LI-COR Biosciences), and analyzed using standard densitometry techniques using FIJI (Schindelin et al., 2012). Antibodies utilized for western blot can be seen in Table 2.

\section{Live Cell Staining}

NPC or NCCs were dissociated on day of routine passaging and seeded into 96-well cluster plates for live high content imaging assays. NPCs were seeded at a density of 20,000 cells per well and NCCs were seeded at a density of 7,500 cells per well. 24h after plating media was replenished and, if applicable, cells were administered treatments of rapamycin or chloroquine. After $24 \mathrm{~h}$ incubation (or $72 \mathrm{~h}$ for post-rapamycin Lysosensor staining of NPCs), cells were prepared for live imaging by washing with media, followed by the addition of live cell dyes in NIM with $2 \mu \mathrm{g} / \mathrm{ml}$ Hoechst 33342: 1:1000 Lysosensor Green DND-189 (Thermo Fisher \#7535), 1:2000 Cyto-ID Autophagy Detection dye (ENZO \# ENZ-51031), 20nM Mitotracker Deep Red FM (Thermo Fisher \#M22426), or 25 $\mu$ M carboxy-H2DCFDA (Thermo Fisher \#I36007). Cells were incubated with live cell dyes for 30min under maintenance conditions. Cultures were then carefully washed three times for 5min with NIM, and media was replenished with appropriate treatments for imaging. Imaging for high content quantification was performed using the Thermo Fisher ArrayScan VTI High Content Screening (HCS) platform, 
utilizing the live cell chamber at $37^{\circ} \mathrm{C}, 5 \% \mathrm{CO}_{2}$. Image analysis was facilitated by HCS Studio software (version 6.5.0).

\section{Cytotoxicity Assays}

Cells were seeded and grown following maintenance conditions for 24 hours. They were then treated with 100nM Rapamycin (Calbiochem \#553211) and/or 10 $\mu \mathrm{M}$ Chloroquine (Sigma, C6628) and/or various concentrations of Bortezomib (Adooq Bioscience \#A10160) or Carfilzomib (Adooq Bioscience \#A11278) as well as $0.1 \%$ DMSO for 24 or 48 hours. They were then stained with $2 \mu \mathrm{g} / \mathrm{mL}$ Hoechst and $10 \mathrm{nM}$ Sytox Green (Thermo Fisher \#S7020) for 30 minutes. Imaging was performed using the Thermo Fisher ArrayScan VTI HCS platform, utilizing the live cell chamber at $37^{\circ} \mathrm{C}, 5 \% \mathrm{CO}$. Image analysis was facilitated by HCS Studio software, in which cell death was assessed using the percentage of Sytox Green positive cells in a given population.

\section{Immunofluorescence}

Unless specified for specific antibody targets, all immunostaining was performed as follows: Cells were fixed with $3.7 \%$ PFA for $15 \mathrm{~min}$ at room temperature after removing media, followed by 3 washes with PBS $^{-/ .}$. Cells were permeabilized and blocked in excess immunofluorescence staining buffer (IF-SB; 1\% BSA, 0.1\% Triton-X in $\mathrm{PBS}^{--}$) for $1 \mathrm{~h}$ at room temperature. IF-SB used for blocking was removed, and IF-SB containing diluted primary antibodies (see Table 2) was added to each sample and incubated overnight at $4^{\circ} \mathrm{C}$. Samples were then washed three times for 10min before the addition of secondary antibody diluted 1:1000 (Table 2) in IF-SB. Samples were incubated in secondary antibody solution for $1 \mathrm{~h}$ at room temperature, followed by three washes with $\mathrm{PBS}^{-/-}$, in which $2 \mu \mathrm{g} / \mathrm{ml}$ Hoechst 33342 was included in the final wash step. Images were captured using the Zeiss Observer A1 or Observer Z1 fluorescence microscopes or captured for high content analysis using the ArrayScan VTI HCS platform and Studio software.

Alterations to the immunostaining protocol: HNK-1 cell surface staining was completed after PFA fixation, but prior to cell permeabilization. For HMB45 staining, samples were permeabilized using 100\% ice-cold methanol 
for 10min on ice following PFA fixation. For LAMP1 and LC3ß immunostaining, cells were fixed in ice-cold $100 \%$ methanol prior to proceeding with blocking and staining.

\section{Proteostat Staining}

Cells were fixed with $3.7 \%$ PFA for $15 \mathrm{~min}$ at room temperature, followed by three washes with $\mathrm{PBS}^{-/}$. Cells were then permeabilized with $0.1 \%$ Triton-X diluted in $\mathrm{PBS}^{-/-}$for $10 \mathrm{~min}$, followed by three washes with $\mathrm{PBS}^{-/}$. Proteostat aggresomes detection dye (ENZO \#ENZ-51035-K100) was diluted 1:2000 in $\mathrm{PBS}^{-/-}$containing $2 \mu \mathrm{g} / \mathrm{ml}$ Hoechst 33342 . Samples were incubated for $30 \mathrm{~min}$ at room temperature, followed by three washes, 10min each, with $\mathrm{PBS}^{-/}$. Images were captured using the Zeiss Observer A1 or Observer Z1 fluorescence microscopes, or captured for high content analysis using the ArrayScan VTI HCS platform and Studio software.

\section{Motility Assay}

NCCs were dissociated for plating on day of routine passaging and seeded into 96-well cluster plates at increasing densities of 1,000 to 6,000 cells per well in NIM. 24h later, media was replenished and 100nM rapamycin or DMSO was added to appropriate samples. Time lapse imaging (15 minute intervals over $6 \mathrm{~h}$ ) of mCherry or CellTracker Deep Red (Thermo Fisher \#C34565) signal was performed utilizing the Thermo Fisher ArrayScan VTI HCS platform, utilizing the live cell chamber at $37^{\circ} \mathrm{C}, 5 \% \mathrm{CO}_{2}$. CellTracker Deep Red staining was performed according to the manufacturers recommended protocol. Cell tracking image analysis was performed on wells displaying 30-60\% confluence, using HCS Studio software.

\section{Extracellular Flux Analysis}

Extracellular flux assays were performed by Seahorse technologies, using the 96XF platform (Agilent Technologies), as previously described for mitochondrial stress test (Julian et al., 2017). Modifications are: cells were seeded in Seahorse XF plates on Matrigel at 50,000 cells/well for NPCs and 25,000 cells/well for NCCs 1 day prior to analysis. Monensin was used, at $20 \mu \mathrm{M}$, to stimulate maximal ATP demand and glycolytic capacity through the plasma membrane $\mathrm{Na}^{+} / \mathrm{K}^{+}$-ATPase (Mookerjee et al., 2016). Each 'measurement' recorded consisted of a 3-minute mixing period at resting state or following addition of indicated chemicals, followed by a 3-minute 
interval during which $\mathrm{O}_{2}$ consumption rates were actively measured and recorded. $\mathrm{O}_{2}$ consumption rates were normalized to the number of cells plated, based on an equivalent \# of cells remaining in WT and TSC2 ${ }^{-/}$wells at assay end-point (Figure S7B\&C). ATP production rates and Bioenergetic capacity were calculated as described (Mookerjee et al., 2018).

\section{RNA-Seq sample preparation and sequencing}

Cells were dissociated using Accutase and diluted 1:4 in $\mathrm{PBS}^{-/-}$prior to pelleting (250g, 5min). Cells were resuspended in $\mathrm{PBS}^{-/-}$and total cell count was noted. Cells were pelleted $(250 \mathrm{~g}, 5 \mathrm{~min})$ and resuspended in TRIzol reagent (Thermo Fisher \# 15596026). Samples were stored immediately at $-80^{\circ} \mathrm{C}$ until processing for RNA extraction. RNA extraction was performed in batches including all differentiation time points within a WT and $T S C 2^{-/}$cell line pairing. RNA extraction was performed according to the manufacturer's protocol followed by DNase digestion (Qiagen \#79254) and ethanol precipitation of RNA. RNA concentration was estimated using NanoDrop 2000 spectrophotometer (Thermo Fisher ND-2000) and ERCC spike in (Thermo Fisher \#4456740) was added, normalizing to cell number. Quality control of RNA integrity and total RNA concentration was then measured using the Bioanalyzer Eukaryote Total RNA Pico kit (Agilent \#5067-1513). Only samples with RIN values of 8.0 or greater were submitted for sequencing. Total RNA H9 WT and $T S C 2^{-/} \mathrm{NCC}$ sample libraries were prepared with ribosome depletion (Illumina \# 20020598), all other sample libraries were prepared using the TruSeq Stranded mRNA kit (Illumina \#RS-122-2101). All samples were sequenced on the Illumina NextSeq500 or NovaSeq6000 platform (Illumina) generating at least 30 million reads per sample. Reads were assigned to transcripts from GENCODE release 27 using Salmon (Patro et al., 2017) and differentially expressed genes were identified using DESeq2 v1.20.0 (Love et al., 2014). DESeq2 analysis modelled fold change between time points using the cell line as an independent factor (using the model ' cell_line + condition'), and fold changes were calculated using lfcShrink function, applying the apeglm method (v 1.2.1) (Zhu et al., 2018). Gene ontology enrichment analysis was performed using clusterProfiler R package (Yu et al., 2012). Time course gene expression clustering was performed using Dirichlet process Gaussian process mixture model using the DP_GP_Cluster Python package (McDowell et al., 2018) to cluster TPM values for genes that show a significant expression difference (using a 5\% FDR threshold) between sequential timepoints. Separate gene lists were 
calculated for NPC and NCC time courses, and expression patterns were clustered separately for WT and TSC2 $2^{-/-}$ cells within each protocol. All RNA sequencing datasets are available upon request and are available on GEO (accession \#GSE137614).

\section{Use of publicly available datasets for gene signature analysis}

The gene signature of P-LAM cells and mouse cranial and trunk NCCs was utilized as presented (Guo et al., 2019; Soldatov et al., 2019). All other gene signatures were established as the significantly up-regulated genes presented within each publication: TSC-associated tumors (SEN/SEGA, cortical tubers, rAMLs) (Martin et al., 2017b), 621-101 cells \& Tsc2 $2^{-/}$MEFs (Himes et al., 2018), and Tsc2 $2^{-/}$NDFs (Klover et al., 2017). Mouse gene signatures were converted to human orthologs prior to analysis. Gene set overlap analysis was performed using the GeneOverlap R package, and comparative analysis was performed using the clusterProfiler R package (Yu et al., 2012).

\section{Statistical analysis}

Sample data acquired from H9, H7, H1 and 168 hPSCs and their derivatives were considered biological replicates within a given assay or experiment. Multiple biological replicates from each cell line were utilized within a given experiment whenever possible. When data were normalized to WT samples, test sample data were normalized to their respective isogenic WT control before determining mean values, etc. Unless otherwise indicated, statistical significance was assessed using a one-way ANOVA test followed by Bonferroni post hoc analysis. When only 2 groups were compared a student's t-test was used. 


\section{REFERENCES:}

Abdelwahab, E., Pal, S., Kvell, K., Sarosi, V., Bai, P., Rue, R., Krymskaya, V., McPhail, D., Porter, A., and Pongracz, J. (2019). Mitochondrial dysfunction is a key determinant of the rare disease lymphangioleiomyomatosis and provides a novel therapeutic target. Oncogene 38, 3093.

Arbiser, J.L., Govindarajan, B., Bai, X., Onda, H., Kazlauskas, A., Lim, S.D., Amin, M.B., and Claesson-Welsh, L. (2002). Functional tyrosine kinase inhibitor profiling: a generally applicable method points to a novel role of platelet-derived growth factor receptor-beta in tuberous sclerosis. Am J Pathol 161, 781-786.

Au, K.S., Williams, A.T., Roach, E.S., Batchelor, L., Sparagana, S.P., Delgado, M.R., Wheless, J.W., Baumgartner, J.E., Roa, B.B., and Wilson, C.M. (2007). Genotype/phenotype correlation in 325 individuals referred for a diagnosis of tuberous sclerosis complex in the United States. Genetics in Medicine 9, 88.

Audesse, A.J., and Webb, A.E. (2018). Enhancing Lysosomal Activation Restores Neural Stem Cell Function During Aging. Journal of experimental neuroscience 12, 1179069518795874.

Auricchio, N., Malinowska, I., Shaw, R., Manning, B.D., and Kwiatkowski, D.J. (2012). Therapeutic trial of metformin and bortezomib in a mouse model of tuberous sclerosis complex (TSC). PLoS One 7, e31900.

Babcock, J.T., Nguyen, H.B., He, Y., Hendricks, J.W., Wek, R.C., and Quilliam, L.A. (2013). Mammalian target of rapamycin complex 1 (mTORC1) enhances bortezomib-induced death in tuberous sclerosis complex (TSC)null cells by a c-MYC-dependent induction of the unfolded protein response. Journal of Biological Chemistry $288,15687-15698$.

Bateup, H.S., Johnson, C.A., Denefrio, C.L., Saulnier, J.L., Kornacker, K., and Sabatini, B.L. (2013). Excitatory/inhibitory synaptic imbalance leads to hippocampal hyperexcitability in mouse models of tuberous sclerosis. Neuron 78, 510-522.

Blair, J.D., Hockemeyer, D., and Bateup, H.S. (2018). Genetically engineered human cortical spheroid models of tuberous sclerosis. Nature medicine, 1.

Bronner, M.E. (2012). Formation and migration of neural crest cells in the vertebrate embryo. Histochem Cell Biol 138, 179-186.

Canpolat, M., Gumus, H., Kumandas, S., Coskun, A., and Per, H. (2018). The use of rapamycin in patients with tuberous sclerosis complex: Long-term results. Epilepsy \& Behavior 88, 357-364.

Chambers, S.M., Fasano, C.A., Papapetrou, E.P., Tomishima, M., Sadelain, M., and Studer, L. (2009). Highly efficient neural conversion of human ES and iPS cells by dual inhibition of SMAD signaling. Nature biotechnology 27, 275.

Chang, W.Y., Lavoie, J.R., Kwon, S.Y., Chen, Z., Manias, J.L., Behbahani, J., Ling, V., Kandel, R.A., Stewart, D.J., and Stanford, W.L. (2013). Feeder-independent derivation of induced-pluripotent stem cells from peripheral blood endothelial progenitor cells. Stem Cell Res 10, 195-202.

Chen, G., Gulbranson, D.R., Hou, Z., Bolin, J.M., Ruotti, V., Probasco, M.D., Smuga-Otto, K., Howden, S.E., Diol, N.R., and Propson, N.E. (2011). Chemically defined conditions for human iPSC derivation and culture. Nature methods $8,424$.

Chen, Z., Chang, W.Y., Etheridge, A., Strickfaden, H., Jin, Z., Palidwor, G., Cho, J.H., Wang, K., Kwon, S.Y., and Doré, C. (2017). Reprogramming progeria fibroblasts re-establishes a normal epigenetic landscape. Aging cell 16,870-887. 
Costa, V., Aigner, S., Vukcevic, M., Sauter, E., Behr, K., Ebeling, M., Dunkley, T., Friedlein, A., Zoffmann, S., Meyer, C.A., et al. (2016). mTORC1 Inhibition Corrects Neurodevelopmental and Synaptic Alterations in a Human Stem Cell Model of Tuberous Sclerosis. Cell Rep 15, 86-95.

Crino, P.B., Trojanowski, J.Q., Dichter, M.A., and Eberwine, J. (1996). Embryonic neuronal markers in tuberous sclerosis: single-cell molecular pathology. Proceedings of the National Academy of Sciences 93, 14152-14157.

Crooks, D.M., Pacheco-Rodriguez, G., DeCastro, R.M., McCoy, J.P., Wang, J.-a., Kumaki, F., Darling, T., and Moss, J. (2004). Molecular and genetic analysis of disseminated neoplastic cells in lymphangioleiomyomatosis. Proceedings of the National Academy of Sciences 101, 17462-17467.

D'Armiento, J., Shiomi, T., Marks, S., Geraghty, P., Sankarasharma, D., and Chada, K. (2016). Mesenchymal Tumorigenesis Driven by TSC2 Haploinsufficiency Requires HMGA2 and Is Independent of mTOR Pathway Activation. Cancer Res 76, 844-854.

Dabora, S.L., Franz, D.N., Ashwal, S., Sagalowsky, A., DiMario, F.J., Jr., Miles, D., Cutler, D., Krueger, D., Uppot, R.N., Rabenou, R., et al. (2011). Multicenter phase 2 trial of sirolimus for tuberous sclerosis: kidney angiomyolipomas and other tumors regress and VEGF- D levels decrease. PLoS One 6, e23379.

Dabora, S.L., Jozwiak, S., Franz, D.N., Roberts, P.S., Nieto, A., Chung, J., Choy, Y.-S., Reeve, M.P., Thiele, E., and Egelhoff, J.C. (2001). Mutational analysis in a cohort of 224 tuberous sclerosis patients indicates increased severity of TSC2, compared with TSC1, disease in multiple organs. The American Journal of Human Genetics $68,64-80$.

Darling, T.N., Pacheco-Rodriguez, G., Gorio, A., Lesma, E., Walker, C., and Moss, J. (2010). Lymphangioleiomyomatosis and TSC2-/-cells. Lymphatic research and biology 8, 59-69.

Delaney, S.P., Julian, L.M., and Stanford, W.L. (2014). The neural crest lineage as a driver of disease heterogeneity in Tuberous Sclerosis Complex and Lymphangioleiomyomatosis. Frontiers in cell and developmental biology 2, 69 .

Di Nardo, A., Wertz, M.H., Kwiatkowski, E., Tsai, P.T., Leech, J.D., Greene-Colozzi, E., Goto, J., Dilsiz, P., Talos, D.M., and Clish, C.B. (2014). Neuronal Tsc1/2 complex controls autophagy through AMPK-dependent regulation of ULK1. Human molecular genetics 23, 3865-3874.

Dixon, B.P., Hulbert, J.C., and Bissler, J.J. (2011). Tuberous sclerosis complex renal disease. Nephron Experimental Nephrology 118, e15-e20.

Ebrahimi-Fakhari, D., Saffari, A., Wahlster, L., Di Nardo, A., Turner, D., Lewis Jr, T.L., Conrad, C., Rothberg, J.M., Lipton, J.O., and Kölker, S. (2016). Impaired mitochondrial dynamics and mitophagy in neuronal models of tuberous sclerosis complex. Cell reports 17, 1053-1070.

Feliciano, D.M., Su, T., Lopez, J., Platel, J.C., and Bordey, A. (2011). Single-cell Tsc1 knockout during corticogenesis generates tuber-like lesions and reduces seizure threshold in mice. J Clin Invest 121, 1596-1607.

Fokkema, I.F., Taschner, P.E., Schaafsma, G.C., Celli, J., Laros, J.F., and den Dunnen, J.T. (2011). LOVD v. 2.0: the next generation in gene variant databases. Human mutation 32, 557-563.

Franz, D.N., and Capal, J.K. (2017). mTOR inhibitors in the pharmacologic management of tuberous sclerosis complex and their potential role in other rare neurodevelopmental disorders. Orphanet journal of rare diseases 12,51 . 
Gagnon, J.A., Valen, E., Thyme, S.B., Huang, P., Ahkmetova, L., Pauli, A., Montague, T.G., Zimmerman, S., Richter, C., and Schier, A.F. (2014). Efficient mutagenesis by Cas9 protein-mediated oligonucleotide insertion and large-scale assessment of single-guide RNAs. PloS one 9, e98186.

Gao, L., Yue, M.M., Davis, J., Hyjek, E., and Schuger, L. (2014). In pulmonary lymphangioleiomyomatosis expression of progesterone receptor is frequently higher than that of estrogen receptor. Virchows Archiv 464, 495-503.

Gilbert, E.R., Eby, J.M., Hammer, A.M., Klarquist, J., Christensen, D.G., Barfuss, A.J., Boissy, R.E., Picken, M.M., Love, R.B., and Dilling, D.F. (2013). Positioning ganglioside D3 as an immunotherapeutic target in lymphangioleiomyomatosis. The American journal of pathology 183, 226-234.

Goncharova, E.A., Goncharov, D.A., Fehrenbach, M., Khavin, I., Ducka, B., Hino, O., Colby, T.V., Merrilees, M.J., Haczku, A., and Albelda, S.M. (2012). Prevention of alveolar destruction and airspace enlargement in a mouse model of pulmonary lymphangioleiomyomatosis (LAM). Science translational medicine 4, 154ra134$154 \mathrm{ra134.}$

Goto, J., Talos, D.M., Klein, P., Qin, W., Chekaluk, Y.I., Anderl, S., Malinowska, I.A., Di Nardo, A., Bronson, R.T., and Chan, J.A. (2011). Regulable neural progenitor-specific Tsc1 loss yields giant cells with organellar dysfunction in a model of tuberous sclerosis complex. Proceedings of the National Academy of Sciences 108, E1070-E1079.

Grzegorek, I., Lenze, D., Chabowski, M., Janczak, D., SZOLKOWSKA, M., Langfort, R., Szuba, A., and Dziegiel, P. (2015). Immunohistochemical evaluation of pulmonary lymphangioleiomyomatosis. Anticancer research 35, 3353-3360.

Gunhanlar, N., Shpak, G., van der Kroeg, M., Gouty-Colomer, L.A., Munshi, S.T., Lendemeijer, B., Ghazvini, M., Dupont, C., Hoogendijk, W.J.G., Gribnau, J., et al. (2018). A simplified protocol for differentiation of electrophysiologically mature neuronal networks from human induced pluripotent stem cells. Mol Psychiatry 23, 1336-1344.

Guo, M., Yu, J.J., Perl, A.K., Wikenheiser-Brokamp, K.A., Riccetti, M., Zhang, E.Y., Sudha, P., Adam, M., Potter, A., Kopras, E.J., et al. (2019). Identification of the lymphangioleiomyomatosis cell and its uterine origin. bioRxiv, 784199.

Haeussler, M., Schönig, K., Eckert, H., Eschstruth, A., Mianné, J., Renaud, J.-B., Schneider-Maunoury, S., Shkumatava, A., Teboul, L., and Kent, J. (2016). Evaluation of off-target and on-target scoring algorithms and integration into the guide RNA selection tool CRISPOR. Genome biology 17, 148.

Henske, E.P., and McCormack, F.X. (2012). Lymphangioleiomyomatosis - a wolf in sheep's clothing. The Journal of clinical investigation 122, 3807-3816.

Himes, B.E., Obraztsova, K., Lian, L., Shumyatcher, M., Rue, R., Atochina-Vasserman, E.N., Hur, S.K., Bartolomei, M.S., Evans, J.F., and Krymskaya, V.P. (2018). Rapamycin-independent IGF2 expression in Tsc2null mouse embryo fibroblasts and human lymphangioleiomyomatosis cells. PLoS One 13, e0197105.

Hoon, V., Thung, S.N., Kaneko, M., and Unger, P.D. (1994). HMB-45 reactivity in renal angiomyolipoma and lymphangioleiomyomatosis. Archives of pathology \& laboratory medicine 118, 732-734.

Hsu, P.D., Scott, D.A., Weinstein, J.A., Ran, F.A., Konermann, S., Agarwala, V., Li, Y., Fine, E.J., Wu, X., Shalem, O., et al. (2013). DNA targeting specificity of RNA-guided Cas9 nucleases. Nat Biotechnol 31, 827832. 
Johnson, C.E., Dunlop, E.A., Seifan, S., McCann, H.D., Hay, T., Parfitt, G.J., Jones, A.T., Giles, P.J., Shen, M.H., and Sampson, J.R. (2018). Loss of tuberous sclerosis complex 2 sensitizes tumors to nelfinavirbortezomib therapy to intensify endoplasmic reticulum stress-induced cell death. Oncogene 37, 5913.

Julian, L.M., Delaney, S.P., Wang, Y., Goldberg, A.A., Dore, C., Yockell-Lelievre, J., Tam, R.Y., Giannikou, K., McMurray, F., Shoichet, M.S., et al. (2017). Human Pluripotent Stem Cell-Derived TSC2-Haploinsufficient Smooth Muscle Cells Recapitulate Features of Lymphangioleiomyomatosis. Cancer Res 77, 5491-5502.

Kenerson, H.L., Aicher, L.D., True, L.D., and Yeung, R.S. (2002). Activated mammalian target of rapamycin pathway in the pathogenesis of tuberous sclerosis complex renal tumors. Cancer Res 62, 5645-5650.

Klarquist, J., Barfuss, A., Kandala, S., Reust, M.J., Braun, R.K., Hu, J., Dilling, D.F., McKee, M.D., Boissy, R.E., and Love, R.B. (2009). Melanoma-associated antigen expression in lymphangioleiomyomatosis renders tumor cells susceptible to cytotoxic T cells. The American journal of pathology 175, 2463-2472.

Klover, P.J., Thangapazham, R.L., Kato, J., Wang, J.A., Anderson, S.A., Hoffmann, V., Steagall, W.K., Li, S., McCart, E., Nathan, N., et al. (2017). Tsc2 disruption in mesenchymal progenitors results in tumors with vascular anomalies overexpressing Lgals3. Elife 6 .

Kobayashi, T., Minowa, O., Kuno, J., Mitani, H., Hino, O., and Noda, T. (1999). Renal carcinogenesis, hepatic hemangiomatosis, and embryonic lethality caused by a germ-line Tsc2 mutation in mice. Cancer research 59, 1206-1211.

Kobayashi, T., Minowa, O., Sugitani, Y., Takai, S., Mitani, H., Kobayashi, E., Noda, T., and Hino, O. (2001). A germ-line Tsc1 mutation causes tumor development and embryonic lethality that are similar, but not identical to, those caused by Tsc2 mutation in mice. Proceedings of the National Academy of Sciences 98, 8762-8767.

Krymskaya, V.P. (2008). Smooth muscle-like cells in pulmonary lymphangioleiomyomatosis. Proceedings of the American Thoracic Society 5, 119-126.

Kwiatkowski, D.J. (2010). Animal models of lymphangioleiomyomatosis (LAM) and tuberous sclerosis complex (TSC). Lymphatic research and biology 8, 51-57.

Lee, A., Maldonado, M., Baybis, M., Walsh, C.A., Scheithauer, B., Yeung, R., Parent, J., Weiner, H.L., and Crino, P.B. (2003). Markers of cellular proliferation are expressed in cortical tubers. Ann Neurol 53, 668-673.

Leeman, D.S., Hebestreit, K., Ruetz, T., Webb, A.E., McKay, A., Pollina, E.A., Dulken, B.W., Zhao, X., Yeo, R.W., and Ho, T.T. (2018). Lysosome activation clears aggregates and enhances quiescent neural stem cell activation during aging. Science 359, 1277-1283.

Liang, N., Zhang, C., Dill, P., Panasyuk, G., Pion, D., Koka, V., Gallazzini, M., Olson, E.N., Lam, H., Henske, E.P., et al. (2014). Regulation of YAP by mTOR and autophagy reveals a therapeutic target of tuberous sclerosis complex. J Exp Med 211, 2249-2263.

Liang, S., Cuellar, T., Nowacki, M., Nayak, B.K., Dong, L., Li, B., Sharma, K., and Habib, S.L. (2018). A new drug combination significantly reduces kidney tumor progression in kidney mouse model. Oncotarget 9, 3290032916.

Love, M.I., Huber, W., and Anders, S. (2014). Moderated estimation of fold change and dispersion for RNA-seq data with DESeq2. Genome biology 15, 550.

Magri, L., Cominelli, M., Cambiaghi, M., Cursi, M., Leocani, L., Minicucci, F., Poliani, P.L., and Galli, R. (2013). Timing of mTOR activation affects tuberous sclerosis complex neuropathology in mouse models. Dis Model Mech 6, 1185-1197. 
Martin, K.R., Zhou, W., Bowman, M.J., Shih, J., Au, K.S., Dittenhafer-Reed, K.E., Sisson, K.A., Koeman, J., Weisenberger, D.J., and Cottingham, S.L. (2017a). The genomic landscape of tuberous sclerosis complex. Nature communications 8,15816 .

Martin, K.R., Zhou, W., Bowman, M.J., Shih, J., Au, K.S., Dittenhafer-Reed, K.E., Sisson, K.A., Koeman, J., Weisenberger, D.J., Cottingham, S.L., et al. (2017b). The genomic landscape of tuberous sclerosis complex. Nat Commun $8,15816$.

Martina, J.A., Diab, H.I., Brady, O.A., and Puertollano, R. (2016). TFEB and TFE3 are novel components of the integrated stress response. EMBO J 35, 479-495.

Mayshar, Y., Ben-David, U., Lavon, N., Biancotti, J.C., Yakir, B., Clark, A.T., Plath, K., Lowry, W.E., and Benvenisty, N. (2010). Identification and classification of chromosomal aberrations in human induced pluripotent stem cells. Cell Stem Cell 7, 521-531.

McCormack, F.X., Inoue, Y., Moss, J., Singer, L.G., Strange, C., Nakata, K., Barker, A.F., Chapman, J.T., Brantly, M.L., and Stocks, J.M. (2011). Efficacy and safety of sirolimus in lymphangioleiomyomatosis. New England Journal of Medicine 364, 1595-1606.

McDowell, I.C., Manandhar, D., Vockley, C.M., Schmid, A.K., Reddy, T.E., and Engelhardt, B.E. (2018). Clustering gene expression time series data using an infinite Gaussian process mixture model. PLoS computational biology 14 , e1005896.

McKenna III, J., Kapfhamer, D., Kinchen, J.M., Wasek, B., Dunworth, M., Murray-Stewart, T., Bottiglieri, T., Casero Jr, R.A., and Gambello, M.J. (2018). Metabolomic studies identify changes in transmethylation and polyamine metabolism in a brain-specific mouse model of tuberous sclerosis complex. Human molecular genetics 27, 2113-2124.

Mehlem, A., Hagberg, C.E., Muhl, L., Eriksson, U., and Falkevall, A. (2013). Imaging of neutral lipids by oil red O for analyzing the metabolic status in health and disease. Nat Protoc 8, 1149-1154.

Mookerjee, S.A., Gerencser, A.A., Nicholls, D.G., and Brand, M.D. (2018). Quantifying intracellular rates of glycolytic and oxidative ATP production and consumption using extracellular flux measurements. J Biol Chem 293, 12649-12652.

Mookerjee, S.A., Nicholls, D.G., and Brand, M.D. (2016). Determining Maximum Glycolytic Capacity Using Extracellular Flux Measurements. PLoS One 11, e0152016.

Moss, J., Avila, N.A., Barnes, P.M., Litzenberger, R.A., Bechtle, J., Brooks, P.G., Hedin, C.J., Hunsberger, S., and Kristof, A.S. (2001). Prevalence and clinical characteristics of lymphangioleiomyomatosis (LAM) in patients with tuberous sclerosis complex. Am J Respir Crit Care Med 164, 669-671.

Onda, H., Lueck, A., Marks, P.W., Warren, H.B., and Kwiatkowski, D.J. (1999). Tsc2+/-mice develop tumors in multiple sites that express gelsolin and are influenced by genetic background. The Journal of clinical investigation 104, 687-695.

Oprescu, N., McCormack, F., Byrnes, S., and Kinder, B. (2013). Clinical predictors of mortality and cause of death in lymphangioleiomyomatosis: a population-based registry. Lung 191, 35-42.

Pacheco-Rodriguez, G., Steagall, W.K., Crooks, D.M., Stevens, L.A., Hashimoto, H., Li, S., Wang, J.-a., Darling, T.N., and Moss, J. (2007). TSC2 loss in lymphangioleiomyomatosis cells correlated with expression of CD44v6, a molecular determinant of metastasis. Cancer research 67, 10573-10581. 
Parkhitko, A., Myachina, F., Morrison, T.A., Hindi, K.M., Auricchio, N., Karbowniczek, M., Wu, J.J., Finkel, T., Kwiatkowski, D.J., and Jane, J.Y. (2011). Tumorigenesis in tuberous sclerosis complex is autophagy and p62/sequestosome 1 (SQSTM1)-dependent. Proceedings of the National Academy of Sciences 108, 1245512460.

Parkhitko, A.A., Priolo, C., Coloff, J.L., Yun, J., Wu, J.J., Mizumura, K., Xu, W., Malinowska, I.A., Yu, J., and Kwiatkowski, D.J. (2014). Autophagy-dependent metabolic reprogramming sensitizes TSC2-deficient cells to the antimetabolite 6-aminonicotinamide. Molecular Cancer Research 12, 48-57.

Patro, R., Duggal, G., Love, M.I., Irizarry, R.A., and Kingsford, C. (2017). Salmon provides fast and bias-aware quantification of transcript expression. Nature methods $14,417$.

Ran, F.A., Hsu, P.D., Wright, J., Agarwala, V., Scott, D.A., and Zhang, F. (2013). Genome engineering using the CRISPR-Cas9 system. Nature protocols 8, 2281.

Raudvere, U., Kolberg, L., Kuzmin, I., Arak, T., Adler, P., Peterson, H., and Vilo, J. (2019). g:Profiler: a web server for functional enrichment analysis and conversions of gene lists (2019 update). Nucleic Acids Res 47, W191-W198.

Saxton, R.A., and Sabatini, D.M. (2017). mTOR signaling in growth, metabolism, and disease. Cell 168, 960976.

Schindelin, J., Arganda-Carreras, I., Frise, E., Kaynig, V., Longair, M., Pietzsch, T., Preibisch, S., Rueden, C., Saalfeld, S., and Schmid, B. (2012). Fiji: an open-source platform for biological-image analysis. Nature methods 9, 676 .

Seyama, K., Kumasaka, T., Souma, S., Sato, T., Kurihara, M., Mitani, K., Tominaga, S., and Fukuchi, Y. (2006). Vascular endothelial growth factor-D is increased in serum of patients with lymphangioleiomyomatosis. Lymphat Res Biol 4, 143-152.

Simoes-Costa, M., and Bronner, M.E. (2013). Insights into neural crest development and evolution from genomic analysis. Genome Res 23, 1069-1080.

Siroky, B.J., Yin, H., Babcock, J.T., Lu, L., Hellmann, A.R., Dixon, B.P., Quilliam, L.A., and Bissler, J.J. (2012). Human TSC-associated renal angiomyolipoma cells are hypersensitive to ER stress. American Journal of Physiology-Renal Physiology 303, F831-F844.

Siroky, B.J., Yin, H., Dixon, B.P., Reichert, R.J., Hellmann, A.R., Ramkumar, T., Tsuchihashi, Z., Bunni, M., Dillon, J., Bell, P.D., et al. (2014). Evidence for pericyte origin of TSC-associated renal angiomyolipomas and implications for angiotensin receptor inhibition therapy. Am J Physiol Renal Physiol 307, F560-570.

Soldatov, R., Kaucka, M., Kastriti, M.E., Petersen, J., Chontorotzea, T., Englmaier, L., Akkuratova, N., Yang, Y., Haring, M., Dyachuk, V., et al. (2019). Spatiotemporal structure of cell fate decisions in murine neural crest. Science 364 .

Sun, H., Takesian, A.E., Wang, T.T., Lippman-Bell, J.J., Hensch, T.K., and Jensen, F.E. (2018). Early seizures prematurely unsilence auditory synapses to disrupt thalamocortical critical period plasticity. Cell reports 23 , 2533-2540.

Talos, D.M., Sun, H., Kosaras, B., Joseph, A., Folkerth, R.D., Poduri, A., Madsen, J.R., Black, P.M., and Jensen, F.E. (2012). Altered inhibition in tuberous sclerosis and type Ilb cortical dysplasia. Ann Neurol 71, 539-551.

Tchieu, J., Zimmer, B., Fattahi, F., Amin, S., Zeltner, N., Chen, S., and Studer, L. (2017). A modular platform for differentiation of human PSCs into all major ectodermal lineages. Cell stem cell 21, 399-410. e397. 
Valencia, J.C., Steagall, W.K., Zhang, Y., Fetsch, P., Abati, A., Tsukada, K., Billings, E., Hearing, V.J., Yu, Z.X., Pacheco-Rodriguez, G., et al. (2015). Antibody alphaPEP13h reacts with lymphangioleiomyomatosis cells in lung nodules. Chest 147, 771-777.

Van Scheppingen, J., Broekaart, D., Scholl, T., Zuidberg, M., Anink, J., Spliet, W., van Rijen, P., Czech, T., Hainfellner, J., and Feucht, M. (2016). Dysregulation of the (immuno) proteasome pathway in malformations of cortical development. Journal of neuroinflammation 13, 202.

Villegas, F., Lehalle, D., Mayer, D., Rittirsch, M., Stadler, M.B., Zinner, M., Olivieri, D., Vabres, P., DuplombJego, L., and De Bont, E.S. (2019). Lysosomal signaling licenses embryonic stem cell differentiation via inactivation of Tfe3. Cell stem cell 24, 257-270. e258.

Weddell, J.C., Chen, S., and Imoukhuede, P.I. (2018). VEGFR1 promotes cell migration and proliferation through PLCgamma and PI3K pathways. NPJ Syst Biol Appl 4, 1.

Yu, G., Wang, L.-G., Han, Y., and He, Q.-Y. (2012). clusterProfiler: an R package for comparing biological themes among gene clusters. Omics: a journal of integrative biology 16, 284-287.

Yu, J., Astrinidis, A., and Henske, E.P. (2001). Chromosome 16 loss of heterozygosity in tuberous sclerosis and sporadic lymphangiomyomatosis. American Journal of Respiratory and Critical Care Medicine 164, 1537-1540.

Yu, J., Astrinidis, A., Howard, S., and Henske, E.P. (2004). Estradiol and tamoxifen stimulate LAM-associated angiomyolipoma cell growth and activate both genomic and nongenomic signaling pathways. American Journal of Physiology-Lung Cellular and Molecular Physiology 286, L694-L700.

Zhang, H., Cicchetti, G., Onda, H., Koon, H.B., Asrican, K., Bajraszewski, N., Vazquez, F., Carpenter, C.L., and Kwiatkowski, D.J. (2003). Loss of Tsc1/Tsc2 activates mTOR and disrupts PI3K-Akt signaling through downregulation of PDGFR. J Clin Invest 112, 1223-1233.

Zhang, Y., Nicholatos, J., Dreier, J.R., Ricoult, S.J., Widenmaier, S.B., Hotamisligil, G.S., Kwiatkowski, D.J., and Manning, B.D. (2014). Coordinated regulation of protein synthesis and degradation by mTORC1. Nature $513,440-443$.

Zhou, J., Shrikhande, G., Xu, J., McKay, R.M., Burns, D.K., Johnson, J.E., and Parada, L.F. (2011). Tsc1 mutant neural stem/progenitor cells exhibit migration deficits and give rise to subependymal lesions in the lateral ventricle. Genes Dev 25, 1595-1600.

Zhou, X., Ikenoue, T., Chen, X., Li, L., Inoki, K., and Guan, K.-L. (2009). Rheb controls misfolded protein metabolism by inhibiting aggresome formation and autophagy. Proceedings of the National Academy of Sciences 106, 8923-8928.

Zhu, A., Ibrahim, J.G., and Love, M.I. (2018). Heavy-tailed prior distributions for sequence count data: removing the noise and preserving large differences. Bioinformatics. 


\section{FIGURE LEGENDS}

\section{Figure 1: Generation of $a$ TSC $^{-/-}$hPSC library}

(A) Schematic summary of TSC stem cell modeling strategy. (B) Homologous recombination strategy to knockout TSC2 utilized an ssODN containing a 'STOP-codon' donor sequence containing the unique restriction site, PmeI. PmeI digestion of PCR amplicons containing the target cut site reveals homozygous integration of the donor sequence in $\mathrm{TSC}^{-/} \mathrm{hPSC}$ lines. (C) Imaging flow cytometry image capture following staining with TSC2 antibody revealing clonal populations of $T S C 2^{-/}$cells. (D) Quantification of fluorescence intensity of pluripotency markers OCT4, SOX2, and NANOG in each hPSC line under maintenance conditions, normalized to respective parental WT hPSC lines. Values are the mean $\pm \operatorname{SEM}(n=12 ; 3 x$ for each cell line $)$. No statistical significance between WT and $T S C^{-/}$samples was observed. (E) Haematoxylins and eosin staining of H9 WT and $\mathrm{TSC}^{-/}$teratoma explants. Arrows indicate examples of immature tissues of ectodermal, endodermal, and mesodermal origin. Scale bar, $100 \mu \mathrm{m}$. (F) Schematic of expected phosphorylation status of mTORC1 effectors under supportive and stress conditions. Western blots probing phosphorylated mTOR (P-mTOR), phosphorylated S6K (P-S6K), and phosphorylated S6 (P-S6) of samples treated for 6h under no treatment, 1\% $\mathrm{O}_{2}$, and +100 nM rapamycin conditions. Densitometry quantification of western blots displaying the ratio of phosphorylated to total protein of mTOR, $\mathrm{S} 6 \mathrm{~K}$, and $\mathrm{S} 6(\mathrm{n}=8 ; 2 \mathrm{x}$ for each cell line). Statistical significance was determined using two-way ANOVA and Tukey's post hoc analysis. (G) Schematic representation of monolayerNPC and EB-NCC differentiation protocols. Red asterisks indicate time points harvested for RNA sequencing.

\section{Figure 2: TSC2 $^{-/}$hPSC-derived NPCs and NCCs model key features of TSC neural and mesenchymal manifestations}

(A) Immunofluorescence images of WT and $T S C 2^{-/} \mathrm{NPC}$ maintenance cultures, displaying phenotypic markers of neurological TSC tumors: P-S6, Nestin/PAX6, GFAP/SOX2, and Mitotracker deep red. Scale bar, 50 $\mu \mathrm{m}$. (B) Ratio of P-S6 to total S6 fluorescence intensity in maintenance NPCs, relative to WT levels. Values are \pm SEM $(\mathrm{n}=3 ; 1 \mathrm{x} \mathrm{H9}, 2 \mathrm{x} 168$ between passages 2-5). (C) Quantification of fluorescence intensity of the lineage markers Nestin (neural; top) and GFAP (glial; bottom) over early, mid, and late passage ranges in culture, relative to WT 
NPCs. For all relevant figures, passage (p) ranges are defined as: early (p0-2), mid (3-5), late (p6-8). Values are the mean \pm SEM (For Nestin: [ $n=3$ early ( 1 each H7, H9, 168), $n=5$ mid (2x H1, 1 each H7, H9, 168), $n=3$ late (1x H1, 2x H7)]; for GFAP: [n=5 early $(2 x H 1,2 x$ H7, 1x 168), n=4 mid (1x H9, 3x 168), n=3 late (1x H1, 2x H7)]). (D) Relative intensity of Mitotracker deep red staining in NPCs over early, mid, and late passage ranges, normalized to WT NPCs. Values are the mean \pm SEM ( $n=5$ early $(1 \mathrm{x}$ H1, 2x each H9 and 168), $n=3$ mid ( $1 x$ H9, 2x 168), $\mathrm{n}=4$ late $\left(2 \mathrm{x}\right.$ 168, 1 each H1 and H9) (E) Representative images of WT and TSC2 $^{-/}$neurons and quantification of the morphological features soma size (left) and neurite outgrowths per cell (right) imaged by endogenous mCherry expression, expressed relative to WT. Values are mean $\pm \mathrm{SEM}$ ( $\mathrm{n}=3$ H9). Scale bar, $50 \mu \mathrm{m}$. (F) Quantification of the amplitude of AMPA receptor-mediated spontaneous excitatory post-synaptic currents ( SEPSCs) measured in $\mathrm{H} 7$ and H9 WT ( $\mathrm{n}=6$ cells), $T S C 2^{-/}\left(\mathrm{n}=7\right.$ cells) and $T S C 2^{-/}+$rapamycin $(\mathrm{n}=6$ cells) neurons in culture. Values are mean \pm SEM. (G) Percentage of NCC populations expressing NCC specific lineage markers SOX9 and HNK-1, and NPC specific marker PAX6. Values are mean \pm SEM $(n=9 ; \geq 2 x$ for each cell line), no statistical significance between WT and $T S C 2^{-/-}$samples was observed. (H) Quantification of P-S6 immunofluorescence intensity of NCC maintenance cultures exposed to $24 \mathrm{~h}$ of no treatment, media starvation, and $+100 \mathrm{nM}$ rapamycin. Values are normalized to no treatment samples within each cell lineage, displaying the mean $\pm \operatorname{SEM}(\mathrm{n}=10 ; \geq 2 \mathrm{x}$ for each cell line $)$. Statistical significance was determined using twoway ANOVA and Sidak's post hoc analysis. (I) Mean displacement over $6 \mathrm{~h}$ of NCC cultures under maintenance conditions evaluated through time lapse imaging (see also supplemental multimedia). Values are the mean \pm SEM. Statistical significance was determined using one-way ANOVA and Tukey's post hoc analysis. (J) Percentage of NCCs reactive to HMB45 immunofluorescence staining. Values are the mean $\pm \operatorname{SEM}(\mathrm{n}=14, \geq$ $3 \mathrm{x}$ for each cell line). Statistical significance was determined using unpaired t-test. (K) Representative immunofluorescence TSC marker staining of WT and TSCS2 ${ }^{-/}$NCCs. Scale bar, 50 $\mu \mathrm{m}$. (L) Quantification of western blot of maintenance NCCs probing for VEGFD and PDGFRß via densitometry and normalized to WT protein levels using GAPDH. Values are mean $\pm \operatorname{SEM}(n=8 ; 2 x$ for each cell line $)$. 
Figure 3: RNA-seq time-course analysis reveals that a potent cell stress response underlies neuroepithelial induction in the absence of TSC2.

(A) Representative three-dimensional plotting of PCA of monolayer-NPC (H1 \& 168) and EB-NCC (H7 \& H9) differentiations. (B) Number of total DEGs identified (FDR $<5 \%$ ) over the RNA-seq differentiation time-course in monolayer-NPC and EB-NCC RNA-seq datasets. (C) Venn diagram featuring the intersection of the protein coding gene signatures of WT NCCs, TSC2 $2^{-/}$NCCs, and P-LAM cells. Fischer's exact test was used to determine p-values and odds ratios of gene set overlaps. (D) Comparative KEGG pathway enrichment analysis of $T S C 2^{-/}$NCC, P-LAM cell, $T s c 2^{-/}$NDF, TSC-associated rAML, 621-101 cell, and $T s c 2^{-/}$MEF gene signatures. NDF and MEF gene lists were converted to their human orthologs prior to analysis. (E) Comparative KEGG pathway enrichment analysis of upregulated DEGs (padj $<0.05)$ in $T S C 2^{-/}$samples compared to WT at each respective time point of monolayer-NPC and EB-NCC differentiations. Red boxes highlight enrichment of stress response pathways.

Figure 4: NPCs and NCCs exhibit distinct catabolic signalling profiles during development, which are exacerbated by TSC2-deficiency

(A) Heatmap featuring hallmark lysosome genes displaying $\log _{2} \mathrm{FC}$ of $T S C 2^{--}$compared to WT samples at each respective timepoint of monolayer-NPC and EB-NCC RNA-seq datasets. Red box highlights time points associated with increased lysosome gene expression. Green box highlights time points of minimal differential lysosome gene expression. (B) Representative images (at differentiation day 5) and quantification of LAMP1 immunofluorescence intensity (mean spot analysis) in the presence and absence of rapamycin throughout monolayer-NPC differentiation. Values are mean \pm SEM $(n=10 ; 1 \times$ H9, 3x H1, 2x H7, 4x 168). Scale bar, $50 \mu \mathrm{m}$. (C) Quantification of the cytoplasmic area of Lysosensor staining relative to WT at day 5 of monolayerNPC differentiation. Values are mean \pm SEM $(n=10 ; 1 x$ H9, 3x H1, 2x H7, 4x 168). (D) Immunofluorescent staining of attached neuralized EB clusters and migratory NCC outgrowths at day 7 EB-NCC differentiation. Dotted lines delineate the boundary of attached neuralized EB clusters. Scale bar, $100 \mu \mathrm{m}$.

Figure 5: TSC2-deficiency drives long-term lineage-specific endosomal and proteostatic adaptations 
(A) Representative fluorescence imaging for high content analysis of Lysosensor stain and LAMP2A immunofluorescence in WT and TSC2 $2^{-/}$maintenance NPCs; quantification of Lysosensor intensity with and without 100nM rapamycin, relative to WT NPCs. Values are mean $\pm \operatorname{SEM}(n=7$, representing all cell lines). Scale bar, $50 \mu \mathrm{m}$. (B) Representative fluorescence images of maintenance WT and $T S C 2^{-/}$NCCs; quantification of Lysosensor signal relative to WT NCCs. Values are mean $\pm \operatorname{SEM}(n=9 ; \geq 2 x$ for each line). Scale bar, $50 \mu \mathrm{m}$. (C) Quantification of autophagosome (Cyto-ID staining) fluorescence intensity in maintenance NCCs, relative to WT NCCs. Values are mean $\pm \operatorname{SEM}(n=9 ; \geq 2 x$ for each line), no statistical significance was observed between treatment groups. (D) Representative images for high content analysis of Cyto-ID live cell staining; quantification of autophagosome fluorescence intensity in maintenance NPCs, relative to WT NPCs, with and without 5-20nM chloroquine (CQ). Values are mean $\pm \operatorname{SEM}(\mathrm{n}=13$ for basal analysis, $\mathrm{n}=7$ (WT) and 8 (TSC2-

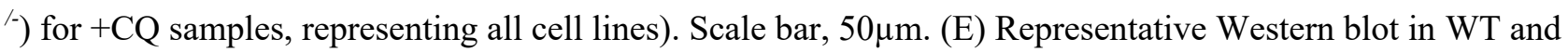
$T S C 2^{-/}$cultures during monolayer-NPC differentiation with and without $20 \mathrm{nM}$ rapamycin initiating $6 \mathrm{~h}$ prior to differentiation. Proteins assessed are TSC2, ribosomal protein S6 and P-S6 at Ser-235/246, ULK1 and P-ULK1 at Serine-555 (AMPK-dependent), and LC3ß. (F) Quantification of Proteostat staining during monolayer-NPC differentiation with and without 100nM rapamycin. Values are mean \pm SEM ( $\mathrm{n}=10 ; 1 \mathrm{x} \mathrm{H9}, 3 \mathrm{x} H 1,2 \mathrm{x} H 7,4 \mathrm{x}$ 168). (G) Representative images of proteostat aggresome staining in WT at day 5 monolayer-NPC differentiation and day 7 of EB-NCC differentiation. Scale bar, $50 \mu \mathrm{m}, 100 \mu \mathrm{m}$.

\section{Figure 6: TSC2 loss drives lineage-specific metabolic reprogramming.}

(A\&B) Plots showing the $\mathrm{O}_{2}$ consumption rate at each time-point in mitochondrial stress test extracellular flux assays for NPC (A) and NCC (B) cultures. Measurements 1-3 were readings taken at resting state; 4-6, following addition of the complex V inhibitor Oligomycin (Oligo); 7-9, after addition of the mitochondrial membrane potential uncoupler FCCP; and 10-12, after addition of the complex I and III inhibitors Rotenone (Rot.) and Antimycin A (AA). Values are mean \pm SEM (NPCs: $n=7$ (2x H1, 3x H7, 1x H9, 1x 168); NCCs: n=7 (1x H1, 2x each H7, H9, 168)). (C\&D) Plots showing the extracellular acidification rate (ECAR) at each time-point in mitochondrial stress test, with time-points and treatments as described for panels 6A\&B. In addition, the plasma membrane $\mathrm{Na}^{+} / \mathrm{K}^{+}$-ATPase agent Monensin (Mon.) was added, to stimulate maximal ATP demand and 
glycolytic capacity, and measured at \# 13-15. Values are mean \pm SEM, with replicates as in panels 6A\&B.

(E\&F) ATP production rates (JATP) from glycolysis (left-hand bars), and Oxidative Phosphorylation (OxPhos)

(right-hand bars) at resting and maximal levels in NPCs (E) and NCCs (F). Values are mean \pm SD, with replicates as in panels $6 \mathrm{~A} \& \mathrm{~B}$. (G\&H) Integration of JATP from OxPhos and glycolysis reveals a high bioenergetic capacity of $T S C 2^{-/}$NPCs between resting and maximal ('max') states (G), while bioenergetic capacity of WT NPCs $(\mathrm{G})$ and WT and $T S C 2^{-/}$NCCs $(\mathrm{H})$ is minimal. Values are mean $\pm \mathrm{SD}$, with replicates as in panels 6A\&B. (I) Spare respiratory capacity, representing the difference in $\mathrm{O}_{2}$ consumption at measurements 7-9 compared to 1-3, in NPCs (left) and NCCs (right). Values are mean $\pm \mathrm{SD}$, with replicates as in panels $6 \mathrm{~A} \& \mathrm{~B}$.

Figure 7: TSC2 $^{-/}$NPCs but not NCCs are selectively sensitive to clinically-relevant proteasome inhibitors. (A-C) Toxicity observed in NPCs (left) and NCCs (right) 48 hours after treatments with Bortezomib (A), Carfilzomib (B) and Rapamycin or Chloroquine (C). (D) Schematic representation of ER stress states and resulting responses to proteosome inhibition. Values are the mean \pm SEM. (A-B) $n=7$ for NPCs; $1 x$ for $H 7$, 4x for $\mathrm{H} 9$ and 2x for 168. $\mathrm{n}=11$ for NCCs; $2 \mathrm{x}$ for H1, 2x for H7, 3x for H9 and 4x for 168. (C) n=4 for NPCs; $1 \mathrm{x}$ for H7and 168, 2x for H9. n=6 for NCCs; $1 \mathrm{x}$ for H7 and H9, 2x for H1 and 168. Statistical significance $(\mathrm{p}<0.05)$ was established by Two-way ANOVA and Tukey's post hoc analysis.

\section{SUPPLEMENTAL FIGURE LEGENDS}

\section{Figure S1: Validation of TSC2 ${ }^{-/-}$hPSCs and NPC monolayer/EB-NCC differentiation.}

(A) Western blot probing for TSC2 in WT and $T S C 2^{-/}$hPSC lines. (B) Haemotoxylin and eosin staining of H7, H1, and $168 \mathrm{WT}_{\text {and }} \mathrm{TSC}^{-/-}$teratoma explants. Arrows indicate examples of immature tissues of ectodermal, endodermal, and mesodermal origin. Scale bars, $100 \mu \mathrm{m}$. (C) Western blots probing for total mTOR, S6K, and $\mathrm{S} 6$ of samples treated for $6 \mathrm{~h}$ under no treatment, $1 \% \mathrm{O}_{2}$, and $+100 \mathrm{nM}$ rapamycin conditions. (D) Venn diagrams featuring the overlap of the P-LAM gene signature with cranial and trunk NCC gene signatures from the developing mouse. Fisher's exact test was used to determine p-values and odds ratios of the gene set overlaps. 
(E) Heatmap displaying $\log _{2}$ fold change of select hallmark NPC and NCC genes at RNAseq endpoint for monolayer-NPC and EB-NCC differentiations. (F) Representative immunofluorescence staining of lineage specific markers PAX6 (neural ectoderm), SOX9 and HNK-1 (neural crest) in WT and TSC2 ${ }^{-/}$cultures at d12 EB-NCC differentiation. Scale bar, $100 \mu \mathrm{m}$. (G) Representative flow cytometry analysis of p75 expression in WT and $T S C 2^{-/}$cultures at d12 EB-NCC differentiation prior establishing maintenance populations. (H) Percent p75 + cells at $\mathrm{d} 12$ of EB-NCC differentiation. Error values are the mean \pm SEM (total $n=8 ; 2 x$ for each cell line), no statistical significance was observed between WT and $T S C 2^{-/}$samples.

\section{Figure S2: Characterization of NPC cultures reveals TSC-associated phenotypes.}

(A) Phase images of WT and $T S C 2^{-/}$cells during monolayer-NPC induction at differentiation days 5 and 12 , displaying increased cell size and vesicle accumulation in $T S C 2^{-/}$cultures. Scale bar, $50 \mu \mathrm{m}$. (B) Exemplary western blot of $\mathrm{H} 1$ and $\mathrm{H} 7$ NPC cultures, probing for TSC2, P-S6 and S6, revealing constitutive S6 phosphorylation in $T S C 2^{-/}$cells. (C) Quantification of NPC volume, relative to WT by Cellomics ArrayScan imaging analysis. Values are the mean \pm SEM ( $n=13$, including all cell lines). (D) Quantification of PAX6 fluorescence intensity in NPCs, relative to WT NPCs. Values are mean \pm SEM ( $\mathrm{n}=5 ; 1 \mathrm{x} \mathrm{H7}, 2 \mathrm{x}$ for H1 and 168 at p0-3). (E) Quantification of SOX2 fluorescence intensity in NPCs over early, mid, and late passage ranges, normalized to WT NPCs. Values are mean \pm SEM ( $n=6$ early, $n=5$ mid, $n=3$ late). (F) Representative immunostaining for neuronal marker MAP2 (top image) and glial marker GFAP (bottom image). Graph (bottom panel) displaying $\%$ of cells in neuronal cultures expressing high levels of GFAP relative to WT. $(n=4 ; 2 x$ each

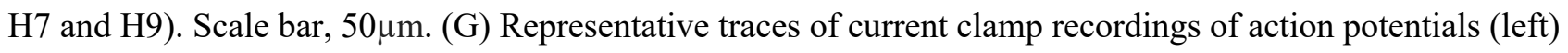
and voltage clamp recordings of AMPA receptor-mediated sEPCs (top) in WT, $T S C 2^{-/}$, and $T S C 2^{-/}+$rapamycin neurons. Quantification of sEPSC frequency (bottom). Values are mean $\pm \mathrm{SEM}$.

\section{Figure S3: EB-NCC differentiation yields highly enriched and multipotent NCC populations.}

(A) Representative immunofluorescence staining of passage 1 maintenance NCC cultures, probing for neural crest specific markers, SOX9 and HNK-1, and the neuroepithelial marker, PAX6 ( $\mathrm{n}=8 ; 2 \mathrm{x}$ for each line). Scale 
bar, $100 \mu \mathrm{m}$. (B) Representative immunofluorescence staining of WT and $T S C 2^{-/} 168$ NCCs differentiated towards neural (neuronal markers: Tuj1, Nestin), glial (Schwann cells: GFAP, maintaining SOX10 expression at endpoint) and mesenchymal lineages (smooth muscle cells: Calponin; adipocytes: oil red staining). Scale bars, $50 \mu \mathrm{m}$. (C) Expression of hallmark EMT genes at d10 of EB-NCC differentiation compared to day 0 of differentiation. (D) Expression levels of significant DEGs (padj $<0.05)$ related to RTK-signaling in $T S C 2^{-/-}$cells relative to WT cells at day 10 of EB-NCC differentiation. (E) Quantification of immunofluorescence intensity of mesenchymal TSC markers, P-S6 ( $\mathrm{n}=10 ; 3 \mathrm{x}$ for H1, H7, 168, 1x for H9) and $\alpha$-smooth muscle actin $(\mathrm{n}=12 ; 3 \mathrm{x}$ for each line), in maintenance NCCs. No statistical significance was observed between WT and $T S C 2^{-/}$samples. (F) Western blot of maintenance NCCs probing for VEGFD and PDGFRß.

\section{Figure S4: RNA-seq analysis reveals lineage-specific transcriptomic profiles.}

(A) Venn diagram featuring the intersection of WT NPCs, $T S C 2^{-/}$NPCs, SEN/SEGA, and cortical tuber gene signatures. NPC gene signatures are comprised of significantly up-regulated genes with $\log _{2} \mathrm{FC}<2$ at differentiation endpoint. Fisher's exact test was used to determine p-values and odds ratios of gene set overlaps.

(B) Comparative KEGG pathway enrichment analysis of up-regulated genes of primary SEN/SEGAs and cortical tubers relative to normal brain tissue, and $T S C 2^{-/-}$NPCs at differentiation endpoint relative to WT NPCs. (C) Comparative gene ontology (GO)-Biological Function enrichment analysis of upregulated DEGs (padj < 0.05 ) between matched $T S C 2^{-/}$and WT samples at each respective time point of monolayer-NPC and EB-NCC differentiations. Red box highlights enrichment of stress response GO terms.

\section{Figure S5: TSC2 $^{-/}$NPCs uniquely display aberrant lysosome and autophagosome biogenesis.}

(A) Quantification of fluorescence intensity of Lysosensor live cell stain in WT and $T S C 2^{-/}$cultures during monolayer-NPC differentiation, $\pm 20 \mathrm{nM}$ rapamycin. Values are mean \pm SEM $(\mathrm{n}=10 ; 1 \mathrm{x} H 9,3 \mathrm{x} H 1,2 \mathrm{x}$ H7, 4x 168); representative images of Lysosensor staining of differentiating NPCs at day 8 of differentiation. Scale bar, 50 $\mu \mathrm{m}$. (B) Representative images of TFE3 immunofluorescence staining of monolayer-NPC cultures at

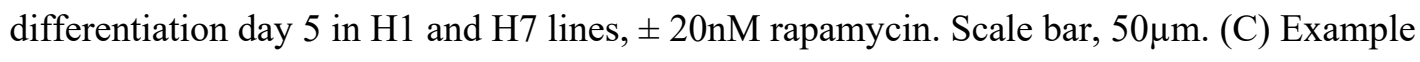
immunofluorescence staining of neuralized EB clusters $\left(\mathrm{PAX}^{+}\right)$and migratory NCCs $\left(\mathrm{SOX} 9^{+}\right)$at day 7 of EB- 
NCC differentiation. Dashed lines delineate borders of attached neuralized EB clusters. Scale bar, 100 $\mu \mathrm{m}$. (D) Example Lysosensor (D) and Autophagosome (E) live cell staining at day 7 EB-NCC differentiation. Dashed lines define the borders of adherent neuralized EB clusters. Scale bars, $100 \mu \mathrm{m}$. (E) Quantification of CytoID autophagosome intensity in monolayer-NPC cultures at day 1 and 8 of lineage induction, in the absence and presence of $20 \mathrm{nM}$ rapamycin. Values are mean \pm SEM ( $\mathrm{n}=10 ; 1 \mathrm{x}$ H9, 3x H1, 2x H7, 4x 168). Scale bar, $100 \mu \mathrm{m}$.

Figure S6: Aberrant autophagy activation and proteostasis dysregulation during TSC2 $^{-/-} \mathrm{NPC}^{-}$ differentiation.

(A) Quantification by densitometry of 1 representative Western blot, as shown in Figure 5E, per cell line (H1, H9, 168). Results displayed are $\log 2 \mathrm{FC}$ of $T S C 2^{-/}$compared to WT. (B) Representative P-S6 immunofluorescence staining at day 7 of EB-NCC differentiation cultures. Dashed lines delineate borders of

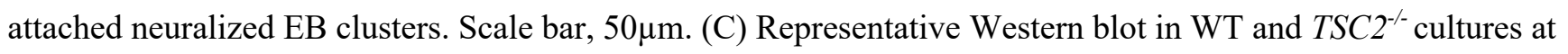
days $0,1,3,5,8$, and 12 of monolayer-NPC differentiation in the absence (left panel) and presence (right panel) of 20nM rapamycin initiating $6 \mathrm{~h}$ prior to differentiation. Proteins assessed are TSC2, ULK1, and P-ULK1 at Serine-757 (mTORC1) (left). Quantification by densitometry of 1 representative Western blot per cell line (H1, H9, 168), displayed as TSC2 ${ }^{--}$over WT fold-change, for P-ULK1 at Serine-757. (D) Western blot image as described in panel S6C during monolayer-NPC differentiation. Proteins assessed are mTOR, P-mTOR at Serine2448, S6K, P-S6K at Threonine-389, AMPK, and GAPDH. (E) Quantification as in panel S6C of P-ULK1 at Serine-555 of western blots exemplified in Figure 5E. (F) Quantification as in panel S6C for total LC3ß signal, LC3ß-I, LC3ß-II, and the LC3ß-II/ LC3ß-I ratio of western blots exemplified in Figure 5E. (G) Representative image of Proteostat staining in WT and $T S C 2^{-/}$NPC maintenance cultures at passage 6. Scale bar, $50 \mu \mathrm{m}$.

Figure S7: $T S C 2^{-/-}$NPCs display increased ROS and are selectively sensitized to proteasome inhibition at 24h of exposure.

(A) Representative images of c-H2DCFDA staining for reactive oxygen species (ROS) in NPCs and undifferentiated hPSCs; quantification of ROS levels in maintenance NPCs. Values are mean $\pm \operatorname{SEM}(n=3,1 x$ each H7, H9, 168). (B\&C) Cell number in dish at end-point of extracellular flux assays relative to WT in NPC 
(B) and NCC (C) cultures, measured as number of Hoechst ${ }^{+}$objects. Values are mean \pm SEM ( $n=16$ WT, $n=10$ and $11 \mathrm{TSC}^{-/}$). (D-F) Toxicity observed in neural progenitor cells (left) and neural crest cells (right) 24 hours after treatments with Bortezomib (D), Carfilzomib (E) and Rapamycin or Chloroquine (F). Values are the mean \pm SEM. (D-E)) n=7 for NPCs; $1 \mathrm{x}$ for H7, 4x for H9 and 2x for 168. n=11 for NCCs; $2 \mathrm{x}$ for H1, 2x for H7, 3x for H9 and 4x for 168. (F) n=4 for NPCs; $1 \mathrm{x}$ for H7 and 168, 2x for H9. $\mathrm{n}=4$ for NCCs; $1 \mathrm{x}$ for H7 and H9, 2x for H1 and 168. Statistical significance $(\mathrm{p}<0.05)$ was established by Two-way ANOVA and Tukey's post hoc analysis. (G) Bliss independence analysis of interactions between the proteasome inhibitors (Bortezomib and Carfilzomib), Rapamycin and Chloroquine after $48 \mathrm{~h}$ of exposure. Values are the mean degree of synergy (difference between theoretical and observed toxicities) \pm SE. $n=4$ for NPCs; $1 x$ for H7 and 168, 2x for H9. $n=6$ for NCCs; $1 \mathrm{x}$ for $\mathrm{H} 7$ and H9, 2x for H1 and 168)). Statistical significance $(\mathrm{p}<0.05)$ was determined by the Holm-Sidak method. 
bioRxiv preprint doi: https://doi.org/10.1101/683359; this version posted February 14,2020 . The copyright holder for this preprint (which was not certified by peer review) is the author/funder, who has granted bioRxiv a license to display the preprint in perpetuity. It is made available under aCC-BY-NC-ND 4.0 International license.

\section{FIGURES}

\section{Figure 1}

A

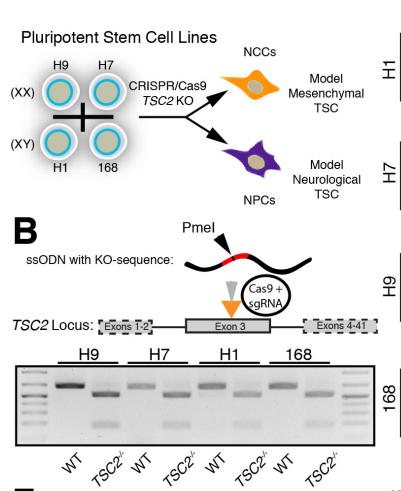

F

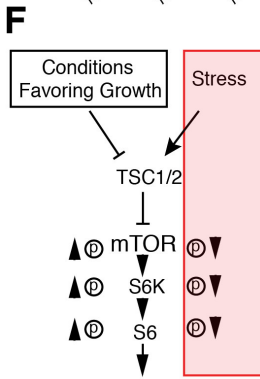

Cell Growth/Proliferation

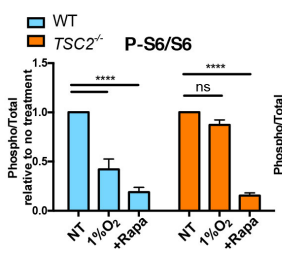

C

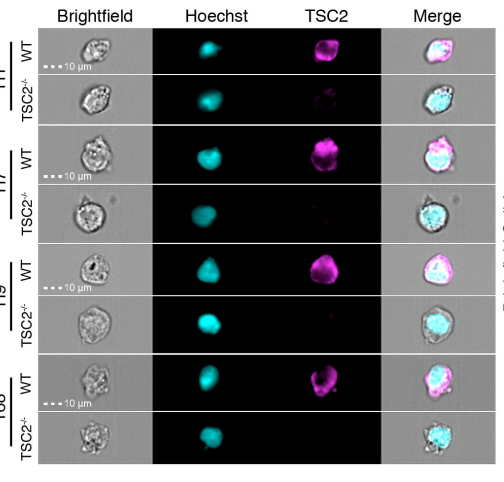

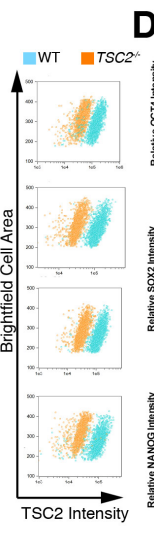
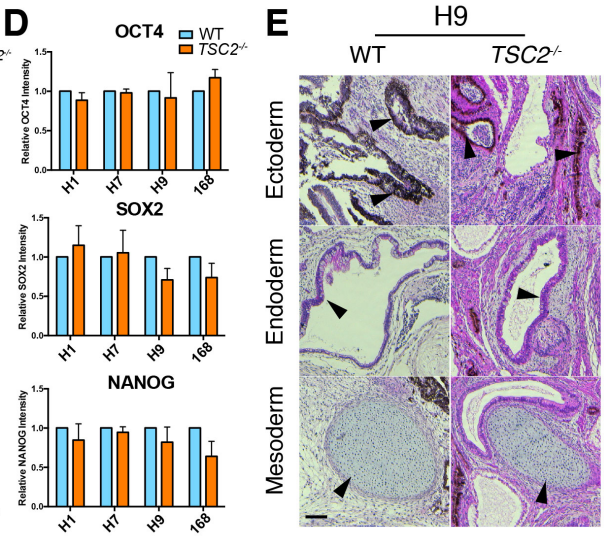

G

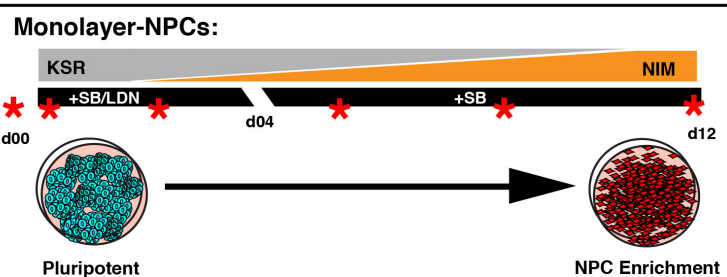

EB-NCCs:

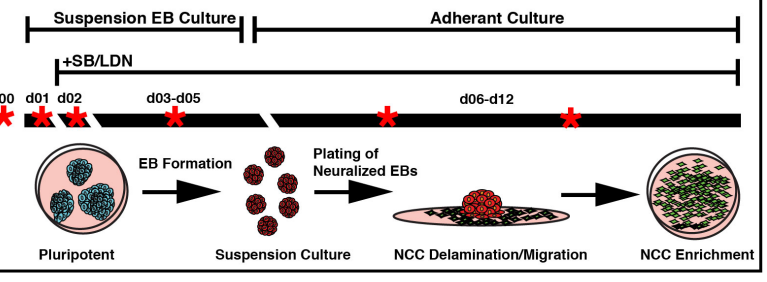


Figure 2

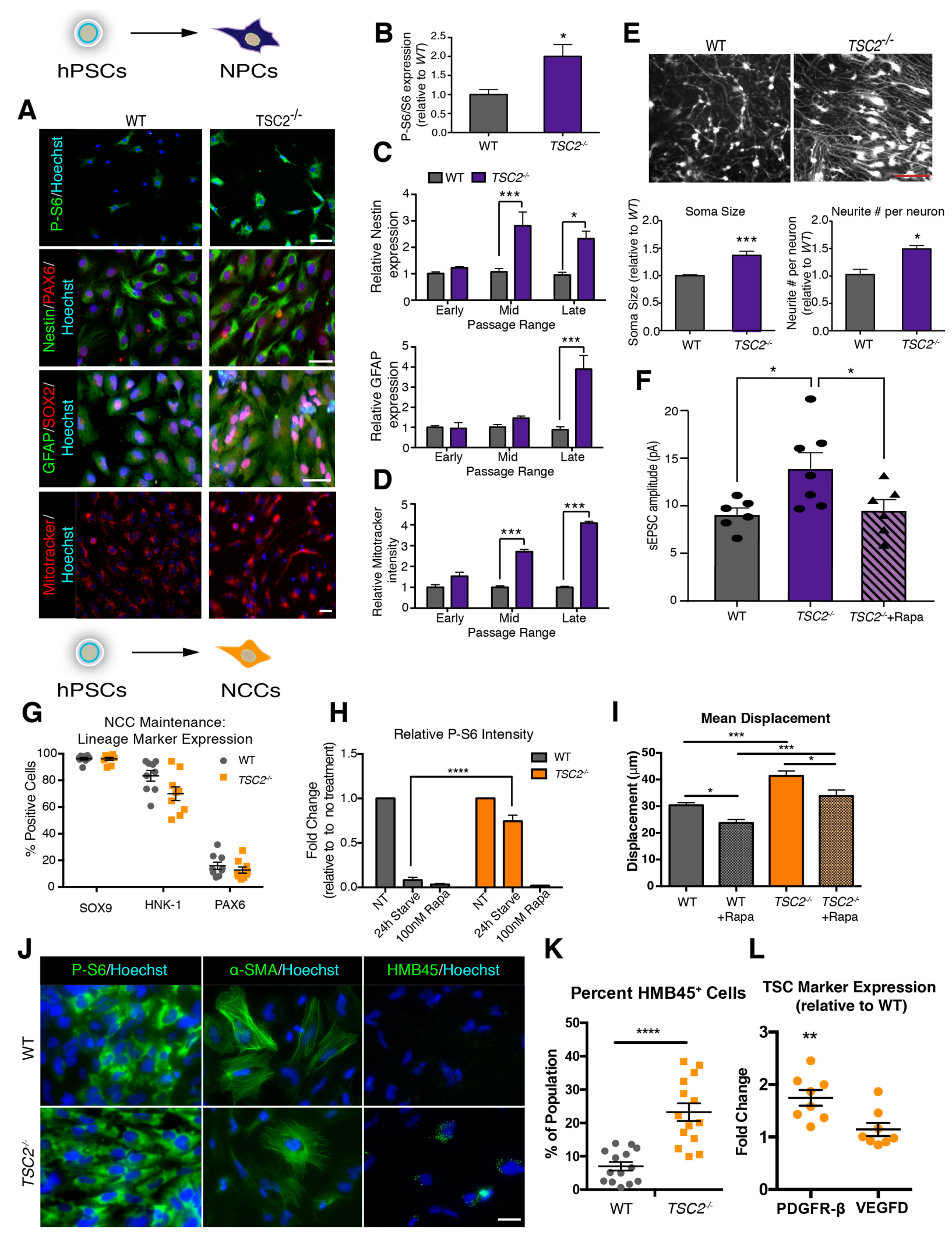


bioRxiv preprint doi: https://doi.org/10.1101/683359; this version posted February 14,2020 . The copyright holder for this preprint (which was not certified by peer review) is the author/funder, who has granted bioRxiv a license to display the preprint in perpetuity. It is made available under aCC-BY-NC-ND 4.0 International license.

Figure 3

A
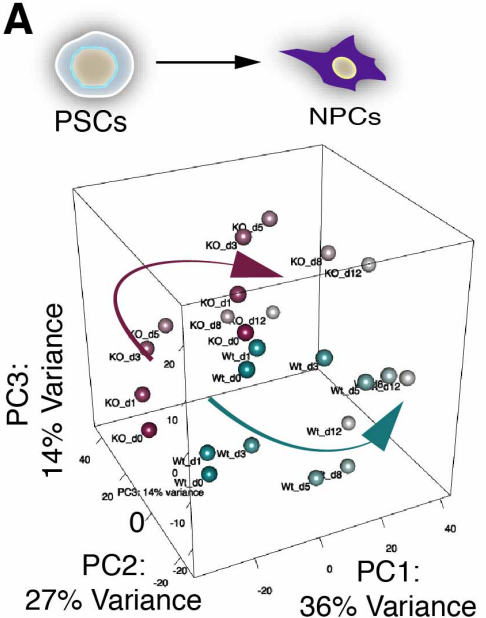

$\square:$ WT $\square:$ TSC2 $^{\prime-}$

\section{C $\operatorname{TSC}^{-\sim \mathrm{NCC}}$}

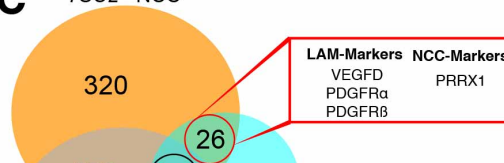

26

698 83 605 P-LAM

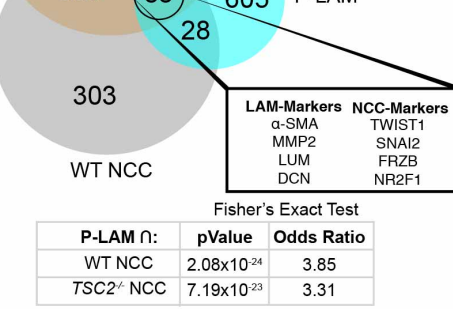

E

Up-Regulated DEGs:

KEGG Pathway

Protein processing in endoplasmic reticulum. Carbon metabolism mTOR signaling pathway Protein export Vibrio cholerae infection Oxidative phosphorylationCollecting duct acid secretion LysosomeSteroid biosynthesis Kaposi sarcoma-associated herpesvirus infectionLegionellosis Rheumatoid arthritis Rheumatoid arthritis-
Antigen processing and presentationAmino sugar and nucleotide sugar metabolismHuman immunodeficiency virus 1 infectionOther glycan degradation Glycosaminoglycan degradation Complement and coagulation cascades Non-alcoholic fatty liver disease (NAFLD) Alzheimer diseaseProtein digestion and absorption -

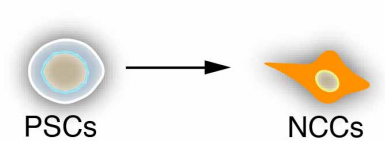

B
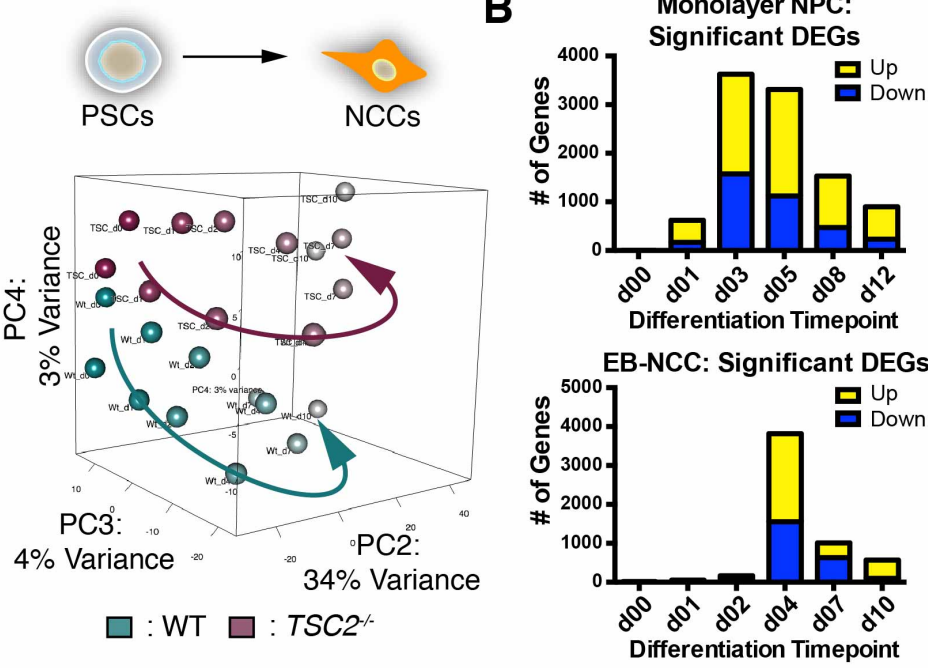

\section{D}

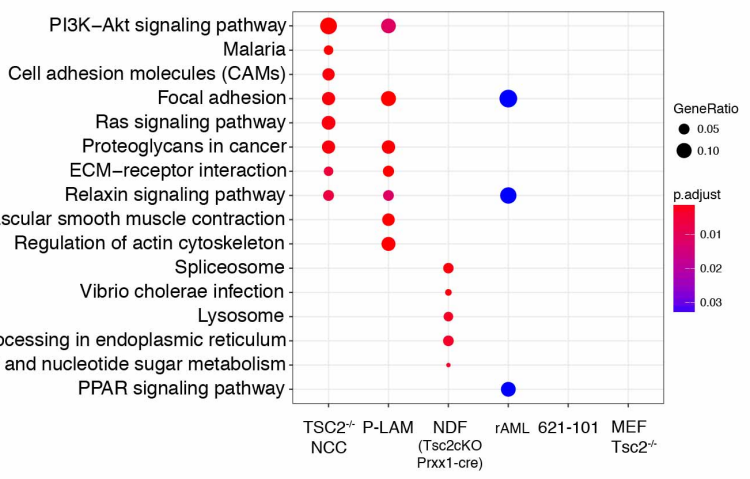

TSC2 $/$ vs WT

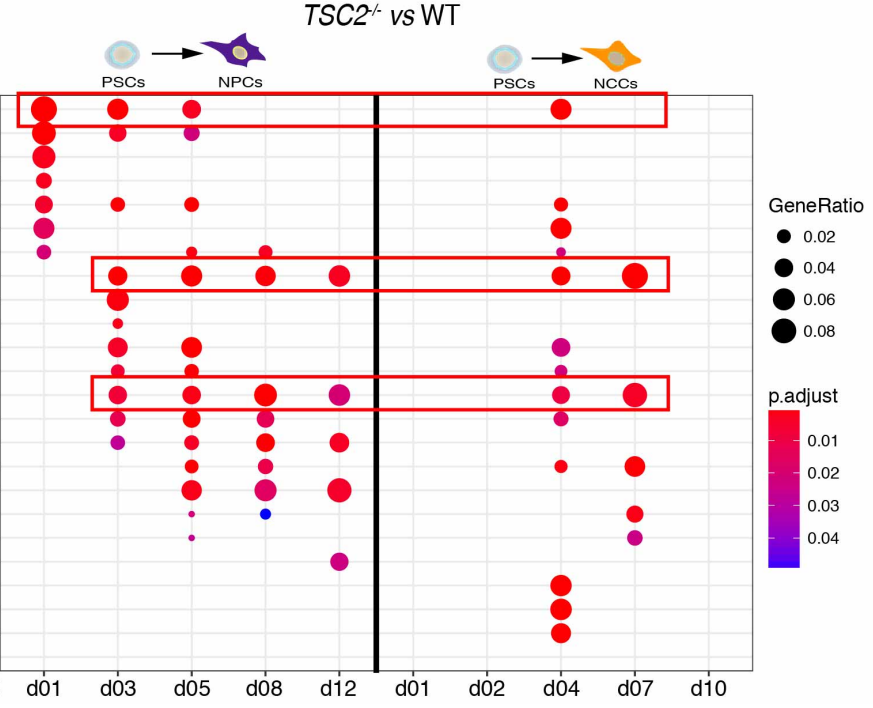




\section{Figure 4}

A
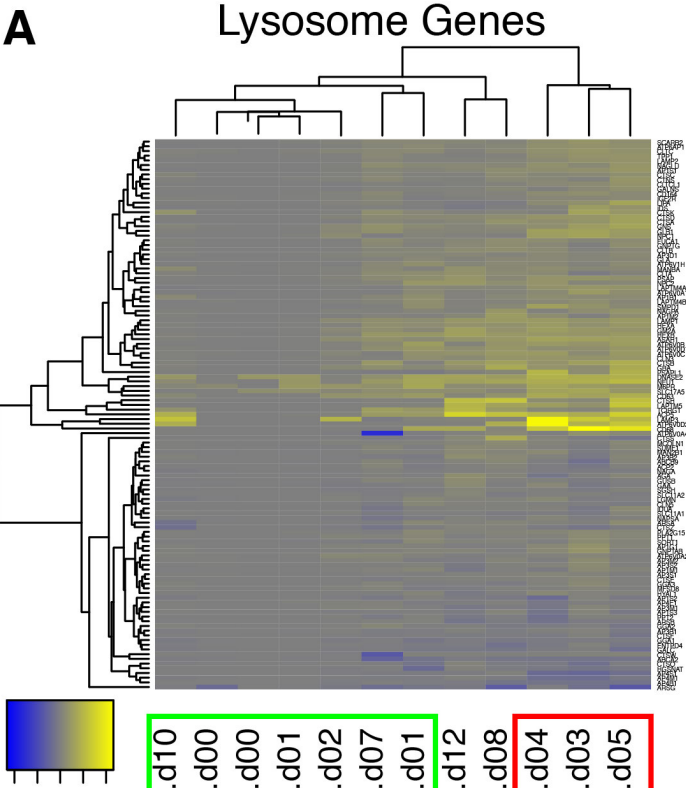

$\begin{array}{lll}-4 & 0 & 4\end{array}$

$\log _{2} \mathrm{FC}$

C
B
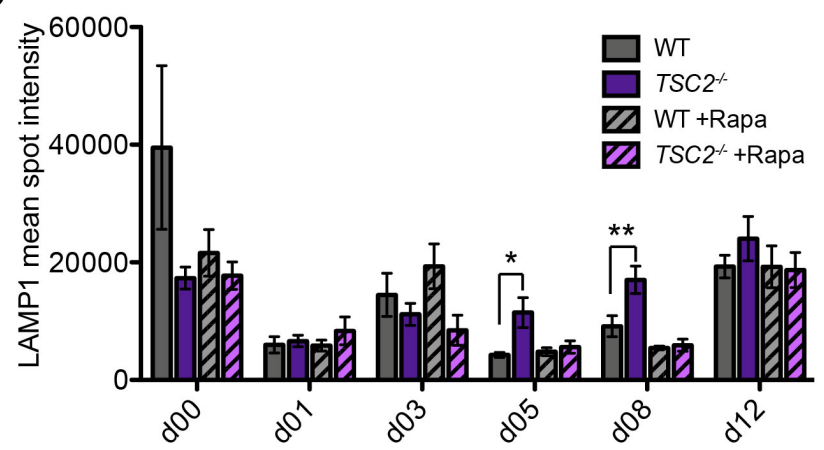

day 5:

day of differentiation

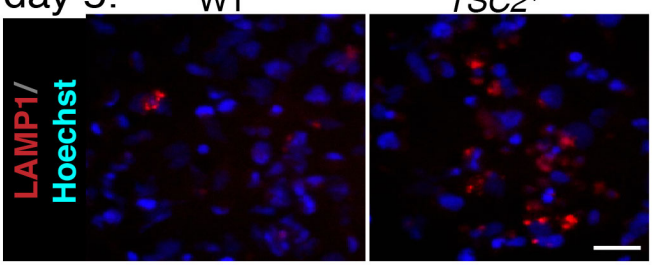

D
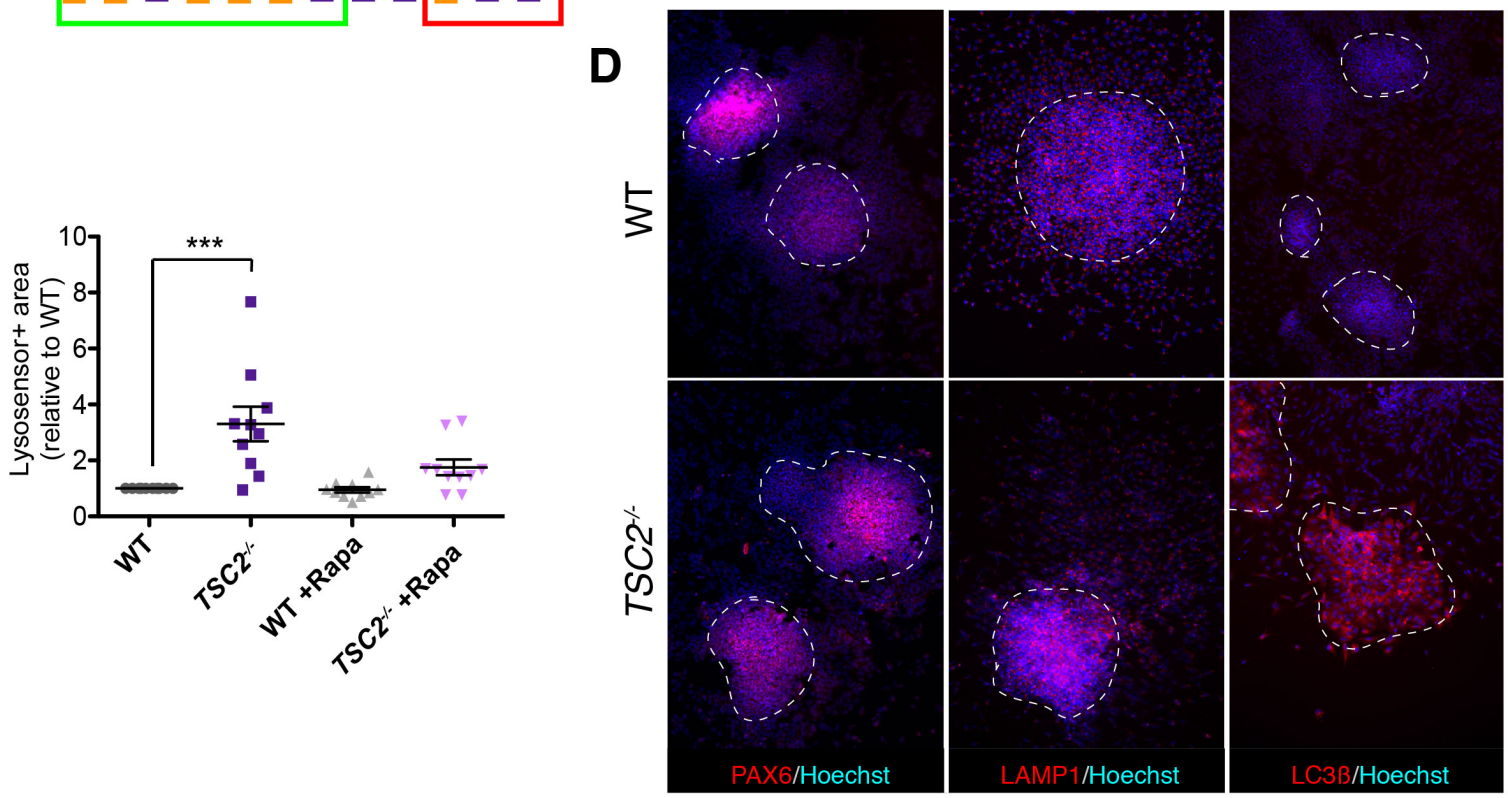
Figure 5
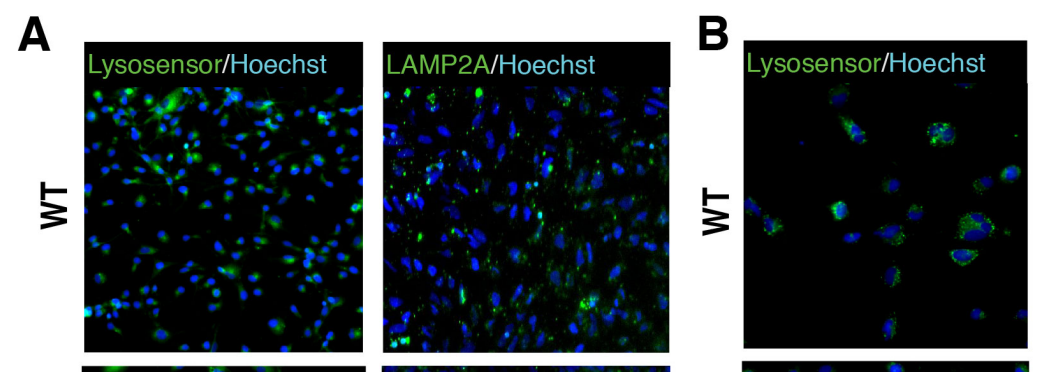

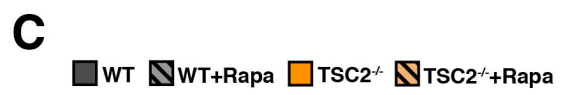
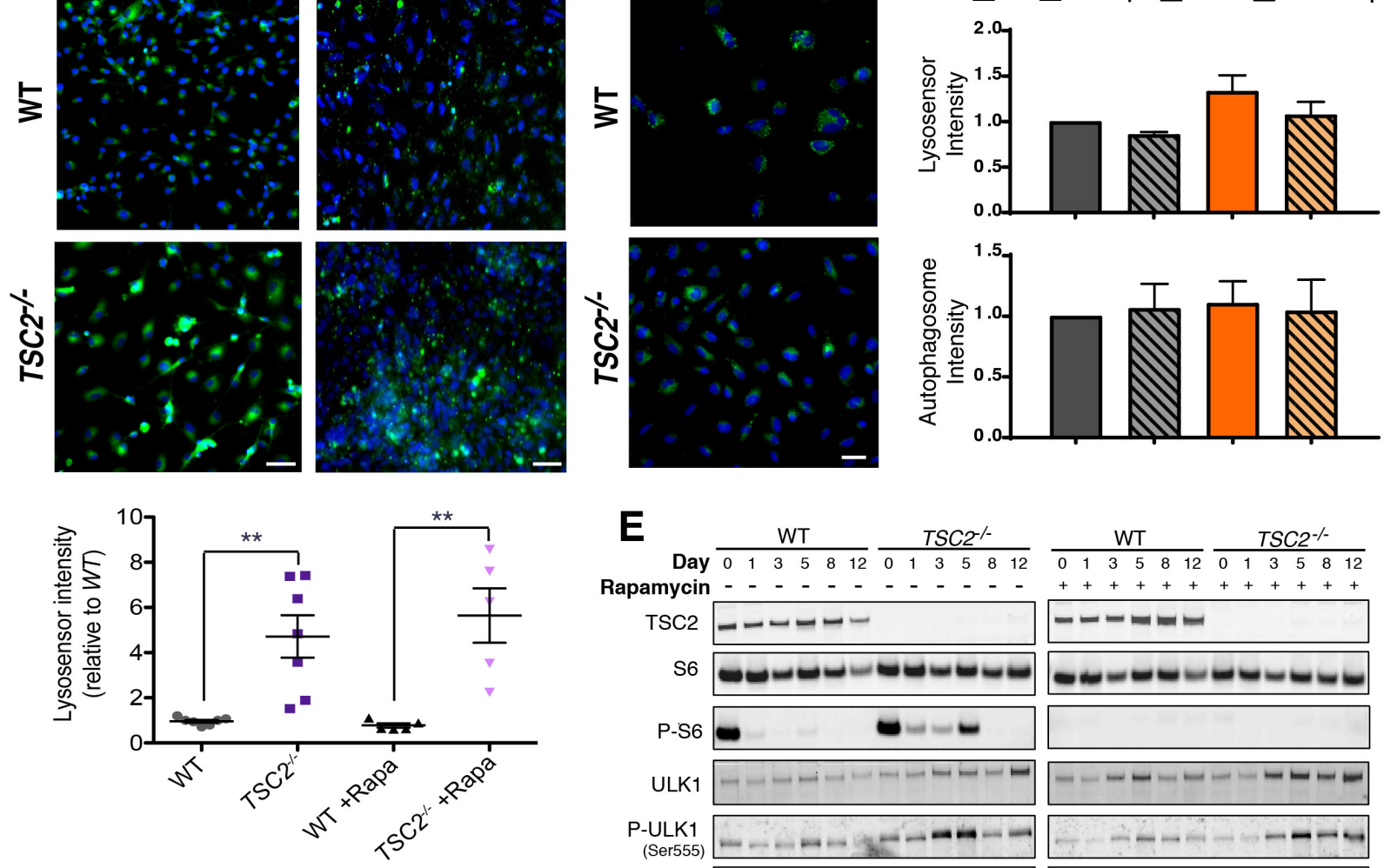

E
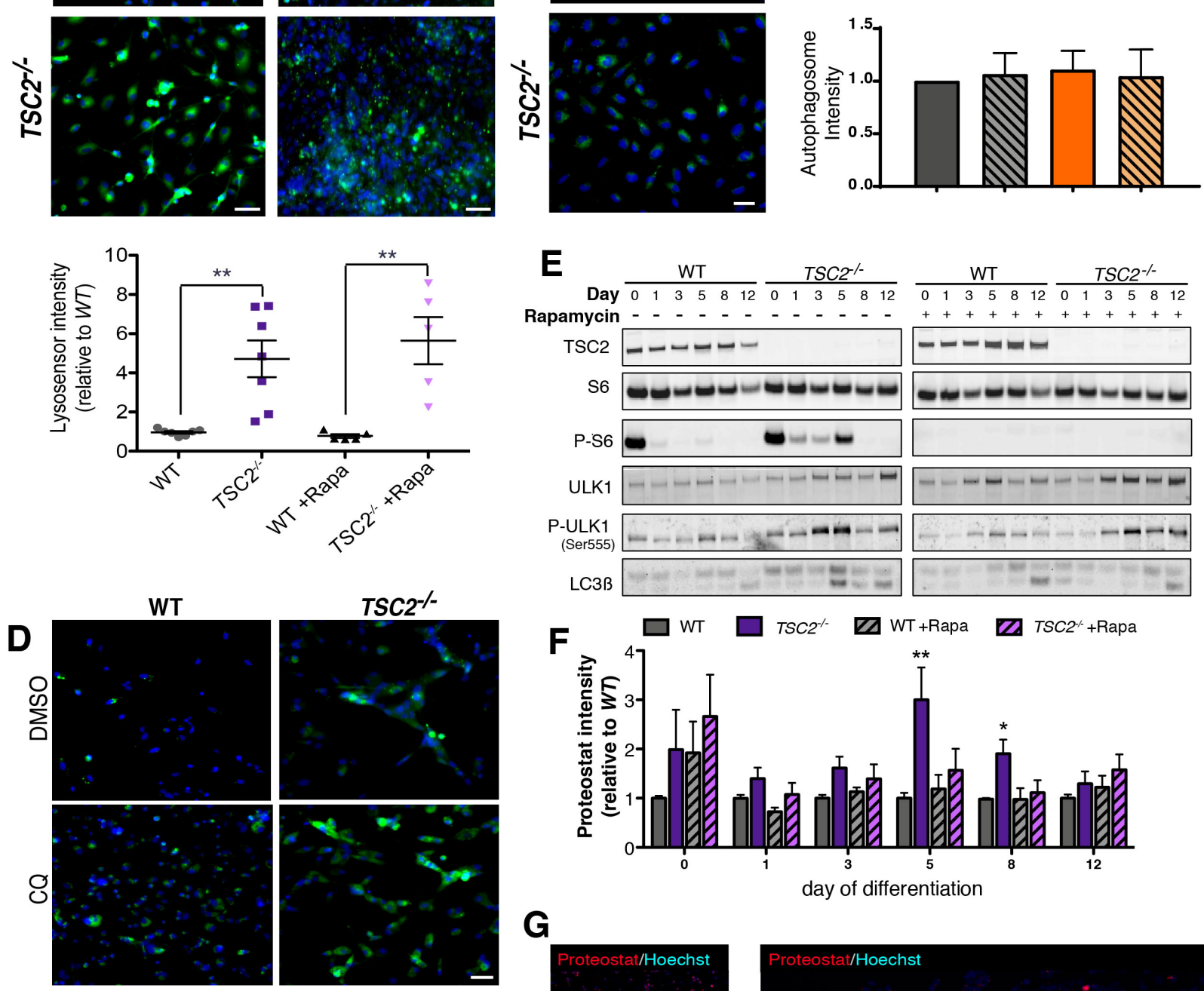

Rapamycin - - - - - - - + + + + + + + + +
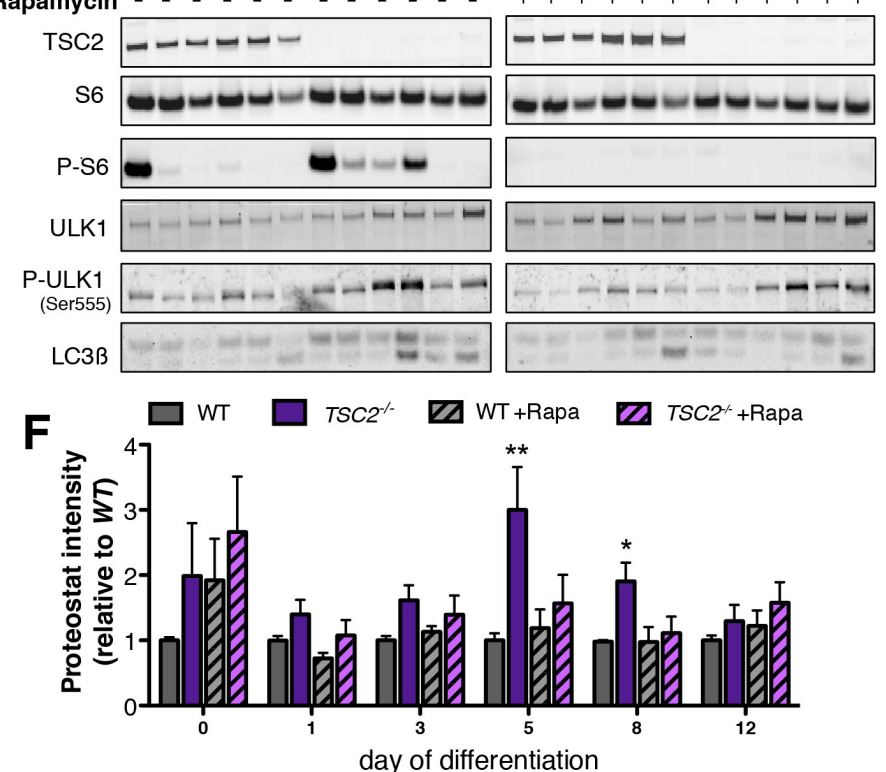

G
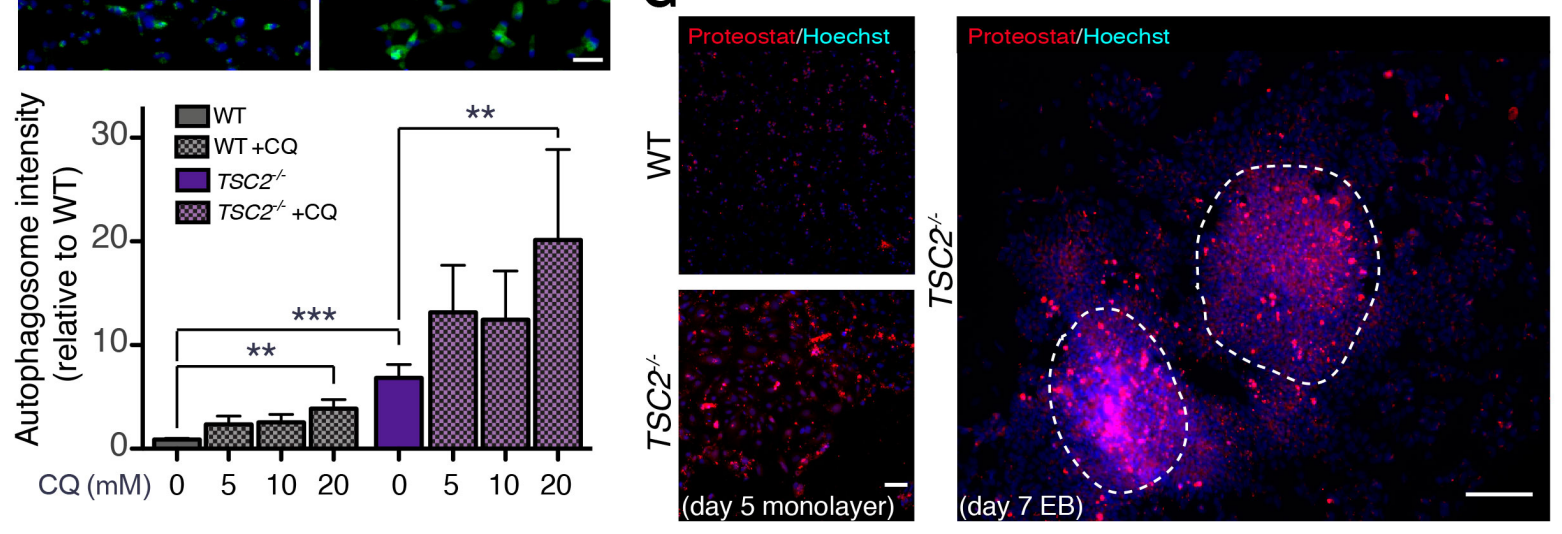


\section{Figure 6}

A

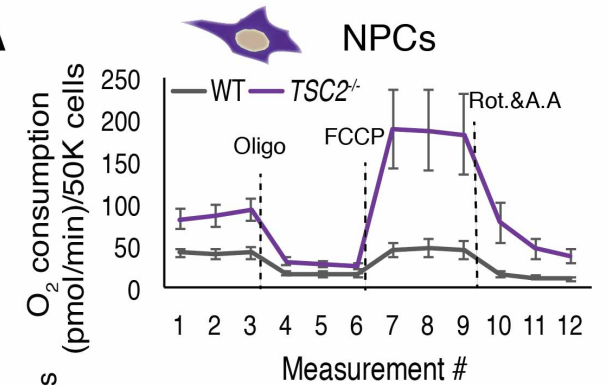

C $\stackrel{\infty}{\overline{\mathrm{d}}} 120]-W T-T S C 2^{\prime}$

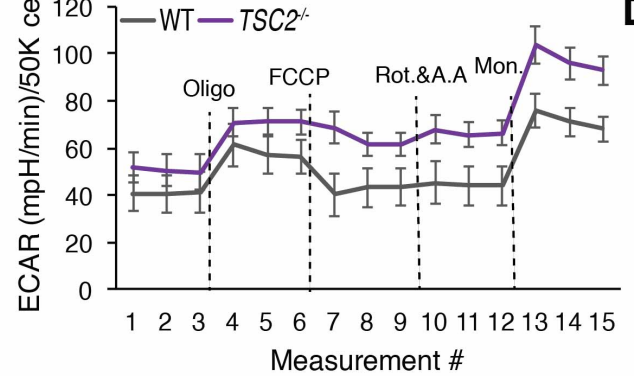

E

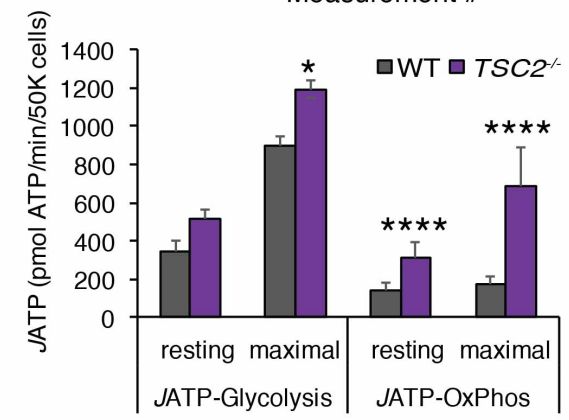

B

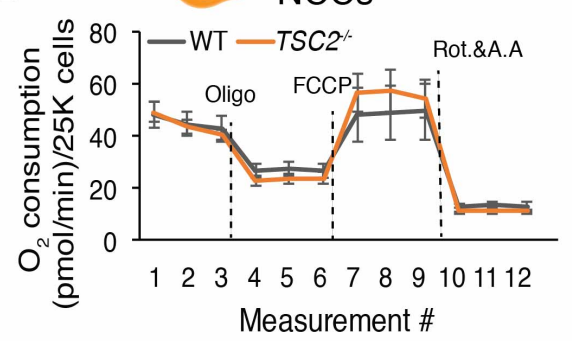

D $\stackrel{0}{g}$

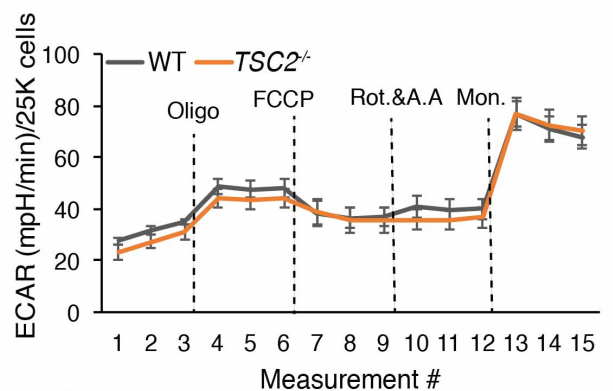

$\mathbf{F}$

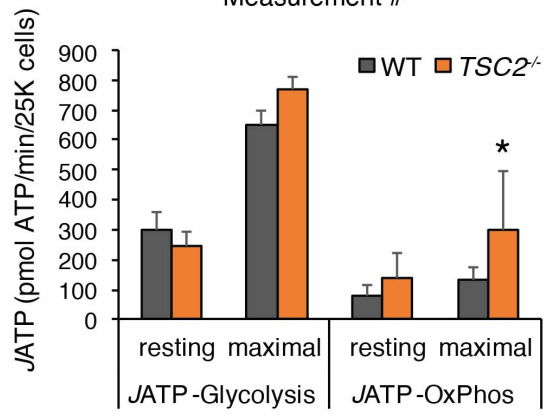

G

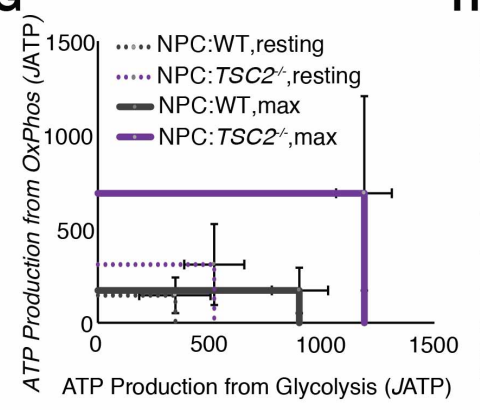

$\mathrm{H}_{2}$

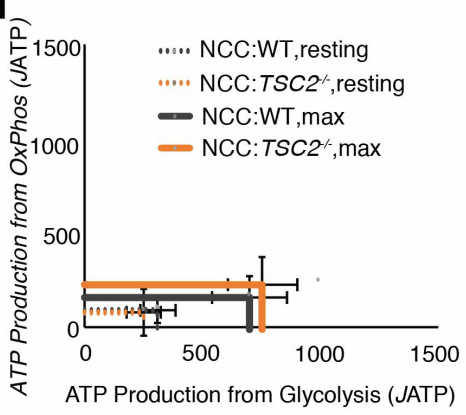

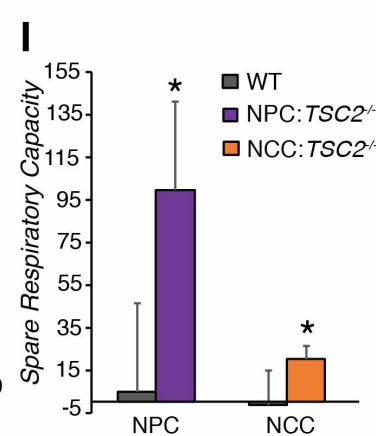


bioRxiv preprint doi: https://doi.org/10.1101/683359; this version posted February 14, 2020. The copyright holder for this preprint (which was not certified by peer review) is the author/funder, who has granted bioRxiv a license to display the preprint in perpetuity. It is made available under aCC-BY-NC-ND 4.0 International license.

Figure 7
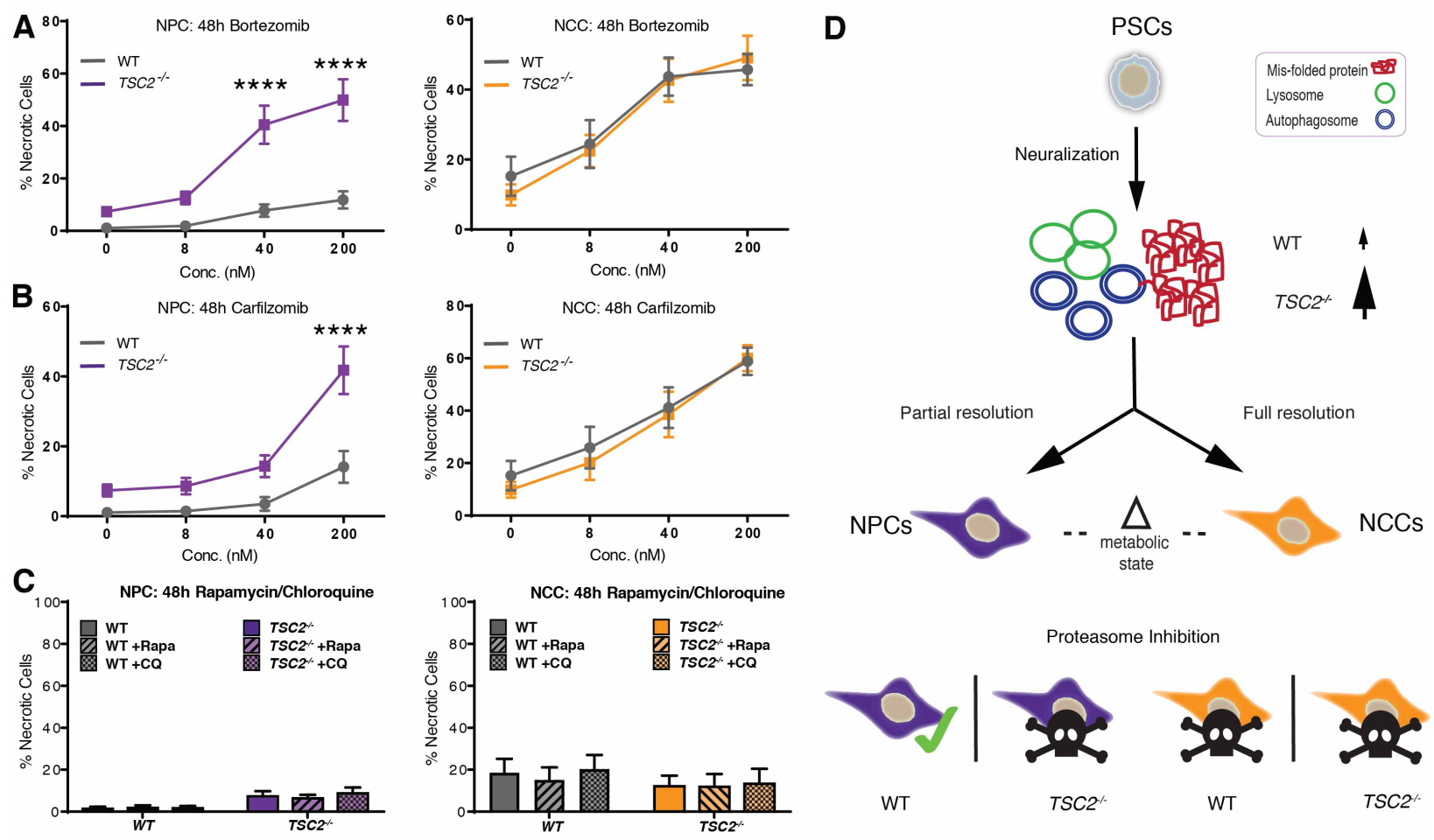
Table 1: DNA/Oligo sequences utilized for genome editing. (GE: genome editing, ssODN: single stranded oligonucleotide, PCR: polymerase chain reaction)

\begin{tabular}{|c|c|c|c|}
\hline Name & Application & Manufacturer & DNA/Oligo sequence \\
\hline TSC2 Exon3 gRNA & GE & Invitrogen & TCATCCGGATGCGATTGTTG \\
\hline $\begin{array}{l}\text { TSC2 Exon3 stop } \\
\text { codon donor ssODN }\end{array}$ & GE & $\begin{array}{l}\text { Integrated DNA } \\
\text { Technologies }\end{array}$ & $\begin{array}{l}\text { AAATTTCTTGGTTTTTGCGACTTCACAA } \\
\text { ATCTGCCCTATCCTACAACAGCTTAATT } \\
\text { AAGGTTTAAACGCCATGACATCCGGAT } \\
\text { GCGATTGTTGAGGCCACATTCCATGCTC } \\
\text { AGTT }\end{array}$ \\
\hline TSC2 Exon3 PCR F & PCR & Invitrogen & TCCTCGGGATGGAGCAGTAA \\
\hline TSC2 Exon3 PCR R & PCR & Invitrogen & TGCAAACCAGATCATCGGCA \\
\hline AAVS1 gRNA & GE & Invitrogen & GTCACCAATCCTGTCCCTAG \\
\hline Name & Application & Manufacturer & DNA/Oligo sequence \\
\hline TSC2 Exon3 gRNA & GE & Invitrogen & TCATCCGGATGCGATTGTTG \\
\hline $\begin{array}{l}\text { TSC2 Exon3 stop } \\
\text { codon donor ssODN }\end{array}$ & GE & $\begin{array}{l}\text { Integrated DNA } \\
\text { Technologies }\end{array}$ & $\begin{array}{l}\text { AAATTTCTTGGTTTTTGCGACTTCACAA } \\
\text { ATCTGCCCTATCCTACAACAGCTTAATT } \\
\text { AAGGTTTAAACGCCATGACATCCGGAT } \\
\text { GCGATTGTTGAGGCCACATTCCATGCTC } \\
\text { AGTT }\end{array}$ \\
\hline TSC2 Exon3 PCR F & PCR & Invitrogen & TCCTCGGGATGGAGCAGTAA \\
\hline TSC2 Exon3 PCR R & PCR & Invitrogen & TGCAAACCAGATCATCGGCA \\
\hline AAVS1 gRNA & GE & Invitrogen & GTCACCAATCCTGTCCCTAG \\
\hline
\end{tabular}


Table 2: Antibodies used in this study. (IF = Immunofluorescence, IFC = Imaging flow cytometry, FC = flow cytometry, WB = western blot)

\begin{tabular}{|c|c|c|c|c|}
\hline Antibody & Manufacturer & Catalog \# & Dilution & $\begin{array}{l}\text { Applica } \\
\text { tion }\end{array}$ \\
\hline 4E-BP1 & $\begin{array}{l}\text { Cell Signalling } \\
\text { Technology }\end{array}$ & 9452 & $1: 1000$ & WB \\
\hline AMPK $\alpha$ & $\begin{array}{l}\text { Cell Signalling } \\
\text { Technology }\end{array}$ & 5832 & $1: 1000$ & WB \\
\hline Calponin & DAKO & M3556 & $1: 250$ & IF \\
\hline CD271 (p75) & BD Biosciences & 560326 & $1: 20$ & $\mathrm{FC}$ \\
\hline GAPDH & Abcam & ab8245 & $1: 5000$ & WB \\
\hline GFAP & ThermoFisher & $\begin{array}{l}\text { MA5- } \\
12023\end{array}$ & $1: 40$ & IF \\
\hline IgG1 $\kappa$ Isotype control & BD Biosciences & 55778 & $1: 20$ & $\mathrm{FC}$ \\
\hline LAMP1 & $\begin{array}{l}\text { Cell Signalling } \\
\text { Technology }\end{array}$ & 9091 & $1: 400$ & IF \\
\hline$\overline{L C} 3 \beta$ & $\begin{array}{l}\text { Cell Signalling } \\
\text { Technology }\end{array}$ & 3868 & $\begin{array}{l}1: 200 / 1: 50 \\
0\end{array}$ & $\mathrm{IF} / \mathrm{WB}$ \\
\hline MAP2 & Invitrogen & $13-1500$ & $1: 100$ & IF \\
\hline mTOR & $\begin{array}{l}\text { Cell Signalling } \\
\text { Technology }\end{array}$ & 4517 & $1: 1000$ & WB \\
\hline NANOG & $\begin{array}{l}\text { Cell Signalling } \\
\text { Technology }\end{array}$ & 4903 & $1: 200$ & IF \\
\hline Nestin & Millipore & $\begin{array}{l}\text { MAB532 } \\
6\end{array}$ & $1: 100$ & IF \\
\hline OCT3/4 & BD Biosciences & 611203 & $1: 400$ & IF \\
\hline
\end{tabular}




\begin{tabular}{|c|c|c|c|c|}
\hline p70 S6 Kinase & $\begin{array}{l}\text { Cell Signalling } \\
\text { Technology }\end{array}$ & 2708 & $1: 1000$ & WB \\
\hline PAX6 & BD Biosciences & 561462 & $1: 200$ & IF \\
\hline PAX6 & Biolegend & 901301 & $1: 100$ & IF \\
\hline Phospho-4E-BP1 (Thr37/46) & $\begin{array}{l}\text { Cell Signalling } \\
\text { Technology }\end{array}$ & 2855 & $1: 1000$ & WB \\
\hline Phospho-AMPK $\alpha$ (Thr172) & $\begin{array}{l}\text { Cell Signalling } \\
\text { Technology }\end{array}$ & 2535 & $1: 1000$ & WB \\
\hline Phospho-mTOR (Ser 2448) & $\begin{array}{l}\text { Cell Signalling } \\
\text { Technology }\end{array}$ & 5536 & $1: 1000$ & WB \\
\hline $\begin{array}{l}\text { Phospho-p70 S6 Kinase } \\
\text { (Thr389) }\end{array}$ & $\begin{array}{l}\text { Cell Signalling } \\
\text { Technology }\end{array}$ & 9206 & $1: 1000$ & WB \\
\hline Phospho-S6 (Ser235/236) & $\begin{array}{l}\text { Cell Signalling } \\
\text { Technology }\end{array}$ & 2211 & $\begin{array}{l}1: 200 / 1: 10 \\
00\end{array}$ & IF/WB \\
\hline Phospho-ULK1 (Ser555) & $\begin{array}{l}\text { Cell Signalling } \\
\text { Technology }\end{array}$ & 5869 & $1: 500$ & WB \\
\hline Phospho-ULK1 (Ser757) & $\begin{array}{l}\text { Cell Signalling } \\
\text { Technology }\end{array}$ & 6888 & $1: 1000$ & WB \\
\hline PMEL (HMB45) & ThermoFisher & $\begin{array}{l}\text { MA5- } \\
13232\end{array}$ & $1: 50$ & IF \\
\hline S6 & $\begin{array}{l}\text { Cell Signalling } \\
\text { Technology }\end{array}$ & 2317 & $1: 1000$ & WB \\
\hline SOX10 & R\&D Systems & $\begin{array}{l}\text { MAB286 } \\
4\end{array}$ & $1: 200$ & IF \\
\hline SOX2 & Millipore & AB5603 & $1: 200$ & IF \\
\hline
\end{tabular}




\begin{tabular}{|c|c|c|c|c|}
\hline TSC2 & $\begin{array}{l}\text { Cell Signalling } \\
\text { Tecnology }\end{array}$ & 4308 & $\begin{array}{l}1: 200 / 1: 10 \\
00\end{array}$ & $\begin{array}{l}\mathrm{IF} / \mathrm{IFC} / \\
\mathrm{WB}\end{array}$ \\
\hline Tubulin- $\beta 3$ (Tuj1) & Biolegend & 801201 & $1: 100$ & IF \\
\hline ULK1 (total) & $\begin{array}{l}\text { Cell Signalling } \\
\text { Technology }\end{array}$ & 8054 & $1: 1000$ & WB \\
\hline$\alpha$-Smooth Muscle Actin & Millipore & CBL171 & $1: 250$ & IF \\
\hline$\beta$-Actin & $\begin{array}{l}\text { Cell Signalling } \\
\text { Technology }\end{array}$ & 3700 & $1: 1000$ & WB \\
\hline $\begin{array}{l}\text { DyLight } 800 \text { goat anti Ms } \\
\text { IgG }\end{array}$ & Invitrogen & $\begin{array}{l}\text { SA53552 } \\
1\end{array}$ & $1: 10,000$ & WB \\
\hline $\begin{array}{l}\text { Alexa Fluor } 680 \text { goat anti } \\
\text { rabbit IgG }\end{array}$ & Life Tech & A21076 & $1: 10,000$ & WB \\
\hline $\begin{array}{l}\text { Alexa Fluor } 488 \text { goat anti } \\
\text { Ms IgM }\end{array}$ & Life Tech & A21042 & $1: 1000$ & IF \\
\hline $\begin{array}{l}\text { Alexa Fluor } 488 \text { goat anti } \\
\text { Ms IgG1 }\end{array}$ & Life Tech & A21121 & $1: 1000$ & IF \\
\hline $\begin{array}{l}\text { Alexa Fluor } 488 \text { goat anti } \\
\text { Ms IgG }\end{array}$ & Life Tech & A11001 & $1: 1000$ & IF \\
\hline $\begin{array}{l}\text { Alexa Fluor } 488 \text { goat anti Rb } \\
\text { IgG }\end{array}$ & Life Tech & A11034 & $1: 1000$ & $\mathrm{IF} / \mathrm{IFC}$ \\
\hline $\begin{array}{l}\text { Alexa Fluor } 647 \text { goat anti } \\
\text { Ms IgG }\end{array}$ & Life Tech & A21235 & $1: 1000$ & IF \\
\hline $\begin{array}{l}\text { Alexa Fluor } 647 \text { goat anti Rb } \\
\text { IgG }\end{array}$ & Life Tech & A21245 & $1: 1000$ & IF \\
\hline $\begin{array}{l}\text { Alexa Fluor } 647 \text { goat anti } \\
\text { Ms IgG1 }\end{array}$ & Life Tech & A21240 & $1: 1000$ & IF \\
\hline
\end{tabular}


bioRxiv preprint doi: https://doi.org/10.1101/683359; this version posted February 14,2020 . The copyright holder for this preprint (which was not certified by peer review) is the author/funder, who has granted bioRxiv a license to display the preprint in perpetuity. It is made available under aCC-BY-NC-ND 4.0 International license.

\begin{tabular}{|l|l|l|l|l|}
\hline Alexa Fluor 647 goat anti & Life Tech & A21241 & $1: 1000$ & IF \\
Ms IgG2A & & & & \\
\hline
\end{tabular}


bioRxiv preprint doi: https://doi.org/10.1101/683359; this version posted February 14,2020 . The copyright holder for this preprint (which was not certified by peer review) is the author/funder, who has granted bioRxiv a license to display the preprint in perpetuity. It is made available under aCC-BY-NC-ND 4.0 International license.

\section{SUPPLEMENTAL FIGURES}

\section{Figure S1}

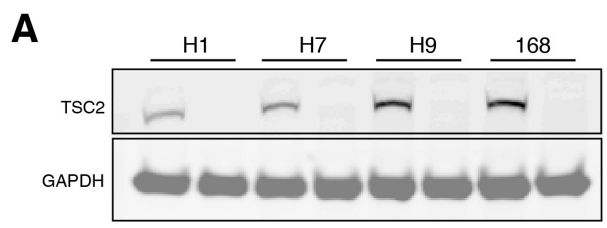

WT TSC2 ${ }^{\star}$ WT TSC2 ${ }^{\circ}$ WT TSC2 $2^{\star}$ WT TSC2

C
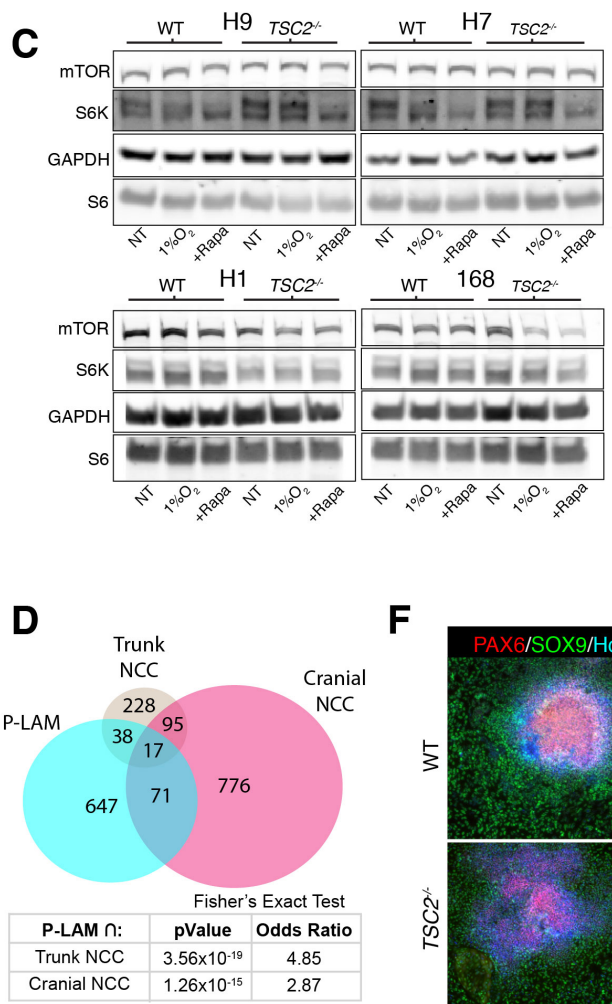

$\mathbf{F}$

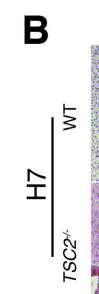

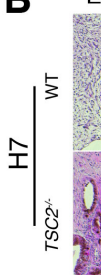

Ectoderm Endoderm Mesoderm
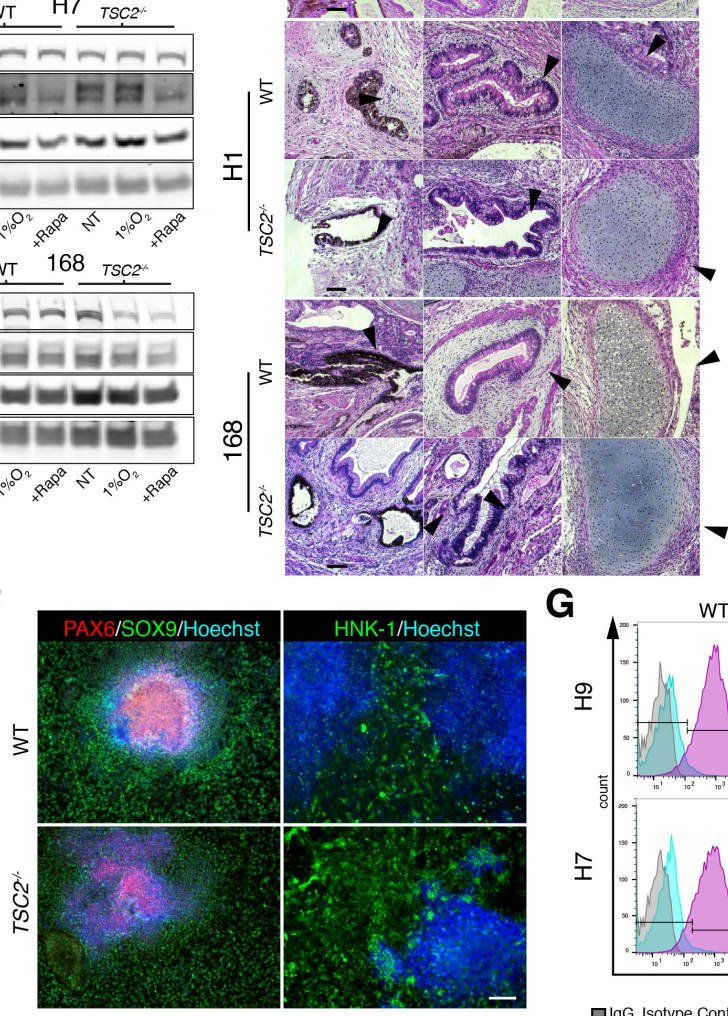
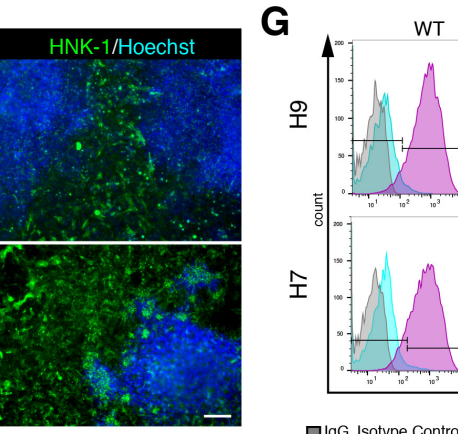

G

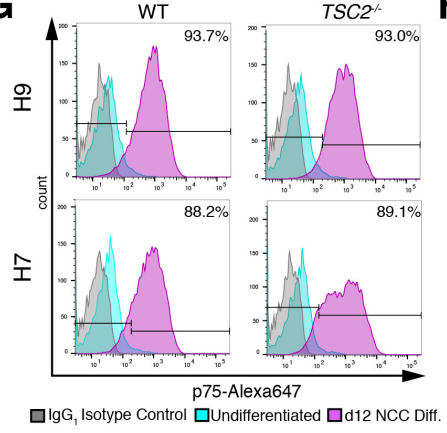

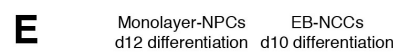

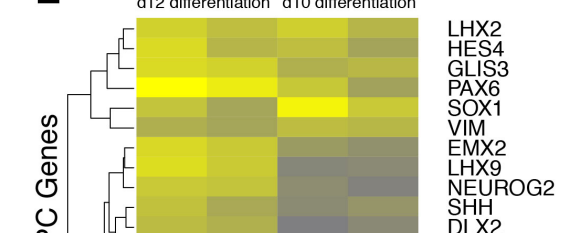

SHX2

OTX1

$\mathrm{CDH} 2$

$\mathrm{NOTCH} 2$

ID4 4

$\mathrm{PTCH} 2$
$\mathrm{GLIS} 2$

NOTCH3

LHX1

SEX1

DXX9
DLX
SNAl2
SNX

SOX5

MMP2

MAX 2

MSX1

ETS1
ETS1
ITGB 1

SOX11

soxi

RXRG

NGX2

H

H

Percent $\mathrm{p} 75^{+}$cells d12 NCC Differentiation

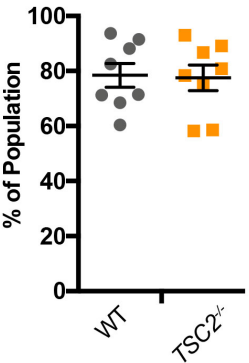


bioRxiv preprint doi: https://doi.org/10.1101/683359; this version posted February 14,2020 . The copyright holder for this preprint (which was not certified by peer review) is the author/funder, who has granted bioRxiv a license to display the preprint in perpetuity. It is made available under aCC-BY-NC-ND 4.0 International license.

Figure S2

A

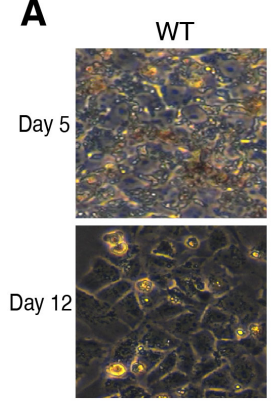

D

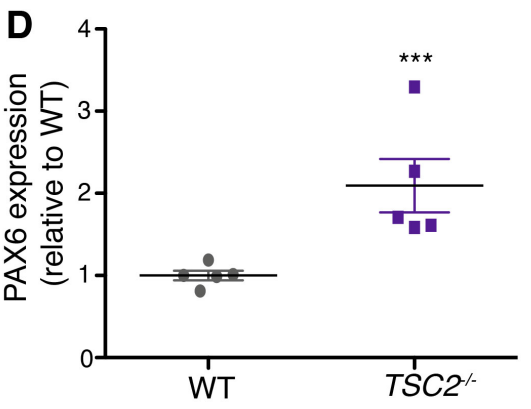

B

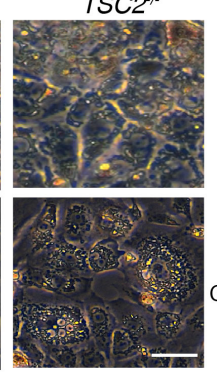

GAPDH

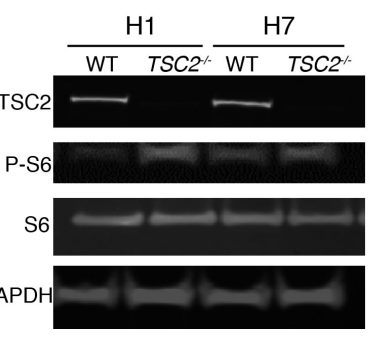

E

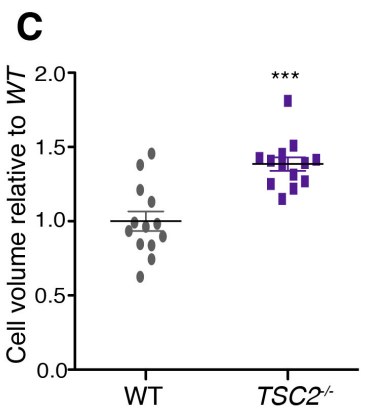

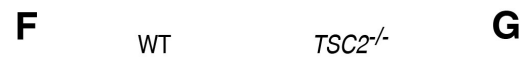

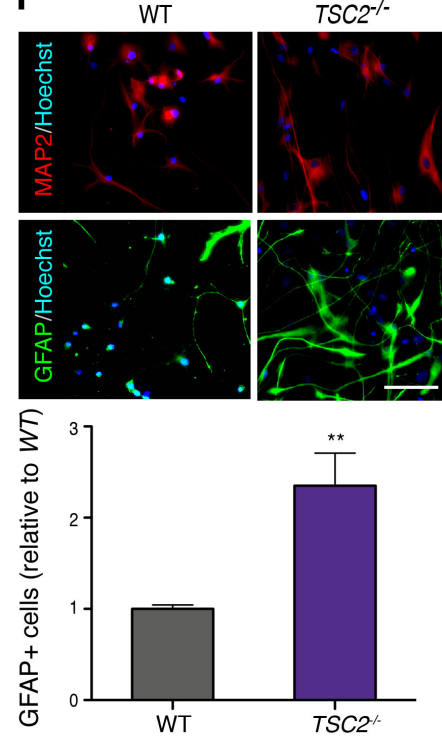

G
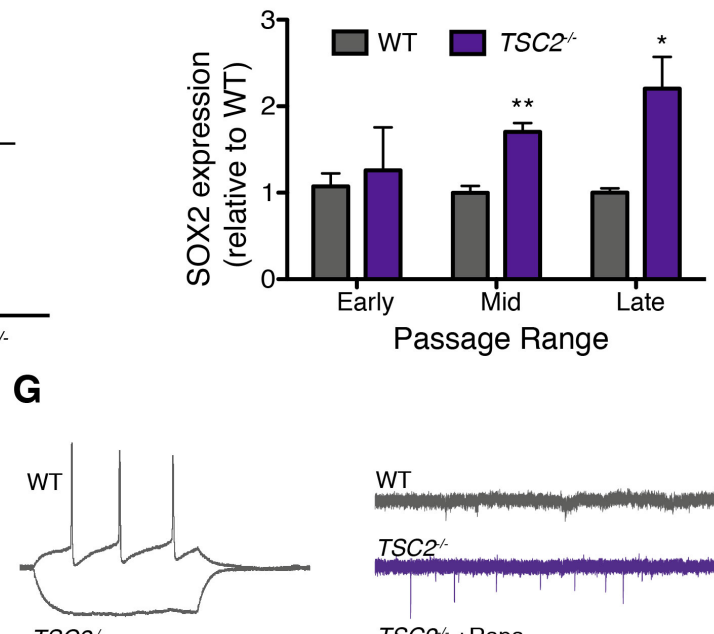

WT
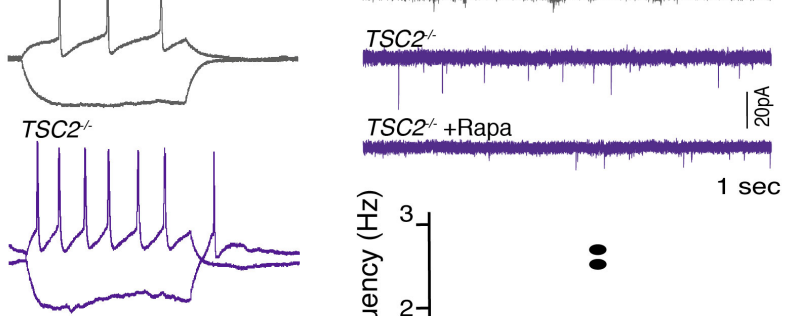

$\mathrm{TSC}^{-}+\mathrm{Rapa}$
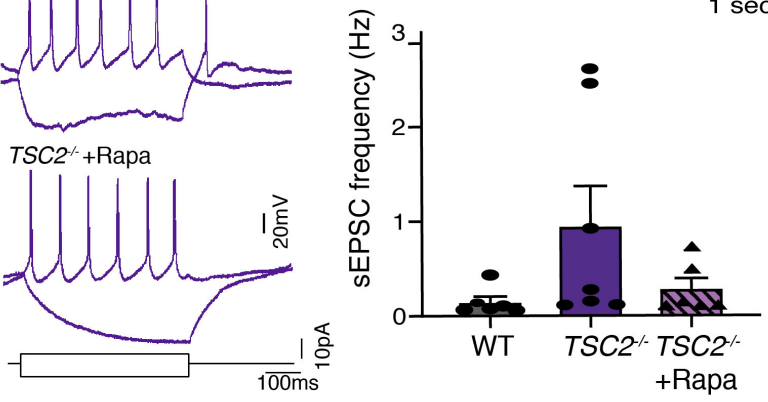
bioRxiv preprint doi: https://doi.org/10.1101/683359; this version posted February 14,2020 . The copyright holder for this preprint (which was not certified by peer review) is the author/funder, who has granted bioRxiv a license to display the preprint in perpetuity. It is made available under aCC-BY-NC-ND 4.0 International license.

\section{Figure S3}

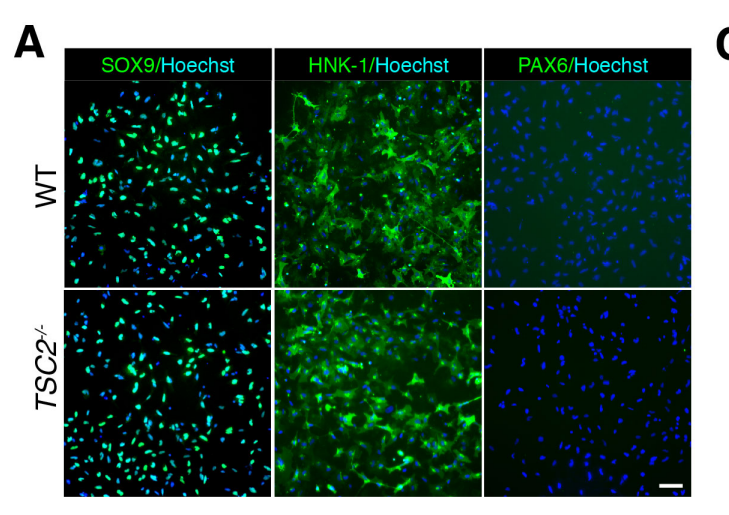

B
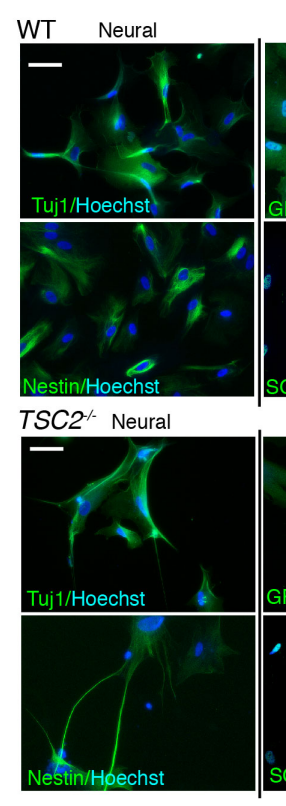

C

EMT Gene Expression
d10 NCC Differentiation

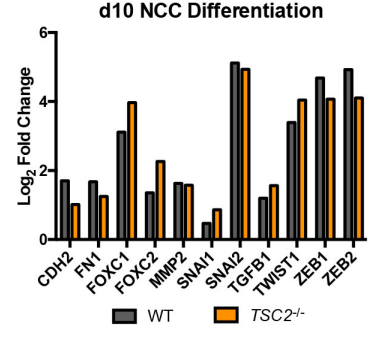

Day 10 NCC Differentiation: Significant DEGs involved in

RTK Signaling (Reactome)

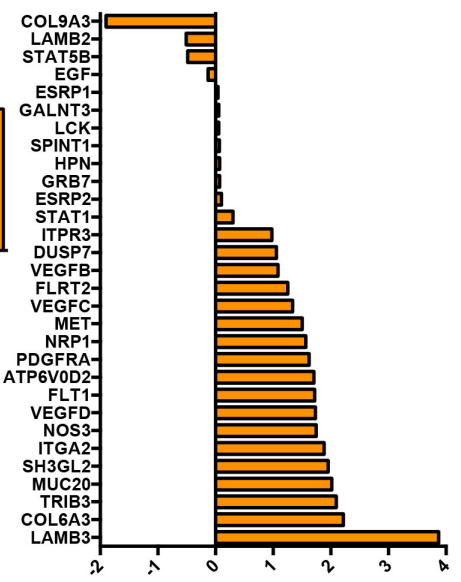

E

(TSC2/- relative to WT)
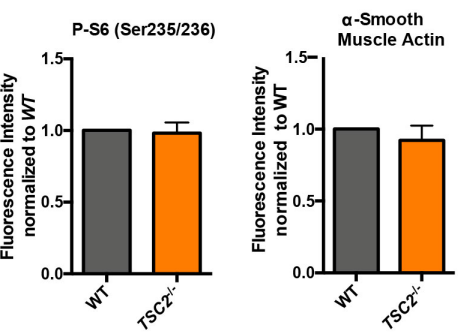

$\mathbf{F}$

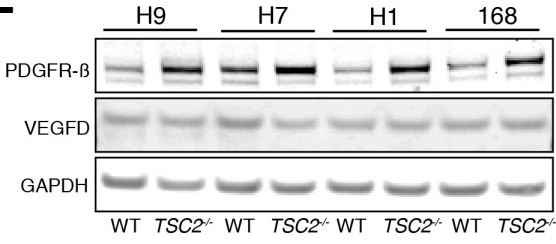


bioRxiv preprint doi: https://doi.org/10.1101/683359; this version posted February 14,2020 . The copyright holder for this preprint (which was not certified by peer review) is the author/funder, who has granted bioRxiv a license to display the preprint in perpetuity. It is made available under aCC-BY-NC-ND 4.0 International license.

\section{Figure S4}

A

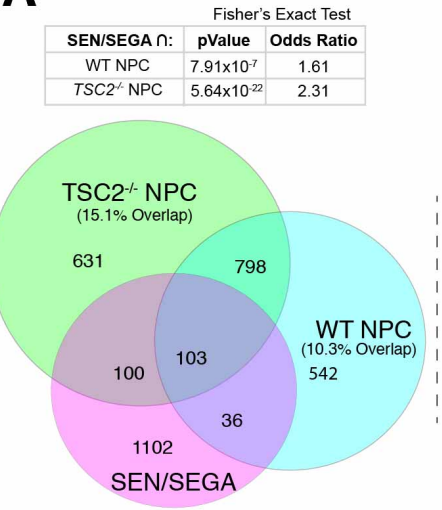

B
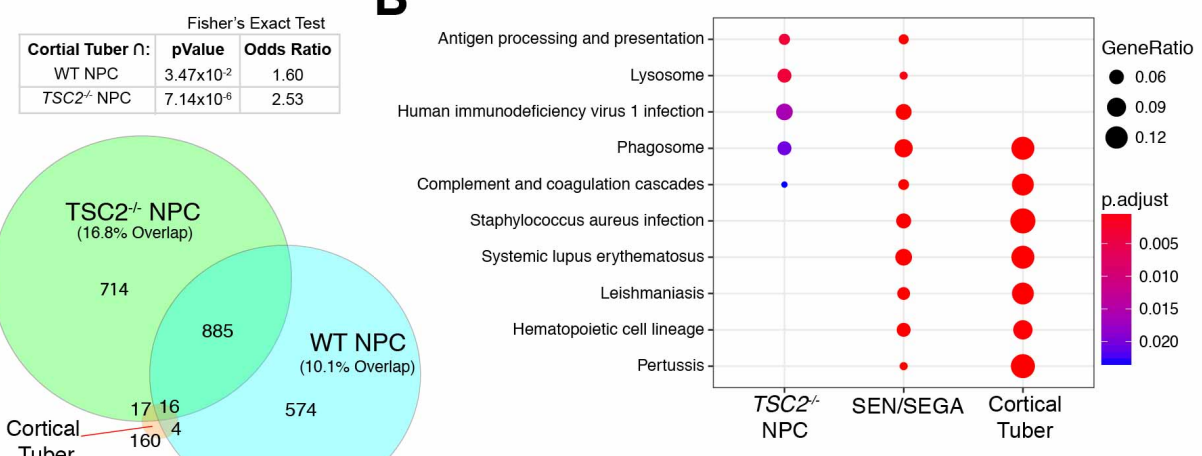

C

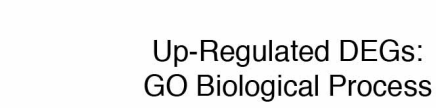

cellular response to topologically incorrect proteinresponse to endoplasmic reticulum stress endoplasmic reticulum unfolded protein response cellular response to unfolded protein response to topologically incorrect protein response to unfolded proteinmacroautophagy regulation of macroautophagy
intrinsic apoptotic signaling pathway neutrophil degranulation neutrophil degranulation
neutrophil activation involved in immune response
neutrophil activation neutrophil mediated immunity response to type I interferon extracellular structure organization positive regulation of binding extracellular matrix organization interferon-gamma-mediated signaling pathwayfat cell differentiation
regulation of water loss via skin multicellular organismal water homeostasis regulation of fibroblast proliferation fibroblast proliferation regulation of ossification
establishment of skin barrier

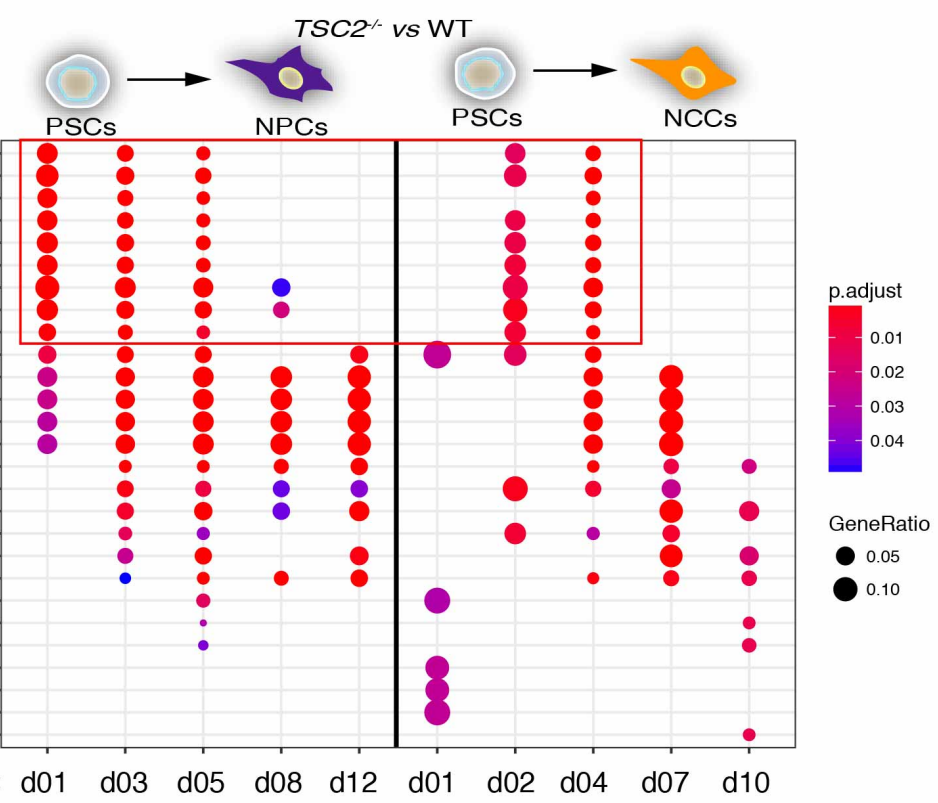

\section{NE marker genes}

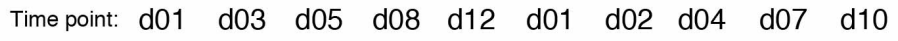

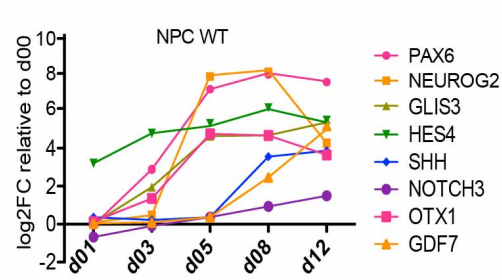

day of differentiation

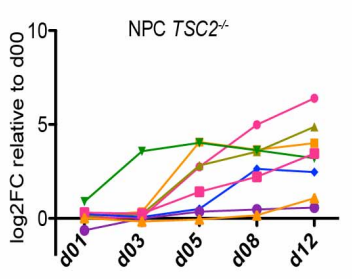

day of differentiation

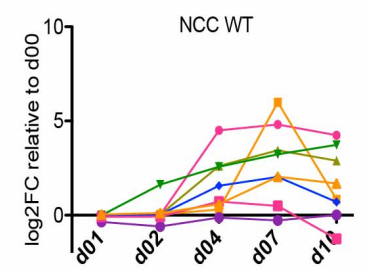

day of differentiation

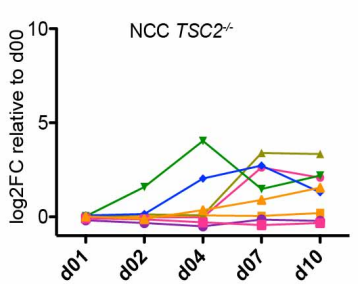

day of differentiation

\section{E}

NCC marker genes

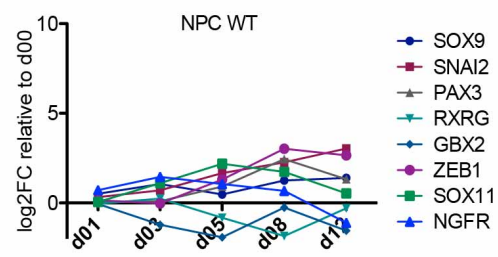

day of differentiation

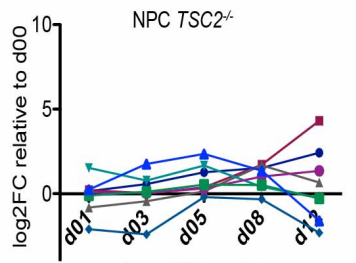

day of differentiation

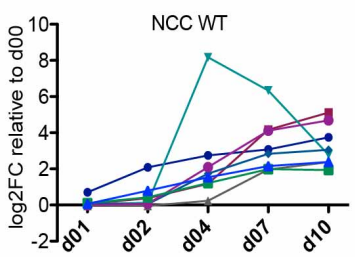

day of differentiation

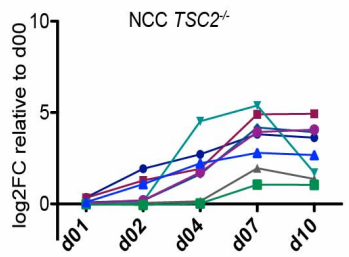

day of differentiation 


\section{Figure S5}
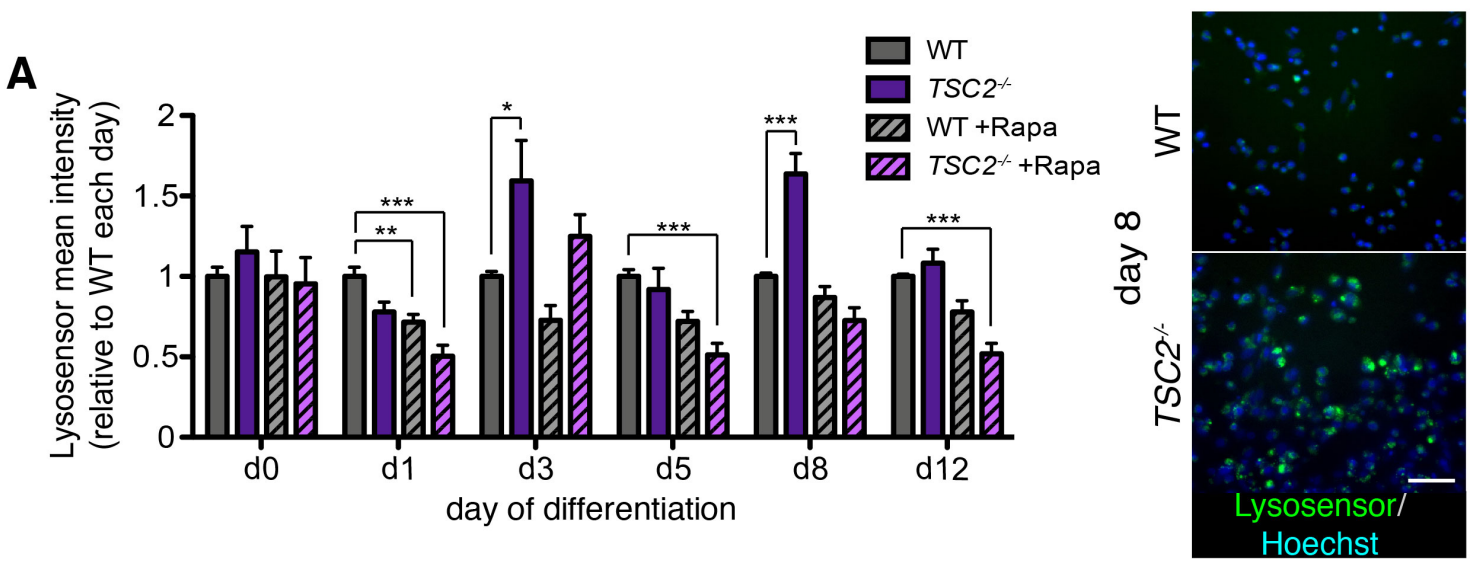

B WT

TSC2
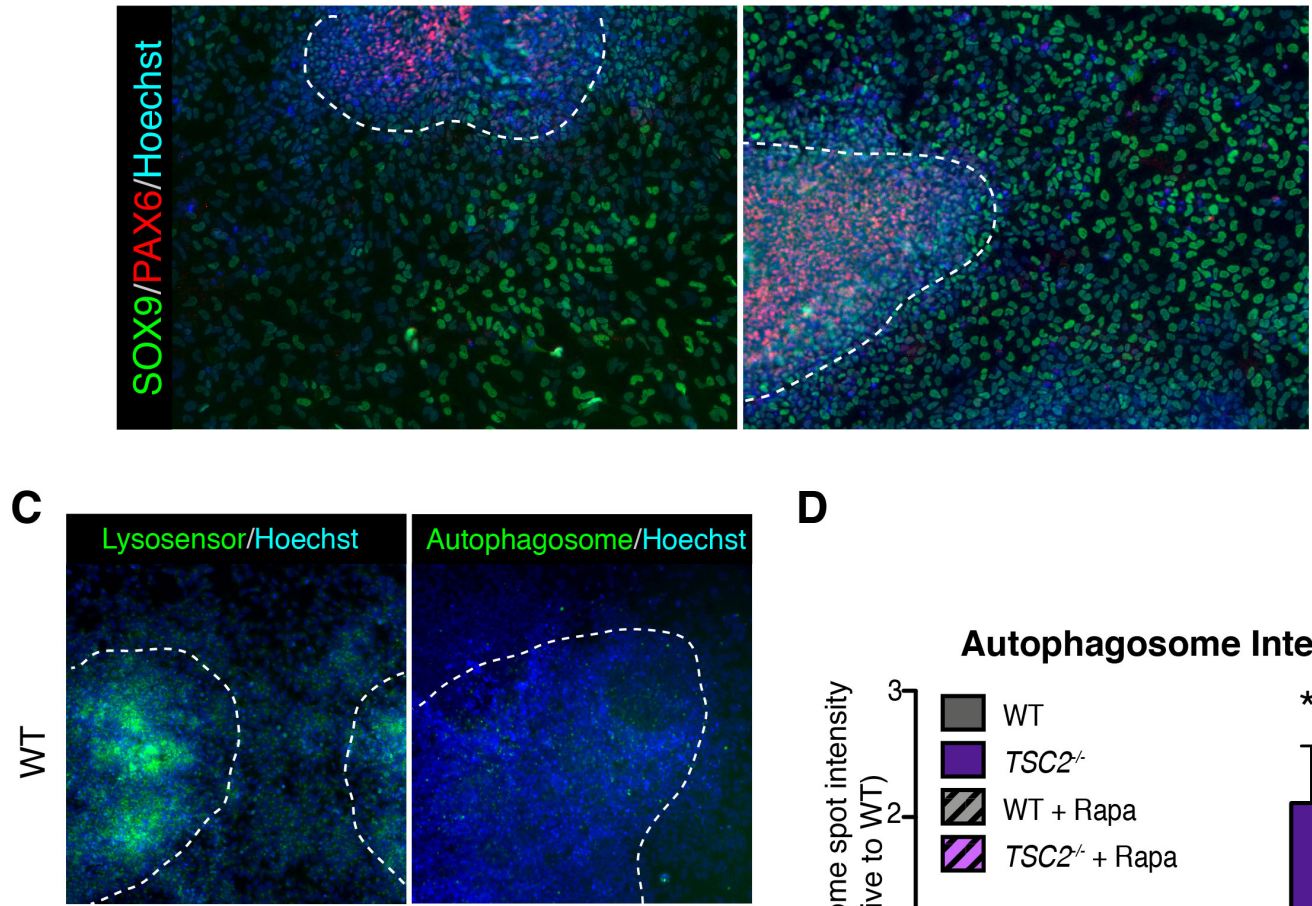

D
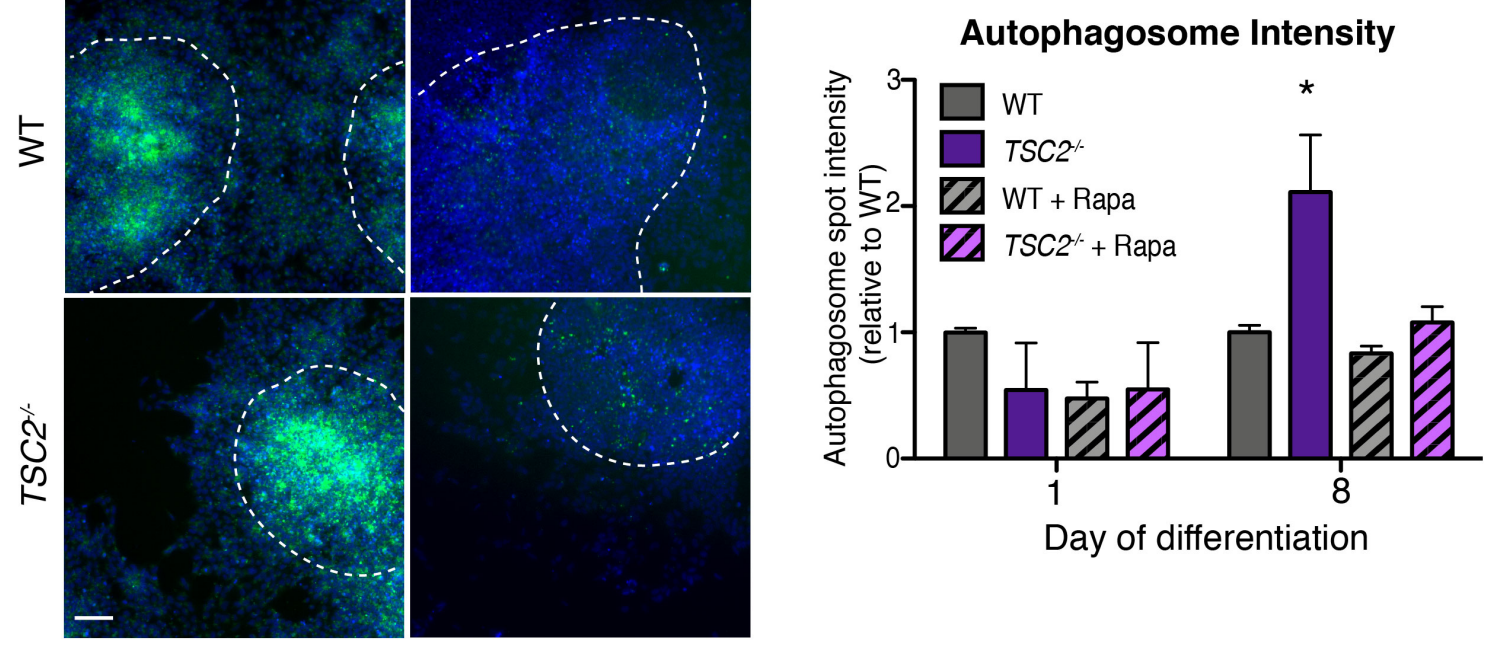
bioRxiv preprint doi: https://doi.org/10.1101/683359; this version posted February 14,2020 . The copyright holder for this preprint (which was not certified by peer review) is the author/funder, who has granted bioRxiv a license to display the preprint in perpetuity. It is made available under aCC-BY-NC-ND 4.0 International license.

\section{Figure S6}

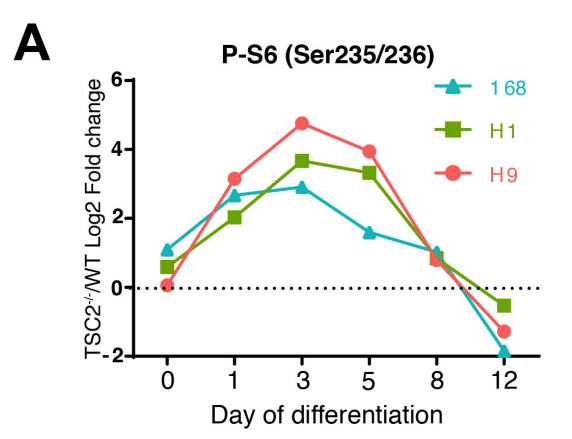

C

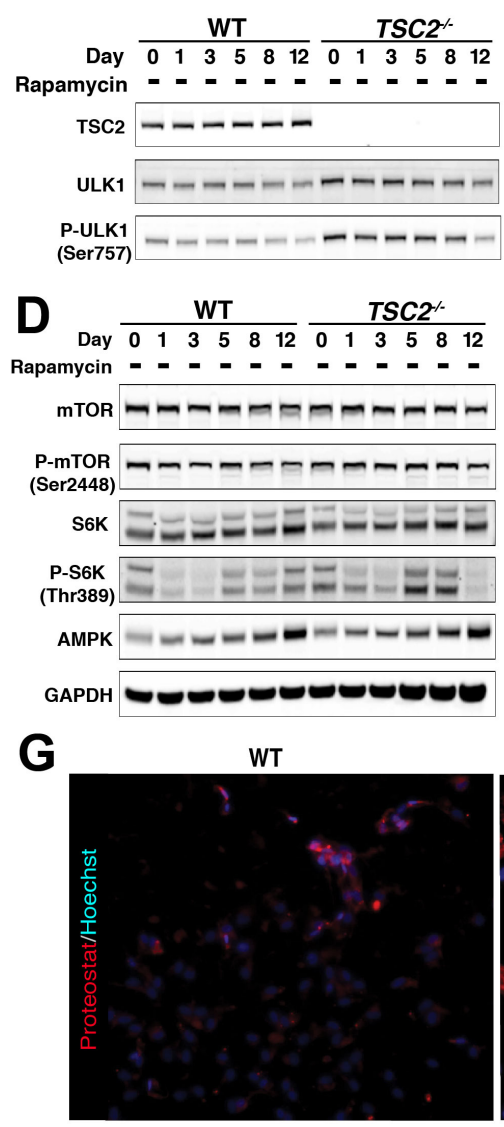

(Passage 6)
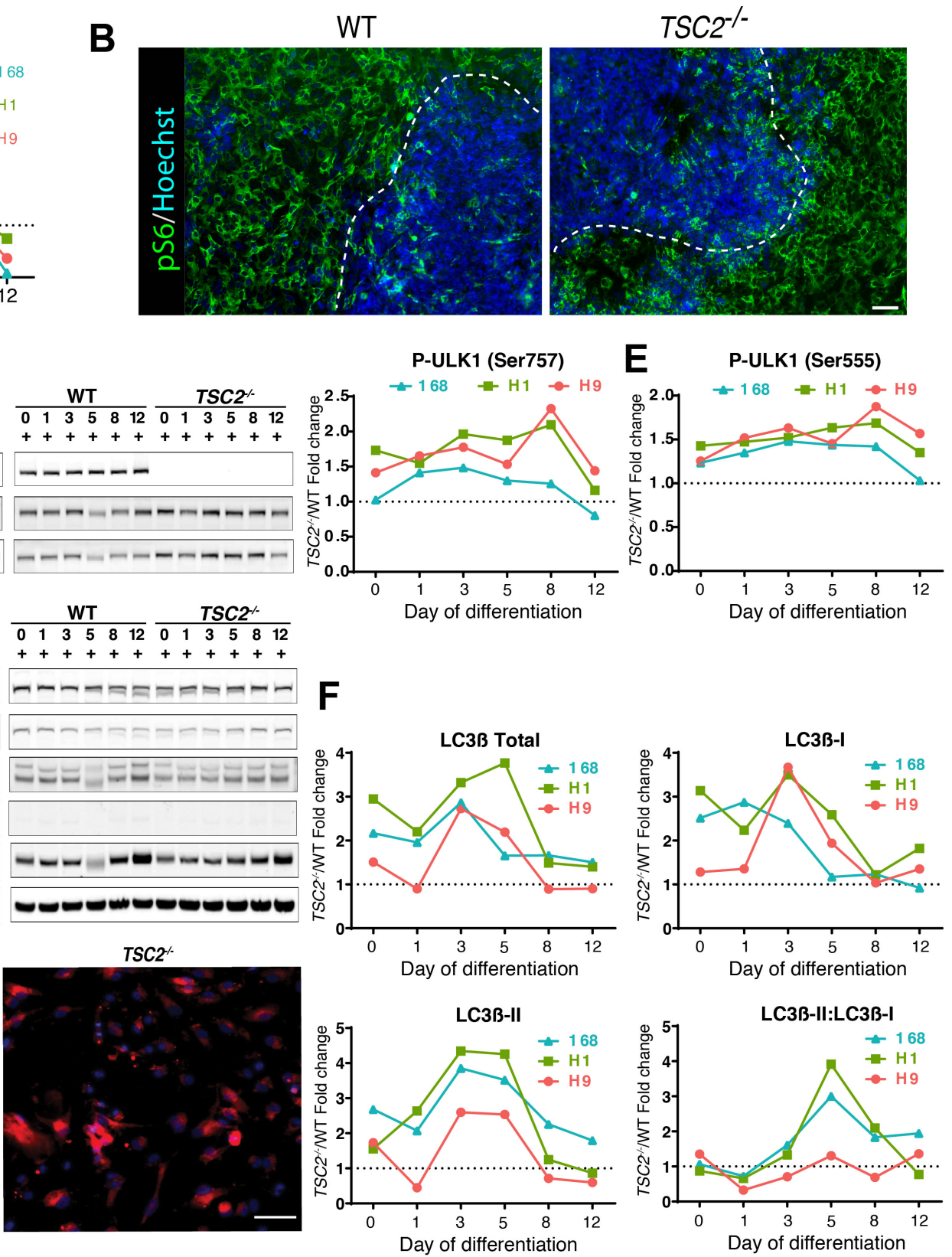
bioRxiv preprint doi: https://doi.org/10.1101/683359; this version posted February 14,2020 . The copyright holder for this preprint (which was not certified by peer review) is the author/funder, who has granted bioRxiv a license to display the preprint in perpetuity. It is made available under aCC-BY-NC-ND 4.0 International license.

\section{Figure S7}
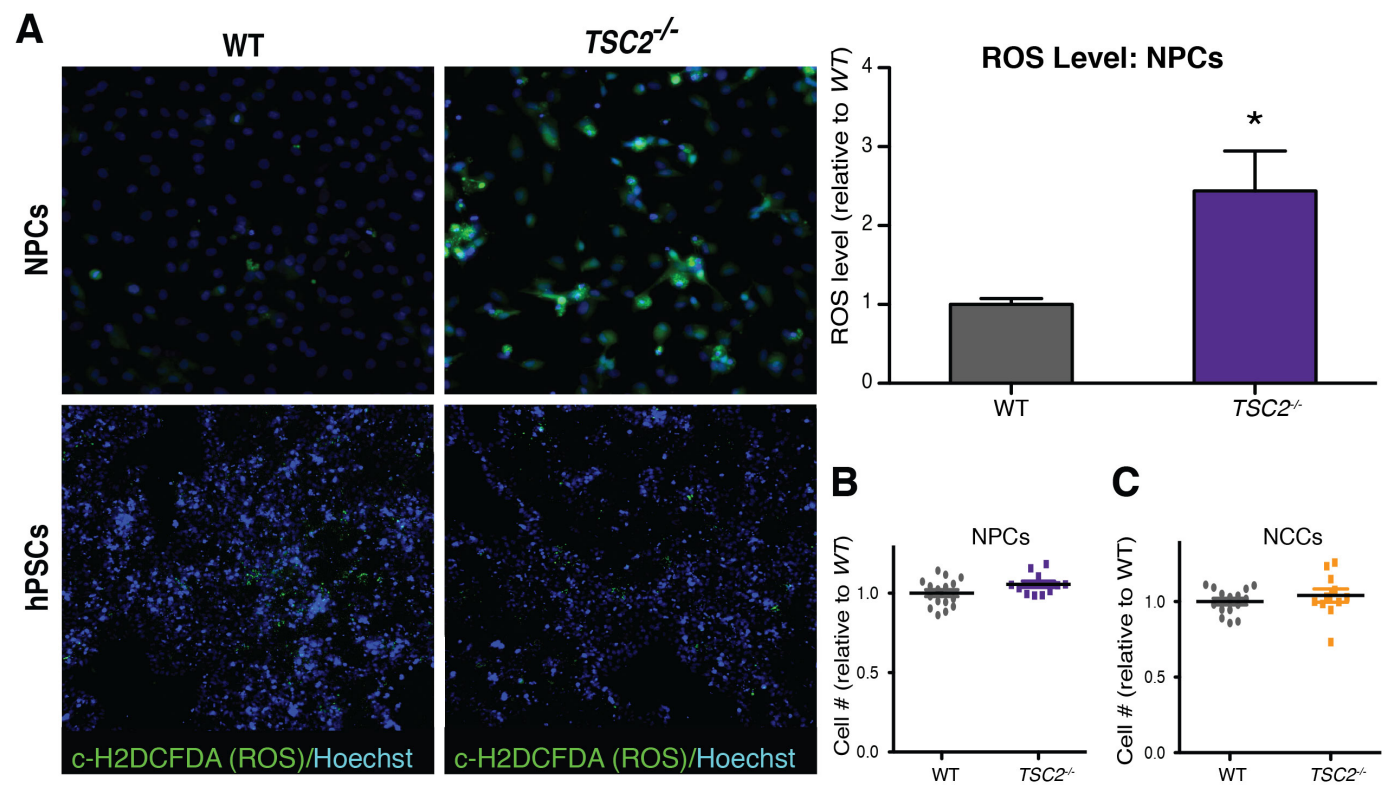

D

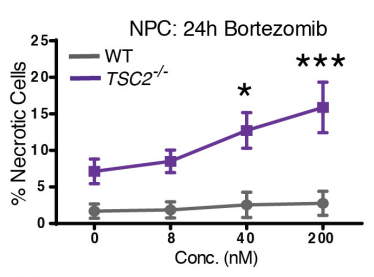

\section{E}

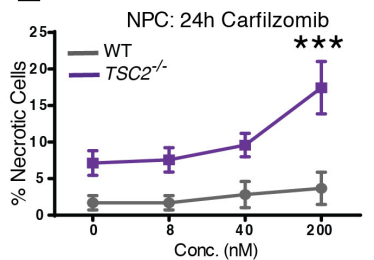

$\mathbf{F}$

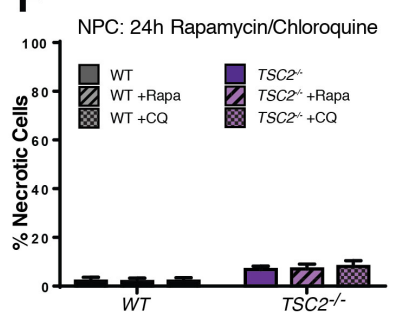

G
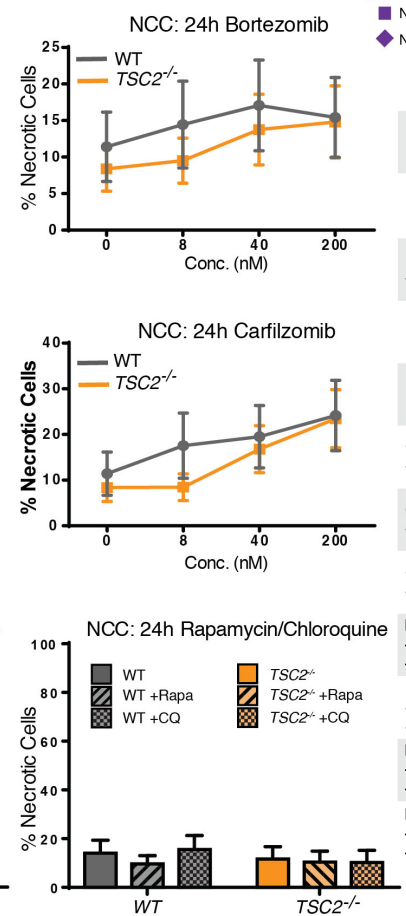

NPC-WT $\mathrm{NCC}-\mathrm{WT}$

NPC-TSC2 $\%$ NCC-TSC2 $\%$ Antagonism Synergism

Rapamycin $100 \mathrm{~nm}$ + Chloroquine (10uM)

Rapamycin 100nM + Bortezomib (40nM) Rapamycin 100nM Bortezomib (200nM) Rapamycin 100nM + Carfilzomib (40nM)

Rapamycin 100nM Rapamycin 100nM
+ Carfilzomib (200nM)

Chloroquine (10uM) + Bortezomib (40nM)

Chloroquine (10uM) + Bortezomib (200nM) Chloroquine (10uM) + Carfilzomib (40nM) Chloroquine (10uM) + Carfilzomib (200nM)

Rapamycin 100nM Chloroquine (10uM) + Chloroquine (10um) + Bortezomib (200nM) Rapamycin 100nM Chloroquine (10uM)
Carfilzomib (40nM)

+ Chloroquine (10uM)
+ Carfilzomib (200nM)

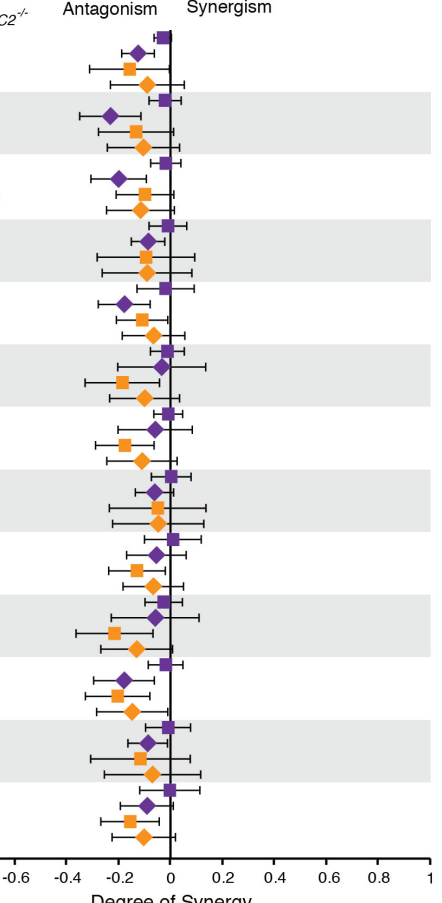


bioRxiv preprint doi: https://doi.org/10.1101/683359; this version posted February 14,2020 . The copyright holder for this preprint (which was not certified by peer review) is the author/funder, who has granted bioRxiv a license to display the preprint in perpetuity. It is made available under aCC-BY-NC-ND 4.0 International license.

\section{Supplemental Multimedia:}

Video S1: Time lapse video of motility assay featuring WT and $T S C 2^{-/} \mathrm{NCCs}$ with and without $100 \mathrm{nM}$ Rapamycin.

\section{Sequencing of TSC2 exon 3 target region of $T S C 2^{-/}$hPSC cell lines:}

Sanger sequencing was performed on all TSC2 $2^{-/}$hPSC cell lines to ensure proper integration of the 'stop-codon' donor sequence (highlighted in chromatograms).

H9 $\mathrm{TSC}^{-/-}$

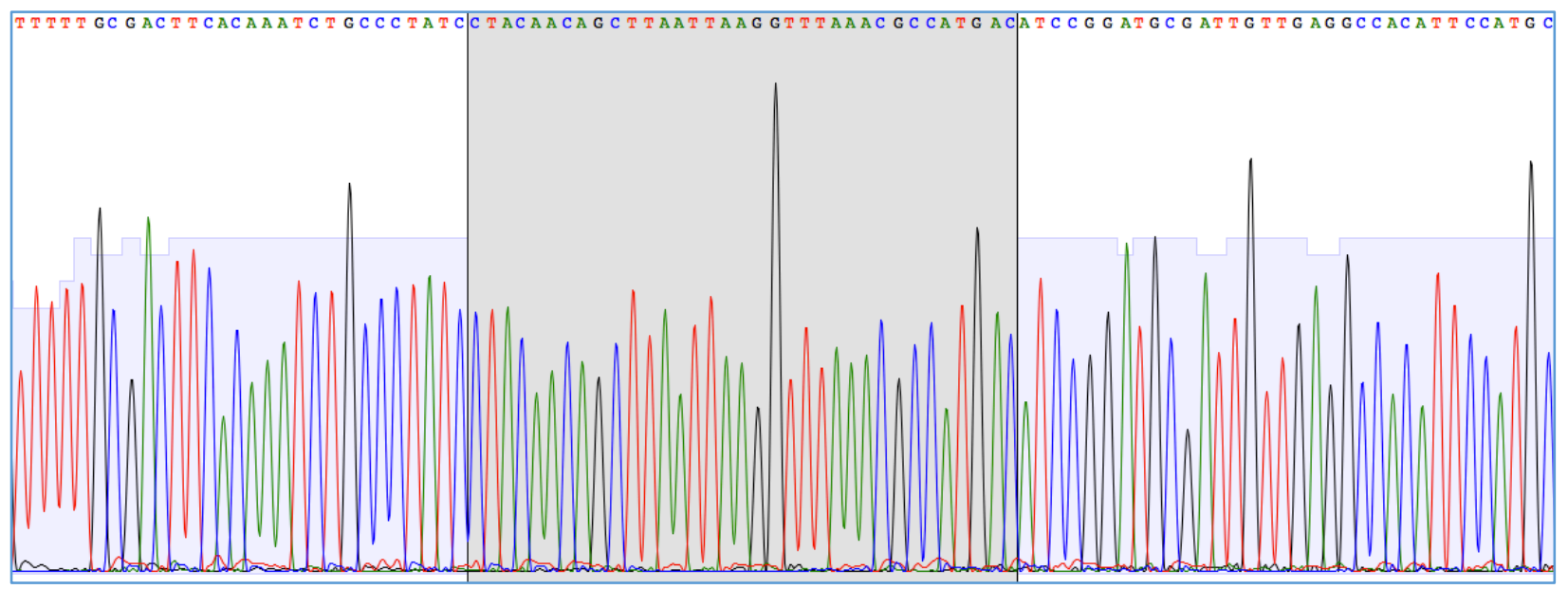

\section{$\mathrm{H} 7 \mathrm{TSC}^{-/-}$}

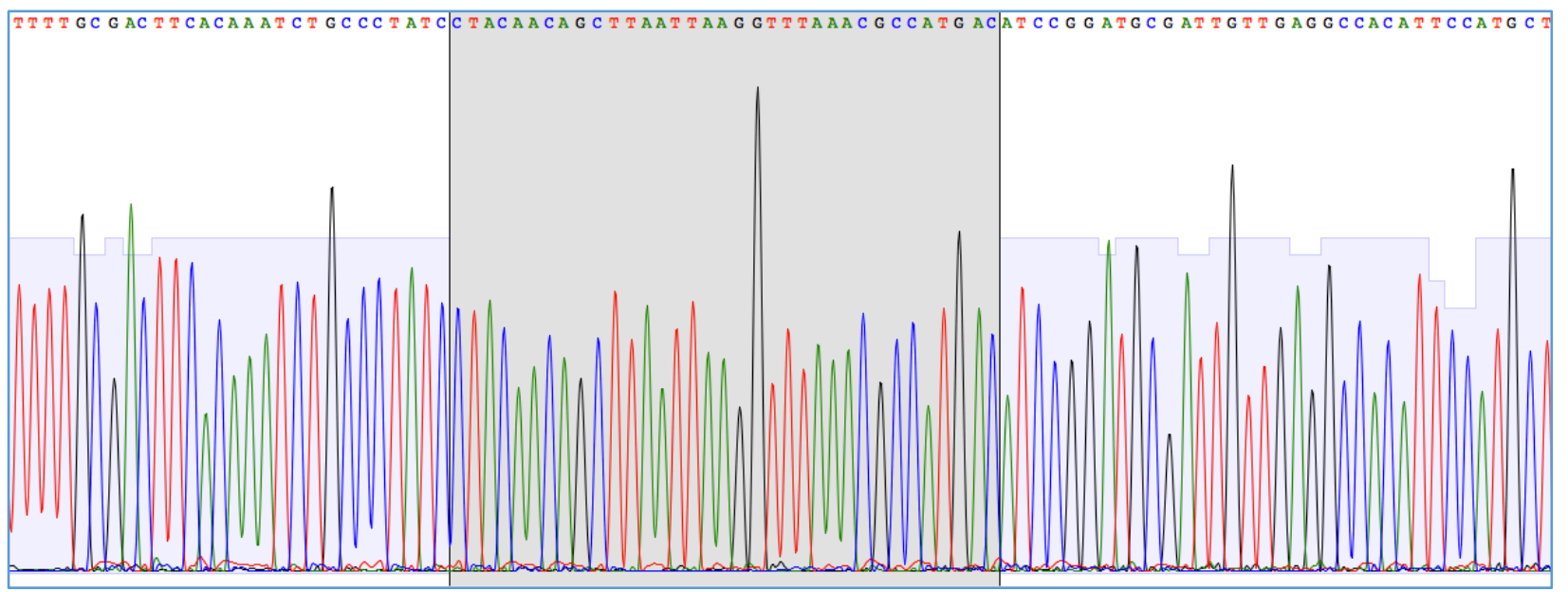




\section{$\mathrm{H} 1 \mathrm{TSC} 2^{-/-}$}

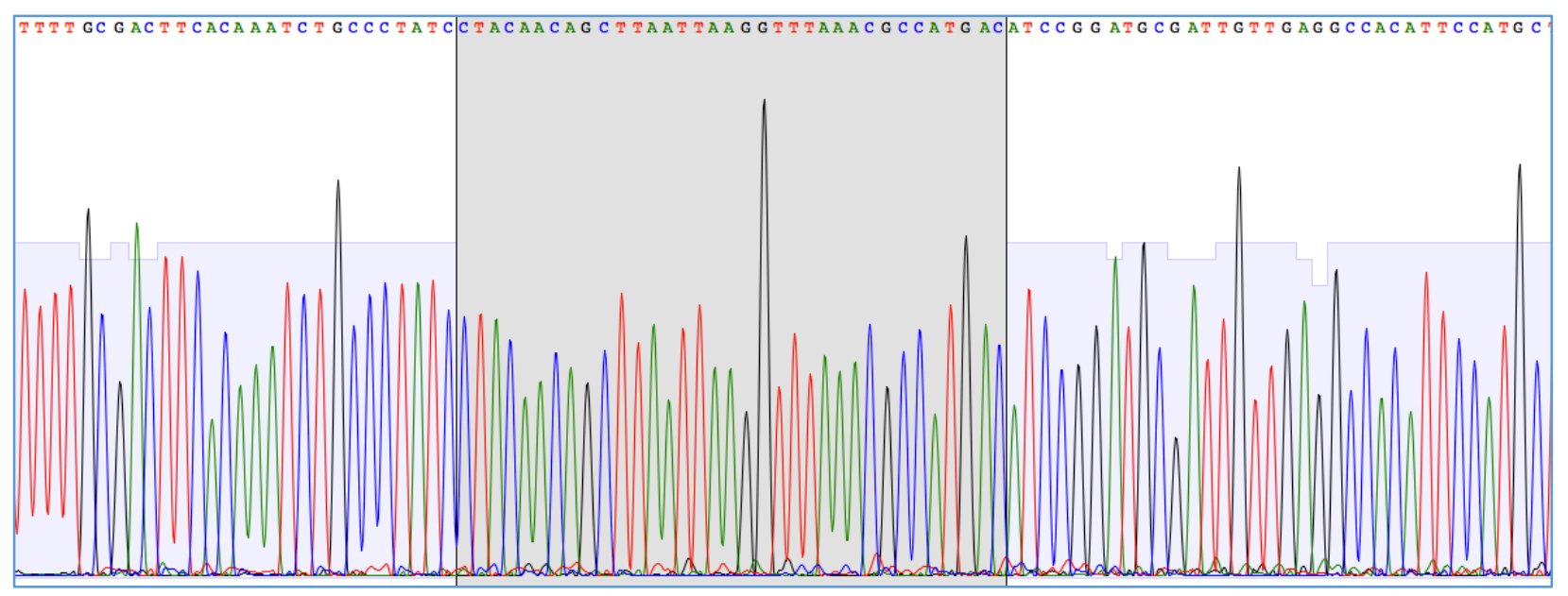

$168 \mathrm{TSC}^{-/-}$

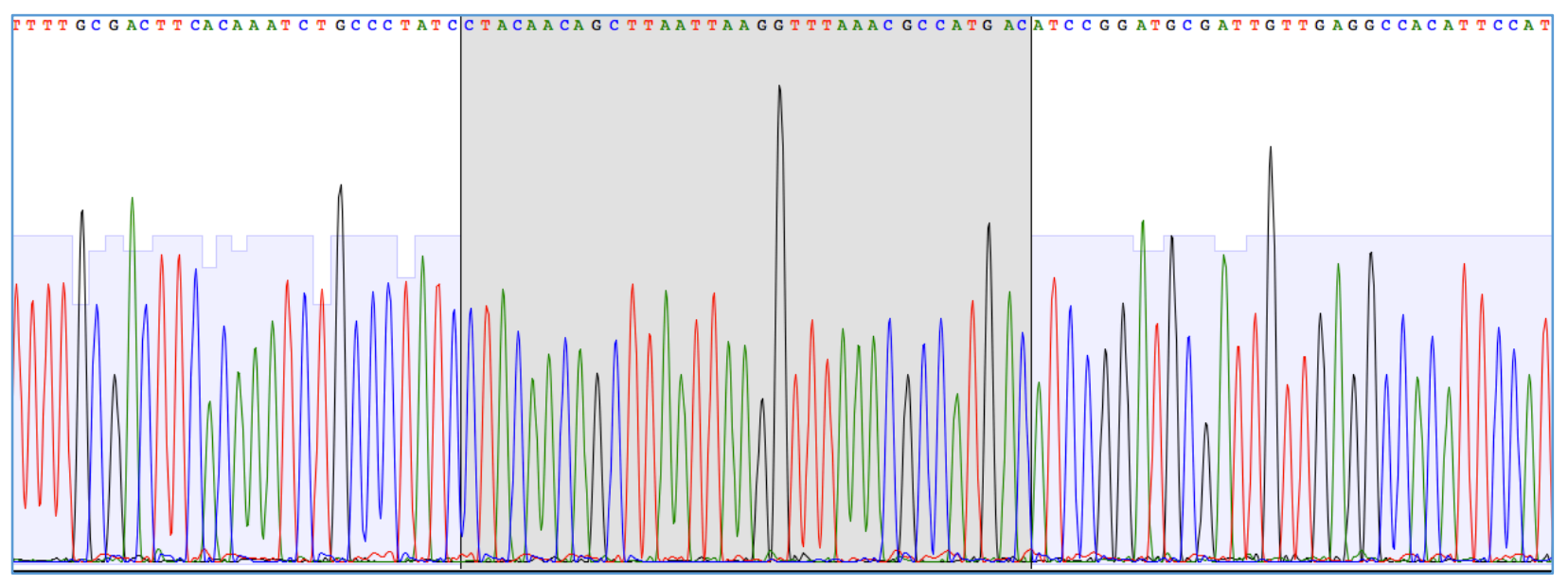

\section{AAVS1 Donor Plasmid Sequence:}

To aid in live cell assays and any potential in vivo studies, a CMV early enhancer/chicken $\beta$ actin (CAG) promoter driven mCherry/Zeocin-resistance transgene was integrated into the AVVS1 locus. All cell lines utilized in this study, excluding $168 \mathrm{TSC}^{-/}$cells, possess this transgene integration.

AAVS1: CAG-mCherry/T2A/Zeocin-Resistance donor plasmid sequence (in pUC19 backbone) and annotated map: 
TCGCGCGTTTCGGTGATGACGGTGAAAACCTCTGACACATGCAGCTCCCGGAGACGGTCACAGCTT GTCTGTAAGCGGATGCCGGGAGCAGACAAGCCCGTCAGGGCGCGTCAGCGGGTGTTGGCGGGTGT CGGGGCTGGCTTAACTATGCGGCATCAGAGCAGATTGTACTGAGAGTGCACCATATGCGGTGTGAA ATACCGCACAGATGCGTAAGGAGAAAATACCGCATCAGGCGCCATTCGCCATTCAGGCTGCGCAA CTGTTGGGAAGGGCGATCGGTGCGGGCCTCTTCGCTATTACGCCAGCTGGCGAAAGGGGGATGTGC TGCAAGGCGATTAAGTTGGGTAACGCCAGGGTTTTCCCAGTCACGACGTTGTAAAACGACGGCCAG TGAATTCCAGGAGAGCCAGGGGCATGAGATGGTGGACGAGGAAGGGGGACAGGGAAGCCTGAGC GCCTCTCCTGGGCTTGCCAAGGACTCAAACCCAGAAGCCCAGAGCAGGGCCTTAGGGAAGCGGGA CCCTGCTCTGGGCGGAGGAATATGTCCCAGATAGCACTGGGGACTCTTTAAGGAAAGAAGGATGG AGAAAGAGAAAGGGAGTAGAGGCGGCCACGACCTGGTGAACACCTAGGACGCACCATTCTCACAA AGGGAGTTTTCCACACGGACACCCCCCTCCTCACCACAGCCCTGCCAGGACGGGGCTGGCTACTGG CCTTATCTCACAGGTAAAACTGACGCACGGAGGAACAATATAAATTGGGGACTAGAAAGGTGAAG AGCCAAAGTTAGAACTCAGGACCAACTTATTCTGATTTTGTTTTTCCAAACTGCTTCTCCTCTTGGG AAGTGTAAGGAAGCTGCAGCACCAGGATCAGTGAAACGCACCAGACGGCCGCGTCAGAGCAGCTC AGGTTCTGGGAGAGGGTAGCGCAGGGTGGCCACTGAGAACCGGGCAGGTCACGCATCCCCCCCTT CCCTCCCACCCCCTGCCAAGCTCTCCCTCCCAGGATCCTCTCTGGCTCCATCGTAAGCAAACCTTAG AGGTTCTGGCAAGGAGAGAGATGGCTCCAGGAAATGGGGGTGTGTCACCAGATAAGGAATCTGCC TAACAGGAGGTGGGGGTTAGACCCAATATCAGGAGACTAGGAAGGAGGAGGCCTAAGGATGGGG CTTTTCTGTCACCAATCCTGTCCCGTCGACgcgttacataacttacggtaaatggecegcetggetgaccgeccaacgaccccegccca ttgacgtcaataatgacgtatgttccatagtaacgccaatagggactttccattgacgtcaatgggtggactatttacggtaaactgcccacttggcagtacatcaagt gtatcatatgecaagtacgeccctattgacgtcaatgacggtaaatggeccgectggcattatgcccagtacatgacettatgggactttcctacttggcagtacatct acgtattagtcatcgctattaccatgggtcgaggtgagcccacgttctgcttcactctccccatctcceccectccecaccccaattttgtatttatttattttttaattatt ttgtgcagcgatgggggcggggggggggggggecgcgcgccaggcggggeggggcggggcgaggggeggggcggggcgaggcggagaggtgcggcg gcagccaatcagagcggcgcgctccgaaagtttccttttatggcgaggcggeggcggcggcggcctataaaaagcgaagcgcgcggcgggegggagtcgct

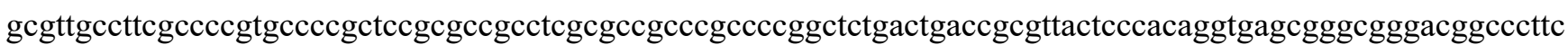
tcctccgggctgtaattagcgcttggtttaatgacggctcgtttcttttctgtggctgcgtgaaagccttaaagggctccgggagggecctttgtgcgggggggagcg 

under aCC-BY-NC-ND 4.0 International license.

gctcggggggtgcgtgcgtgtgtgtgtgcgtggggagcgccgcgtgcggccegcgctgcceggcggctgtgagcgctgcgggcgeggcgcggggctttgtgc gctccgcgtgtgcgcgaggggagcgcggccgggggeggtgcccegcggtgcgggggggctgcgaggggaacaaaggctgcgtgcggggtgtgtgcgtgg gggggtgagcagggggtgtgggegcggcggtcgggctgtaaccccccctgcaccccctccccgagttgctgagcacggeceggettcgggtgcggggctc cgtgcggggcgtggcgcggggetcgccgtgccgggcggggggtggcggcaggtgggggtgccgggeggggeggggecgcctcgggecggggagggct cgggggaggggegcggcggccceggagcgccggcggctgtcgaggcgcggcgagccgcagccattgccttttatggtaatcgtgcgagagggcgcaggga cttcctttgtcccaaatctggcggagccgaaatctgggaggcgccgccgcaccccctctagcgggegcgggcgaagcggtgcggegceggcaggaaggaaat gggcggggagggecttcgtgcgtcgecgcgecgecgtcccettctccatctcagectcggggetgecgcagggggacggetgecttcgggggggacggggc agggcggggttcggcttctggcgtgtgaccggcggctctagagcctctgctaaccatgttcatgccttcttcttttcctacagCTCGAGgccaccatggtgagc aagggcgaggaggataacatggccatcatcaaggagttcatgcgcttcaaggtgcacatggagggetccgtgaacggccacgagttcgagatcgagggcgagg gcgagggccgcccetacgagggcacccagaccgccaagctgaaggtgaccaagggtggecccetgecttcgectgggacatcctgtcccetcagttcatgtac ggctccaaggcctacgtgaagcacccegccgacatcccegactacttgaagctgtccttccccgagggcttcaagtgggagcgegtgatgaacttcgaggacgg cggcgtggtgaccgtgacccaggactcctccetgcaggacggcgagttcatctacaaggtgaagctgcgcggcaccaacttccectccgacggcccegtaatgc agaagaagaccatgggctgggaggectcctccgagcggatgtaccccgaggacggcgecctgaagggegagatcaagcagaggetgaagctgaaggacgg cggccactacgacgctgaggtcaagaccacctacaaggccaagaagccegtgcagctgcceggcgcctacaacgtcaacatcaagttggacatcacctcccaca acgaggactacaccatcgtggaacagtacgaacgcgccgagggccgccactccaccggcggcatggacgagctgtacaagaccggtgagggcagaggaagt cttctaacatgcggtgacgtggaggagaatcceggccttccggtatggccaaactcacttctgcagtcccagtcctcacagcaagggatgttgcaggggctgtag agttctggactgacagattaggattctccagagactttgttgaagatgattttgctggtgttgtcagagatgatgtcaccctcttcatctcagcagttcaggaccaagttgt ccctgacaacaccettgettgggtctgggtcagaggcctagatgagctttatgcagaatggtcagaagtagtcagcacaaatttcagggatgcctctggcccagcca tgacagaaattggtgaacaaccttggggaagggaatttgccctcagagaccctgctggaaattgtgtccattttgtagctgaggaacaggactagaacttgtttattgc agcttataatggttacaaataaagcaatagcatcacaaatttcacaaataaagcattttttcactgcattctagttgtggtttgtccaaactcatcaatgtatcttatcatgtct ACGCGTTAGTGGCCCCACTGTGGGGTGGAGGGGACAGATAAAAGTACCCAGAACCAGAGCCACAT TAACCGGCCCTGGTAATATAAGGTGGTCCCAGCTCGGGGACACAGGATCCCTGGAGGCAGCAAAC ATGCTGTCCTGAAGTGGACATAGGGGCCCGGGTTGGAGGAAGAAGACTAGCTGAGCTCTCGGACC CCTGGAAGATGCCATGACAGGGGGCTGGAAGAGCTAGCACAGACTAGAGAGGTAAGGGGGGTAG GGGAGCTGCCCAAATGAAAGGAGTGAGAGGTGACCCGAATCCACAGGAGAACGGGGTGTCCAGG CAAAGAAAGCAAGAGGATGGAGAGGTGGCTAAAGCCAGGGAGACGGGGTACTTTGGGGTTGTCC AGAAAAACGGTGATGATGCAGGCCTACAAGAAGGGGAGGCGGGACGCAAGGGAGACATCCGTCG 
GAGAAGGCCATCCTAAGAAACGAGAGATGGCACAGGCCCCAGAAGGAGAAGGAAAAGGGAACCC AGCGAGTGAAGACGGCATGGGGTTGGGTGAGGGAGGAGAGATGCCCGGAGAGGACCCAGACACG GGGAGGATCCGCTCAGAGGACATCACGTGGTGCAGCGCCGAGAAGGAAGTGCTCCGGAAAGAGC ATCCTTGGGCAGCAACACAGCAGAGAGCAAGGGGAAGAGGGAGTGGAGGAAGACGGAACCTGAA GGAGGCGGCAGGGAAGGATCTGGGCCAGCCGTAGAGGTGACCCAGGCCACAAGCTGCAGACAGA AAGCGGCACAGGCCCAGGGGAGAGAATGCAGGTCAAAGCTTGGCGTAATCATGGTCATAGCTGTT TCCTGTGTGAAATTGTTATCCGCTCACAATTCCACACAACATACGAGCCGGAAGCATAAAGTGTAA AGCCTGGGGTGCCTAATGAGTGAGCTAACTCACATTAATTGCGTTGCGCTCACTGCCCGCTTTCCA GTCGGGAAACCTGTCGTGCCAGCTGCATTAATGAATCGGCCAACGCGCGGGGAGAGGCGGTTTGC GTATTGGGCGCTCTTCCGCTTCCTCGCTCACTGACTCGCTGCGCTCGGTCGTTCGGCTGCGGCGAGC GGTATCAGCTCACTCAAAGGCGGTAATACGGTTATCCACAGAATCAGGGGATAACGCAGGAAAGA ACATGTGAGCAAAAGGCCAGCAAAAGGCCAGGAACCGTAAAAAGGCCGCGTTGCTGGCGTTTTTC CATAGGCTCCGCCCCCCTGACGAGCATCACAAAAATCGACGCTCAAGTCAGAGGTGGCGAAACCC GACAGGACTATAAAGATACCAGGCGTTTCCCCCTGGAAGCTCCCTCGTGCGCTCTCCTGTTCCGAC CCTGCCGCTTACCGGATACCTGTCCGCCTTTCTCCCTTCGGGAAGCGTGGCGCTTTCTCATAGCTCA CGCTGTAGGTATCTCAGTTCGGTGTAGGTCGTTCGCTCCAAGCTGGGCTGTGTGCACGAACCCCCC GTTCAGCCCGACCGCTGCGCCTTATCCGGTAACTATCGTCTTGAGTCCAACCCGGTAAGACACGAC TTATCGCCACTGGCAGCAGCCACTGGTAACAGGATTAGCAGAGCGAGGTATGTAGGCGGTGCTAC AGAGTTCTTGAAGTGGTGGCCTAACTACGGCTACACTAGAAGAACAGTATTTGGTATCTGCGCTCT GCTGAAGCCAGTTACCTTCGGAAAAAGAGTTGGTAGCTCTTGATCCGGCAAACAAACCACCGCTGG TAGCGGTGGTTTTTTTGTTTGCAAGCAGCAGATTACGCGCAGAAAAAAAGGATCTCAAGAAGATCC TTTGATCTTTTCTACGGGGTCTGACGCTCAGTGGAACGAAAACTCACGTTAAGGGATTTTGGTCATG AGATTATCAAAAAGGATCTTCACCTAGATCCTTTTAAATTAAAAATGAAGTTTTAAATCAATCTAA AGTATATATGAGTAAACTTGGTCTGACAGTTACCAATGCTTAATCAGTGAGGCACCTATCTCAGCG ATCTGTCTATTTCGTTCATCCATAGTTGCCTGACTCCCCGTCGTGTAGATAACTACGATACGGGAGG GCTTACCATCTGGCCCCAGTGCTGCAATGATACCGCGAGACCCACGCTCACCGGCTCCAGATTTAT CAGCAATAAACCAGCCAGCCGGAAGGGCCGAGCGCAGAAGTGGTCCTGCAACTTTATCCGCCTCC 
ATCCAGTCTATTAATTGTTGCCGGGAAGCTAGAGTAAGTAGTTCGCCAGTTAATAGTTTGCGCAAC GTTGTTGCCATTGCTACAGGCATCGTGGTGTCACGCTCGTCGTTTGGTATGGCTTCATTCAGCTCCG GTTCCCAACGATCAAGGCGAGTTACATGATCCCCCATGTTGTGCAAAAAAGCGGTTAGCTCCTTCG GTCCTCCGATCGTTGTCAGAAGTAAGTTGGCCGCAGTGTTATCACTCATGGTTATGGCAGCACTGC ATAATTCTCTTACTGTCATGCCATCCGTAAGATGCTTTTCTGTGACTGGTGAGTACTCAACCAAGTC ATTCTGAGAATAGTGTATGCGGCGACCGAGTTGCTCTTGCCCGGCGTCAATACGGGATAATACCGC GCCACATAGCAGAACTTTAAAAGTGCTCATCATTGGAAAACGTTCTTCGGGGCGAAAACTCTCAAG GATCTTACCGCTGTTGAGATCCAGTTCGATGTAACCCACTCGTGCACCCAACTGATCTTCAGCATCT TTTACTTTCACCAGCGTTTCTGGGTGAGCAAAAACAGGAAGGCAAAATGCCGCAAAAAAGGGAAT AAGGGCGACACGGAAATGTTGAATACTCATACTCTTCCTTTTTCAATATTATTGAAGCATTTATCAG GGTTATTGTCTCATGAGCGGATACATATTTGAATGTATTTAGAAAAATAAACAAATAGGGGTTCCG CGCACATTTCCCCGAAAAGTGCCACCTGACGTCTAAGAAACCATTATTATCATGACATTAACCTAT AAAAATAGGCGTATCACGAGGCCCTTTCGTC

Annotated map:

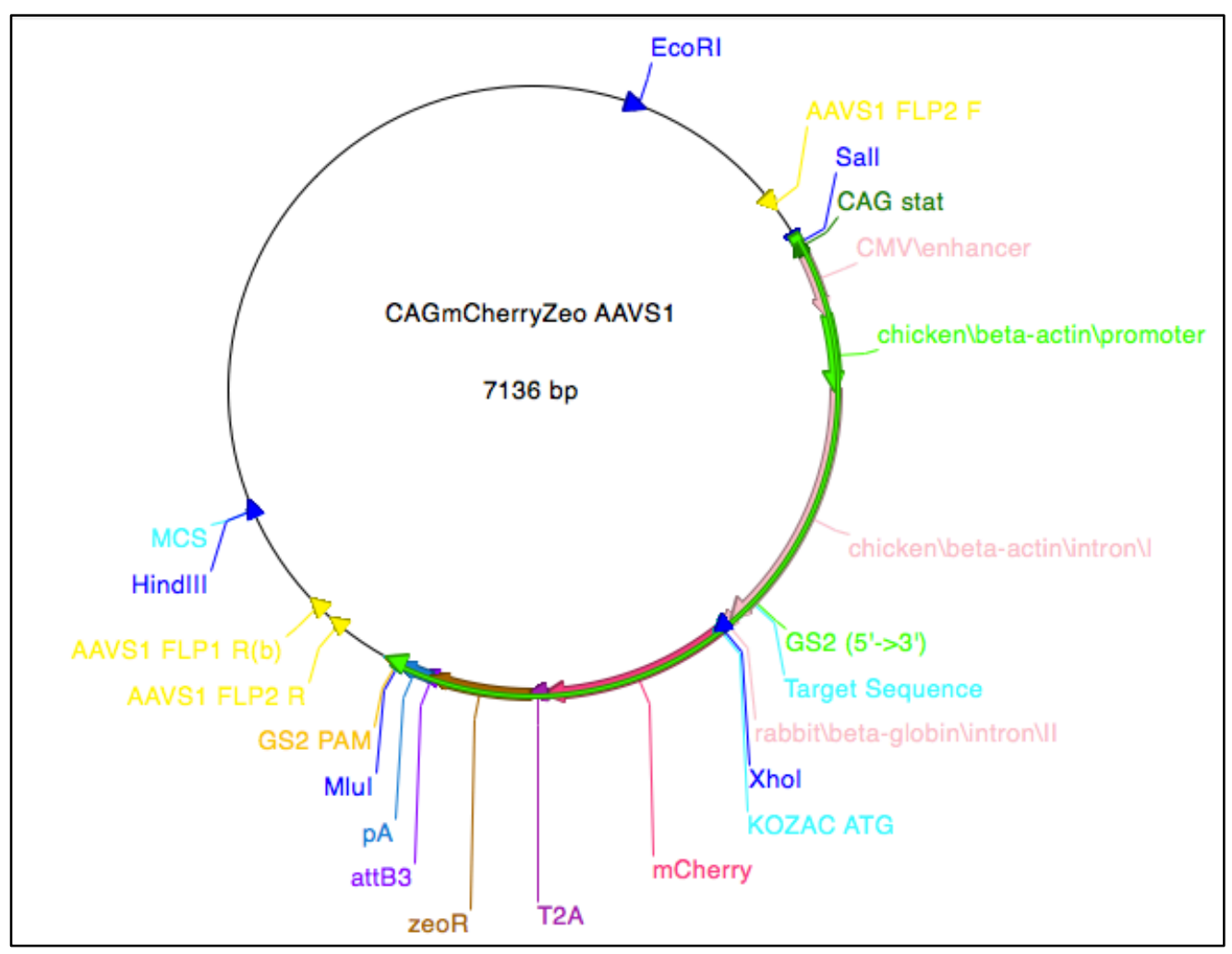




\section{Off-Target Mutation Analysis:}

Off target loci for each gRNA sequence utilized in this study were identified using the CRISPOR algorithm (Haeussler et al., 2016). The 3 highest scoring off target loci falling within an intron or exon were selected for PCR amplification of the off-target region followed by amplicon sequencing to identify potential off target mutations. No off-target cleavage induced indel mutations were detected across all CRISPR/Cas9 genome edited cell lines in this study.

Table S1: Off-target gene information and primer sequences.

\begin{tabular}{|c|c|c|c|c|c|}
\hline $\begin{array}{l}\text { CRISPR/Cas9 } \\
\text { target gene }\end{array}$ & $\begin{array}{l}\text { Gene } \\
\text { name }\end{array}$ & Genomic region & Feature & Primer & Primer sequence \\
\hline \multirow[t]{5}{*}{ AAVS1 } & \multirow[t]{2}{*}{ TTN } & \multirow[t]{2}{*}{$\begin{array}{l}\text { chr2:179,467,749- } \\
179,467,771\end{array}$} & \multirow[t]{2}{*}{ Intron } & $\begin{array}{l}\text { Forward } \\
\text { (w/M13) }\end{array}$ & $\begin{array}{l}\text { GTAAAACGACGGCCAGT } \\
\text { AAGCTGATGAAGTGCTG } \\
\text { GAGTC }\end{array}$ \\
\hline & & & & Reverse & $\begin{array}{l}\text { TGTAGACACTGATCCTG } \\
\text { TCCCTAA }\end{array}$ \\
\hline & \multirow[t]{2}{*}{$\begin{array}{l}\text { APPL } \\
2\end{array}$} & \multirow[t]{2}{*}{$\begin{array}{l}\text { chr12:105,594,36 } \\
3-105,594,385\end{array}$} & \multirow[t]{2}{*}{ Intron } & $\begin{array}{l}\text { Forward } \\
\text { (w/M13) }\end{array}$ & $\begin{array}{l}\text { GTAAAACGACGGCCAGT } \\
\text { AGGCAGCCTAAGCAAGT } \\
\text { TCC }\end{array}$ \\
\hline & & & & Reverse & $\begin{array}{l}\text { CACAGTGCAGAGGAACA } \\
\text { CCT }\end{array}$ \\
\hline & CDK8 & $\begin{array}{l}\text { chr13:26,959,035- } \\
26,959,057\end{array}$ & Intron & $\begin{array}{l}\text { Forward } \\
\text { (w/M13) }\end{array}$ & $\begin{array}{l}\text { GTAAAACGACGGCCAGT } \\
\text { AAACAGCCATGCCCGAA } \\
\text { TAA }\end{array}$ \\
\hline
\end{tabular}




\begin{tabular}{|c|c|c|c|c|c|}
\hline & & & & Reverse & $\begin{array}{l}\text { ATGTGTCACCCCACCGT } \\
\text { TAG }\end{array}$ \\
\hline \multirow[t]{7}{*}{ TSC2 Exon 3} & \multirow[t]{2}{*}{ PPAT } & \multirow[t]{2}{*}{$\begin{array}{l}\text { chr4:57,272,513- } \\
57,272,535\end{array}$} & \multirow[t]{2}{*}{ Intron } & $\begin{array}{l}\text { Forward } \\
\text { (w/M13) }\end{array}$ & $\begin{array}{l}\text { GTAAAACGACGGCCAGT } \\
\text { GCTTTGAACATAGCAAC } \\
\text { AGAGTT }\end{array}$ \\
\hline & & & & Reverse & $\begin{array}{l}\text { TTCATGGGAAGATAGCT } \\
\text { GTGGC }\end{array}$ \\
\hline & \multirow[t]{2}{*}{$\begin{array}{l}\text { XKR } \\
\mathrm{X}\end{array}$} & \multirow[t]{2}{*}{$\begin{array}{l}\text { chr1:89,353,000- } \\
89,353,022\end{array}$} & \multirow[t]{2}{*}{ Intron } & $\begin{array}{l}\text { Forward } \\
\text { (w/M13) }\end{array}$ & $\begin{array}{l}\text { GTAAAACGACGGCCAGT } \\
\text { GCCTAATCGATTCCTCCC } \\
\text { CAC }\end{array}$ \\
\hline & & & & Reverse & $\begin{array}{l}\text { GGGCAAAGGAAGGCAG } \\
\text { TTCA }\end{array}$ \\
\hline & \multirow[t]{3}{*}{$\begin{array}{l}\text { GTF2 } \\
\text { B }\end{array}$} & \multirow[t]{3}{*}{$\begin{array}{l}\text { chrX:100,181,678 } \\
-100,181,700\end{array}$} & \multirow[t]{3}{*}{ Exon } & Forward & $\begin{array}{l}\text { CCAAGCCACATTCAGGA } \\
\text { CAGA }\end{array}$ \\
\hline & & & & Reverse & $\begin{array}{l}\text { AAGAGCACAAACTGGAT } \\
\text { GGTAA }\end{array}$ \\
\hline & & & & $\begin{array}{l}\text { Reverse } \\
\text { sequencing } \\
\text { primer }\end{array}$ & $\begin{array}{l}\text { CTACTTGCCAGTTACTA } \\
\text { GCTGGAA }\end{array}$ \\
\hline
\end{tabular}

